\title{
TUNABILITY OF PHOTOGENERATED CHARGE CARRIER DENSITY ON SEMICONDUCTORS BY IN-SITU ELECTROCHEMICAL TREATMENTS
}

by

$\mathrm{Xu} \mathrm{Liu}$

B.A., Shandong University of Science and Technology, 2013

A THESIS SUBMITTED IN PARTIAL FULFILLMENT OF THE REQUIREMENTS FOR THE DEGREE OF

MASTER OF APPLIED SCIENCE

in

THE FACULTY OF GRADUATE AND POSTDOCTORAL STUDIES

(Mechanical Engineering)

THE UNIVERSITY OF BRITISH COLUMBIA

(Vancouver)

October 2018

(C) Xu Liu, 2018 
The following individuals certify that they have read, and recommend to the Faculty of Graduate and Postdoctoral Studies for acceptance, a thesis/dissertation entitled:

Tunability of Photogenerated Charge Carrier Density on Semiconductors by In-situ Electrochemical Treatments

submitted by $\mathrm{Xu}$ Liu in partial fulfillment of the requirements for

the degree of Master of Applied Science

in Mechanical Engineering

\section{Examining Committee:}

Walter Mérida, Mechanical Engineering

Supervisor

Elöd Gyenge, Chemical and Biological Engineering

Supervisory Committee Member

Jesús Adrián Díaz-Real, Mechanical Engineering

Supervisory Committee Member 


\section{Abstract}

With fossil fuels increasingly being exhausted and environment pollutions getting worse, it is necessary for our generation to look for sustainable, renewable and environmentally safe alternative energy sources. Solar energy is so far the most available resource, with around 120,000 TW of solar energy striking the surface of the earth. However, sunlight is just available in the daytime, can change within hours or seasons, and it is spread over low-density collection areas. An efficient way of energy storage is required for the utilization of solar energy. So far, one of the most practical ways to store a significant amount of energy is through a chemical energy carrier. Hydrogen fuel is one of the prime candidates as a future energy carrier which is environmentally friendly during its production, delivery, and consumption. Hydrogen production by photoelectrochemical water splitting using a semiconductor catalyst could be one of the most promising ways to harvest solar energy.

In this thesis, an in-situ potentiodynamic approach (cyclic voltammetry) was used to modify the photoelectrocatalytic properties of nanostructured electrodes in different media. The effect of the morphology was studied by comparing $\mathrm{TiO}_{2}$ nanotube and nanorod. Also, the influence of the modification on $\mathrm{WO}_{3}, \mathrm{ZnO}$ materials was evaluated. The photogenerated charge carrier separation was studied by cyclic voltammetry (CV), linear sweep voltammetry (LSV), chronoamperometry (CA), and Mott-Schottky plots. The morphologies of the samples were tested by scanning electron microscope (SEM). X-ray diffraction (XRD) was used to analyze crystallinity. X-ray photoelectron spectroscopy (XPS) was used to characterize the surface chemical composition. The experimental data proved that electronic properties could be changed by the self-doping process, 
hence, improving the optical absorption properties and increase charge transfer rates. In this way, the photoelectrocatalytic activity of semiconductors was enhanced. The observed behaviors from electrochemical measurements suggested that morphology has a vital role in the capacitive properties. A semiconductor tailored via band structure modification indicates that the electrochemical treatment can be a systematic and straightforward technique for developing novel photoelectrocatalysts with enhanced performances under visible light. 


\section{Lay Summary}

Photocatalysis and phototelectrocatalysis are promising strategies to capture and store solar energy. Through these processes, the intermittent solar energy can be used as a driven force. The strategies provide a potential solution to the problems of energy shortage and environmental pollution and will benefit human society for sustainable development. The most significant challenge in this field is developing efficient, stable and environmentally friendly materials and devices to work under visible light irradiation for efficient solar conversion. Herein we designed and synthesized micro and nano-structured photoanodes, and improved their properties for photocatalytic and photoelectrocatalytic reaction. This research includes the design of efficient functional photoanodes, and all these investigations provide useful theoretical and experimental supporting for the large-scale manufacturing, industrial development and even pilot realization of photoelectrochemical systems. 


\section{Preface}

The materials presented in this thesis, including the experimental work, data analysis, and thesis preparation, was completed by Xu Liu under the supervision of Professor Walter Mérida and Dr. Jesús Adrián Díaz-Real at the Department of Mechanical Engineering, the University of British Columbia.

The work of Chapter 3 has been presented by the author at the following conference:

1) X. Liu, J. A. Diaz-Real, T. Holm, Y. Liu, M. Li, and W. Mérida, “Tunability of Photogenerated Charge Carrier Density on Semiconductors by In-situ Electrochemical Treatments." 233rd Electrochemical Society Meeting. (2018)

2) X. Liu, J. A. Diaz-Real, P. Elsäßer, T. Holm, Y. Liu, M. Li, and W. Mérida, "Enhancing Photoelectrocatalytic Activity by Partial Reduction Doping of Titanium Dioxide." 7th Annual ECS BC Young Electrochemists Symposium. (2018) 


\section{Table of Contents}

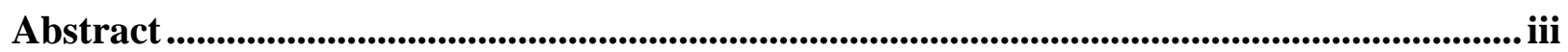

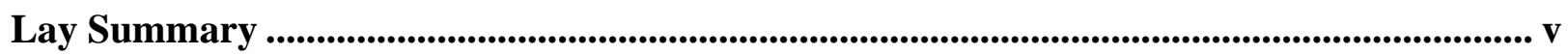

Preface ........................................................................................................................................................... vi

Table of Contents ............................................................................................................................................... vii

List of Figures ..................................................................................................................................... ix

List of Abbreviations......................................................................................................................... xiii

Acknowledgements .......................................................................................................................................... xiv

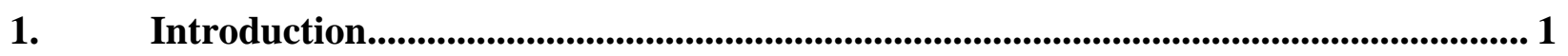

$1.1 \quad$ Research Background and Significance .................................................................. 1

1.2 The Principles of Photocatalysis ................................................................................. 2

1.3 The Principles of Photoelectrocatalysis ...................................................................... 4

$1.4 \quad$ Fundamentals of Photoelectrocatalytic Semiconductors............................................... 7

1.5 The Factors Influencing Efficiency of Photoelectrocatalytic Process …………............. 9

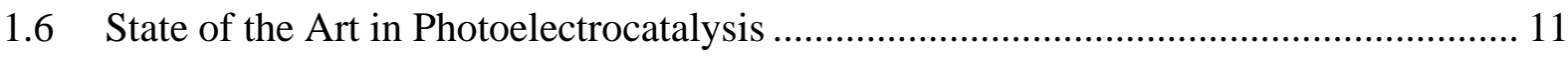

$1.7 \quad$ Hypothesis and Objective.................................................................................... 12

2. Experimental Systems and Experimental Methods....................................................... 13

2.1 Semiconductor Thin Film Deposition Methods .......................................................... 13

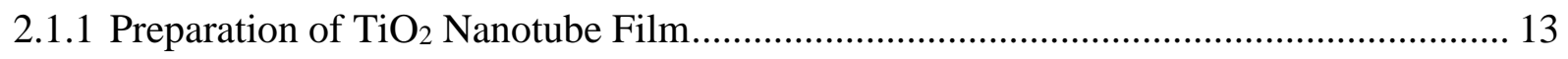

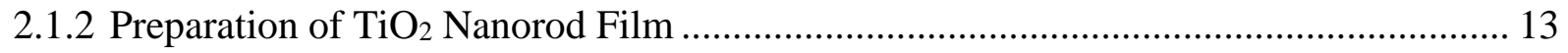


2.1.3 Preparation of $\mathrm{WO}_{3}$ Nanoparticle Film

2.1.4 Preparation of $\mathrm{ZnO}$ Nanorod Film. 15

2.1.5 Preparation of Thin Film Electrode 16

2.1.6 Preparation of Self-doped Thin Film Electrode. 17

2.1.7 Physical Characterization of Thin Film..... 19

2.1.8 Electrochemical and Photoelectrochemical Characterization of Thin Film 20

3. Characterization Results of $\mathrm{TiO}_{2}$ Nanotube/Nanorod Arrays Film 23

3.1 Physical Characterization Results of $\mathrm{TiO}_{2}$ Nanotube/Nanorod Arrays Film 23

3.2 Photoelectrochemical Characterization Results of $\mathrm{TiO}_{2}$ Nanotube/Nanorod Arrays

Evaluation in $\mathrm{H}_{2} \mathrm{SO}_{4}$ Electrolyte 29

3.3 Photoelectrochemical Characterization Results of $\mathrm{TiO}_{2}$ Nanotube/Nanorod Arrays

Evaluation in $\mathrm{NaOH}$ Electrolyte 38

4. Characterization Results of $\mathrm{WO}_{3}$ Arrays Film .................................................................. 46

4.1 Physical Characterization Results of $\mathrm{WO}_{3}$ Arrays Film .............................................. 46

4.2 Photoelectrochemical Characterization Results of $\mathrm{WO}_{3}$ Arrays Film .......................... 50

5. Characterization Results of ZnO Arrays Film .................................................................. 55

5.1 Physical Characterization Results of ZnO Arrays Film .............................................. 55

5.2 Photoelectrochemical Characterization Results of ZnO Arrays Film ............................. 58

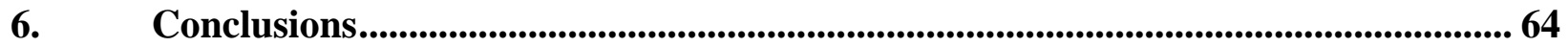

References.............................................................................................................................................................. 66 


\section{List of Figures}

Figure 1.1 Electricity consumption and solar power production [4] ....................................... 1

Figure 1.2 Principle of water splitting using semiconductor photocatalysts [12]...................... 3

Figure 1.3 Mechanism of photoelectrochemical water splitting for hydrogen production............ 5

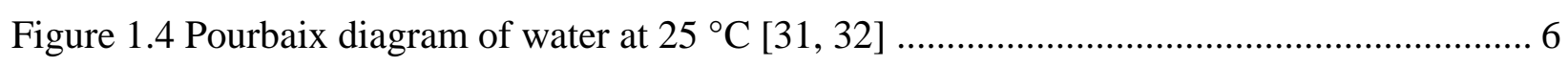

Figure 1.5 Band positions of several semiconductors in contact with aqueous electrolyte at $\mathrm{pH}=$

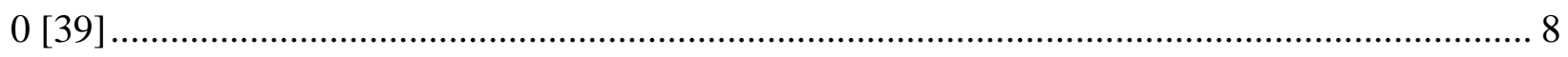

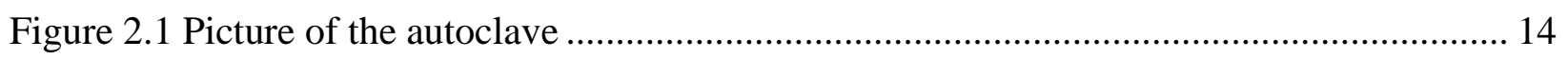

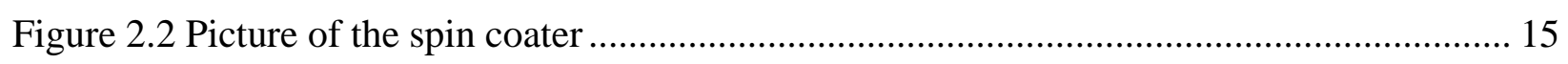

Figure 2.3 Schematic illustration of electrode preparation .............................................. 17

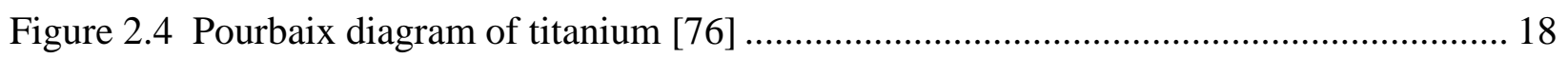

Figure 2.5 Pourbaix diagram of a) $\mathrm{W}-\mathrm{H}_{2} \mathrm{O}[77]$ and b) $\mathrm{Zn}-\mathrm{H}_{2} \mathrm{O}$ [78] system ......................... 19

Figure 2.6 Schematic of electrochemical characterization platform ................................... 20

Figure 3. 1 XRD spectra for the $\mathrm{TiO}_{2}$ a) NT and b) NR before and after modification .............. 24

Figure 3.2 SEM for the $\mathrm{TiO}_{2}$ a) NT and b) NR before and after modification.......................... 25

Figure 3.3 Raman spectra of the $\mathrm{TiO}_{2}$ a) NT and b) NR before and after modification.............. 26

Figure 3.4 High-resolution XPS spectra of the Ti 2p (a, b, and c), and O 1s (d, e, and f) of the

$\mathrm{TiO}_{2}-\mathrm{NT}$ samples before and after the electrochemical reduction...................................... 28

Figure 3.5 High-resolution XPS spectra of the Ti 2p (a, b, and c), and O 1s (d, e, and f) of the $\mathrm{TiO}_{2}$-NR samples before and after the electrochemical reduction ..................................... 29

Figure 3.6 Cyclic voltammograms (CV) of the $\mathrm{TiO}_{2}$ a) NT and b) NR before and after modification; modification process of the $\mathrm{TiO}_{2} \mathrm{c}$ ) $\mathrm{NT}$ and d) $\mathrm{NR}$ in $0.5 \mathrm{M} \mathrm{H}_{2} \mathrm{SO}_{4}$ solution ....... 31 
Figure 3.7 Linear sweep voltammograms (LSV) of the $\mathrm{TiO}_{2}$ a) NT and b) NR before and after modification in $0.5 \mathrm{M} \mathrm{H}_{2} \mathrm{SO}_{4}$ solution

Figure 3.8 Chronoamperometric (CA) response of the $\mathrm{TiO}_{2}$ a) NT and b) NR before and after modification in $0.5 \mathrm{M} \mathrm{H}_{2} \mathrm{SO}_{4}$ solution

Figure 3.9 Incident Photon-to-Current Efficiency and Tauc plots of the $\mathrm{TiO}_{2} \mathrm{a}, \mathrm{c}$ ) NT and b, d) NR before and after modification in $0.5 \mathrm{M} \mathrm{H}_{2} \mathrm{SO}_{4}$ solution 35

Figure 3.10 Mott-Schottky plots of the $\mathrm{TiO}_{2}$ a) NT and b) NR before and after modification in $0.5 \mathrm{M} \mathrm{H}_{2} \mathrm{SO}_{4}$ solution

Figure 3.11 Bandgap structure of the $\mathrm{TiO}_{2} \mathrm{NT}$ and NR before and after modification in $0.5 \mathrm{M}$ $\mathrm{H}_{2} \mathrm{SO}_{4}$ solution 38

Figure 3.12 Cyclic voltammograms (CV) of the $\mathrm{TiO}_{2}$ a) NT and b) NR before and after modification; modification process of the $\mathrm{TiO}_{2} \mathrm{c}$ ) $\mathrm{NT}$ and d) $\mathrm{NR}$ in $1 \mathrm{M} \mathrm{NaOH}$ solution 39 Figure 3.13 Linear sweep voltammograms (LSV) of the $\mathrm{TiO}_{2}$ a) NT and b) NR; and photocurrent density $(j \mathrm{ph})$ for the $\mathrm{TiO}_{2}$ c) $\mathrm{NT}$ and d) NR before and after modification in $1 \mathrm{M} \mathrm{NaOH}$ solution

Figure 3.14 Chronoamperometric (CA) response to light irradiation of the $\mathrm{TiO}_{2}$ a) NT and b) NR before and after modification in $1 \mathrm{M} \mathrm{NaOH}$ solution 42

Figure 3.15 Incident Photon-to-Current Efficiency and Tauc plots of the $\mathrm{TiO}_{2} \mathrm{a}, \mathrm{c}$ ) NT and b, d) NR before and after modification in $1 \mathrm{M} \mathrm{NaOH}$ solution 43

Figure 3.16 Mott-Schottky plots of the $\mathrm{TiO}_{2}$ a) NT and b) NR before and after modification in 1

$\mathrm{M} \mathrm{NaOH}$ solution. 44

Figure 3.17 Bandgap structure of the $\mathrm{TiO}_{2} \mathrm{NT}$ and NR before and after modification in $1 \mathrm{M}$ $\mathrm{NaOH}$ solution 45 
Figure 4.1 SEM images of the $\mathrm{WO}_{3}$ before and after modification............................................. 46

Figure 4.2 a) XRD spectra and b) detailed spectra of the $\mathrm{WO}_{3}$ before and after modification .... 47

Figure 4.3 Raman spectra of the $\mathrm{WO}_{3}$ before and after modification ......................................... 48

Figure 4.4 High-resolution XPS spectra of the $\mathrm{WO}_{3}$ before and after modification .................... 49

Figure 4.5 a) Original and b) zoomed-in cyclic voltammograms (CV) of the $\mathrm{WO}_{3}$ before and

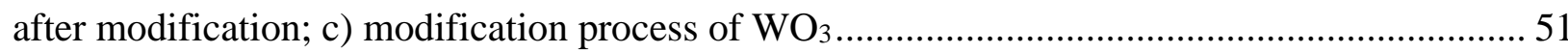

Figure 4.6 a) Linear sweep voltammograms (LSV) and b) photocurrent density $\left(j_{\mathrm{ph}}\right)$ of the $\mathrm{WO}_{3}$

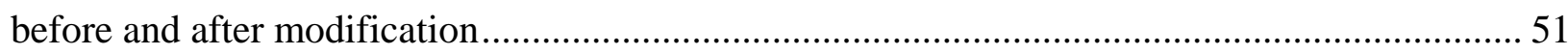

Figure 4.7 Chronoamperometric (CA) response to light irradiation of the $\mathrm{WO}_{3}$ before and after

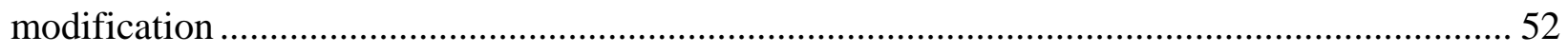
Figure 4.8 a) Incident Photon-to-Current Efficiency and b) Tauc plots of the $\mathrm{WO}_{3}$ before and

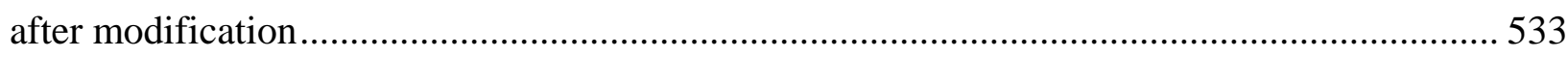

Figure 4.9 Mott-Schottky plots of the $\mathrm{WO}_{3}$ before and after modification .................................544

Figure 4.10 Bandgap structure of the $\mathrm{WO}_{3}$ before and after modification ................................... 54

Figure 5.1 SEM images of the $\mathrm{ZnO}$ a) before and b) after modification....................................... 55

Figure 5.2 a) XRD spectra and b) detailed spectra of the $\mathrm{ZnO}$ before and after modification..... 56

Figure 5.3 Raman spectra of the $\mathrm{ZnO}$ before and after modification ........................................... 57

Figure 5.4 High-resolution XPS spectra of the $\mathrm{ZnO}$ before and after modification...................... 58 Figure 5.5 a) Original and b) zoomed-in cyclic voltammograms (CV) of the $\mathrm{ZnO}$ before and after

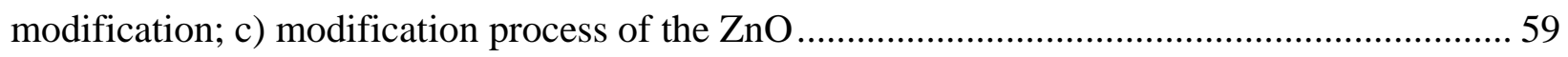
Figure 5.6 a) Linear sweep voltammograms (LSV) and b) photocurrent density ( $\left.j_{\mathrm{ph}}\right)$ of the $\mathrm{ZnO}$

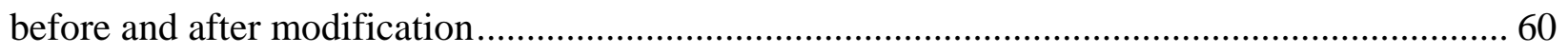


Figure 5.7 Chronoamperometric (CA) response to light irradiation of the $\mathrm{ZnO}$ before and after modification .

Figure 5.8 a) Incident Photon-to-Current Efficiency and b) Tauc plots of the $\mathrm{ZnO}$ before and

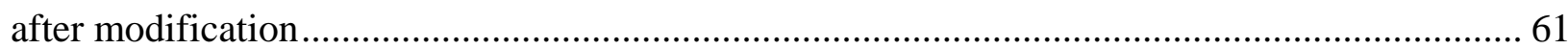

Figure 5.9 Mott-Schottky plots of the $\mathrm{ZnO}$ before and after modification.............................. 62

Figure 5.10 Bandgap structure of the $\mathrm{ZnO}$ before and after modification................................ 63 


\section{List of Abbreviations}

Bandgap $\quad E_{g}$

Chronoamperometry CA

Conduction band $\quad$ CB

Cyclic voltammetry $\quad \mathrm{CV}$

$\begin{array}{ll}\text { Fluorine doped tin oxide } & \text { FTO }\end{array}$

Linear sweep voltammetry $\quad$ LSV

Mott-Schottky M-S

$\begin{array}{ll}\text { Nanorod NR } & \text { NR }\end{array}$

Nanotube $\quad$ NT

Photovoltaics PV

Scanning electron microscope $\quad$ SEM

$\begin{array}{ll}\text { Solar-to-hydrogen } & \text { STH }\end{array}$

Standard hydrogen electrode $\quad$ SHE

Standard temperature and pressure $\quad$ STP

Valence band $\quad$ VB

X-ray diffraction $\quad$ XRD

X-ray photoelectron spectroscopy XPS 


\section{Acknowledgements}

Two roads diverged in a yellow wood. And I took the one less traveled by, and that has made all the difference.

\section{-Robert Frost}

First, I would like to thank my advisor, Prof. Walter Mérida, for his generous support and consistent guidance throughout my master's study at the University of British Columbia. I would also like to say thanks to the postdoctoral researcher in my group, Dr. Jesús Adrián Díaz-Real, for his constant efforts to make my stay at UBC enjoyable. Without their encouragement, I would never have imagined the possibility of finishing my master's courses and thesis in two years. Without their assistance, I doubt I would ever reach this point.

The preparation of $\mathrm{TiO}_{2}$ is conducted at CERC lab at UBC. I appreciate a lot for the support from the International Research Center for Renewable Energy (IRCRE) in China in the preparation of $\mathrm{TiO}_{2}$ nanorod, $\mathrm{WO}_{3}$ nanoparticle and $\mathrm{ZnO}$ nanorod.

I would like to express my gratitude to all the friends I have met at UBC. Especially, I will cherish the great memories of working with Dr. Omar Herrera, Patrick Elsäßer, Zhihao Wang and Ezgi Kisa. Finally, I would like to thank my family members in China, especially my parents, Mr. Zhanli Liu and Ms. Hanxiang Liu for their unconditional love and affection for me. Thanks for their supporting and understanding as always. I am so proud of them and will cherish their love. 


\section{Introduction}

\subsection{Research Background and Significance}

The increasing $\mathrm{CO}_{2}$ levels observed over the last decades have reached their highest levels in 400,000 years [1]. Such an increase is inherently related to our society's dependence on fossil fuels. Along with the direct repercussions on the environment $[2,3]$, the shortage of these fuels has promoted the research on technologies that take advantage of different energy sources. Among the different options, the use of solar energy stands out for its abundance, availability and less contribution to greenhouse gases. However, the generated electricity from solar power systems, like photovoltaics $(\mathrm{PV})$, is not consistent with the tendency of energy demand during the daytime [4]. To comply with such demand, batteries have been used to store the solar electricity. Nevertheless, the current generation of batteries faces several inconveniencies which include high manufacturing costs, shortened durability due to irreversible structural changes in their materials, and low gravimetric energy densities. These facts reflect the need for alternative ways to address the energy storage problem.

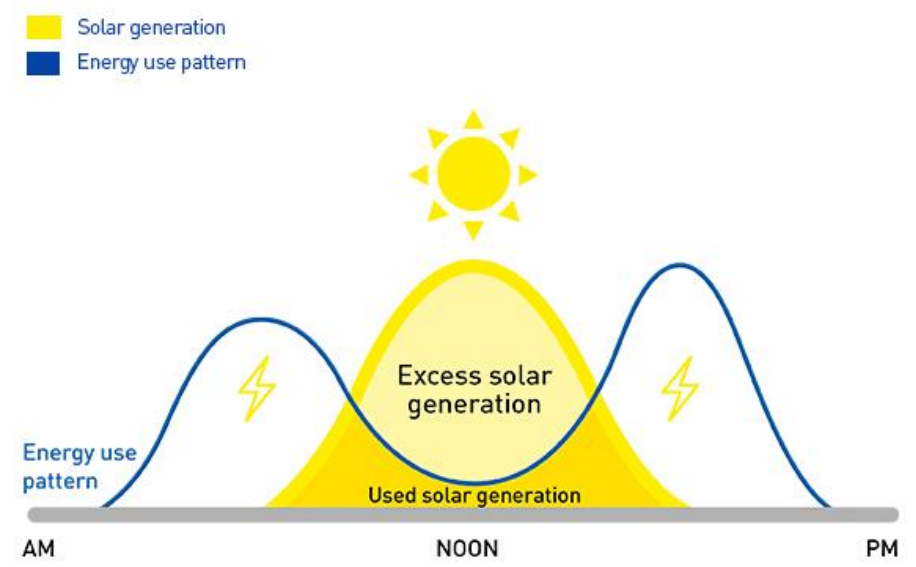

Figure 1.1 Electricity consumption and solar power production data taken from[4] 
Meanwhile, hydrogen has received much attention since it is a low-carbon fuel with a high energy density $(142 \mathrm{MJ} / \mathrm{kg})$ [5]. However, the scarcity of pure hydrogen in nature requires the development of efficient production methods. The different sources that can be used to generate hydrogen include methane, biomass, and water. Several vital disadvantages, however, undermine its mass production. Hydrogen production through natural gas reforming/gasification process results in greenhouse gases emission [6]. Hydrogen reformation from biomass-derived liquid tends to be more difficult, due to the larger sized molecules of biomass with longer alkylated chains, compared with natural gas [7]. A promising method to generate hydrogen is water splitting process, in which hydrogen is produced directly from the photocatalytic oxidation and reduction of water using inexhaustible sunlight and photocatalysts. Thus, water splitting is a more environmentally friendly and feasible way with no carbon dioxide being produced during the process. However, not all types of photocatalysts are suitable for the water-splitting reaction, as the thermodynamic and the kinetic properties of the photocatalysts will influence the efficiency of the systems. The feasibility of this process was firstly demonstrated by Honda and Fujishima in 1972 [8]. In this work, the importance of the characteristics of the semiconductor electrodes was established, giving rise to extensive investigations in material science, electrochemistry, and photocatalysis.

\subsection{The Principles of Photocatalysis}

The word "photocatalysis" was first used as early as 1910 by J. Plotnikov [9]. Generally speaking, photocatalysts can be used to modify the speed of the chemical reaction after activated by light without being consumed itself. Semiconductors are widely used as the photocatalysts because of their unique optoelectronic characteristics during the photocatalytic reaction. Opposite from metals, 
the energy band of the semiconductor is discontinuous [10]. The lower energetic valence band and higher energetic conduction band form the band structure of the semiconductor. The valence band is filled with electrons. Contrary to the former, the conduction band is empty when there is no light irradiating to the semiconductor. Between them, there is an empty energy region where no electron states can exist, called the bandgap $\left(E_{\mathrm{g}}\right)[11]$. The value for the bandgap of each semiconductor will depend on its electronic configuration and chemical composition.

The overall process of photocatalytic water splitting process on a nanoparticulated semiconductor is shown in Figure 1.2. When irradiated by the light with energy higher than the semiconductor $E_{g}$, electrons will be activated. After the excitation, the electrons will migrate from the valence band (VB) to the conduction band (CB). Therefore, electrons are separated from holes (charge carriers) and will migrate to the surface of particles. After migrating to the surface, the adsorbed molecules on this interface can interact with carriers. While the photogenerated electrons can induce (if the energy position of the conduction band is favorable) the reduction of water to produce $\mathrm{H}_{2}$, the holes left in the valence band can participate in the oxidation of water to yield $\mathrm{O}_{2}$.

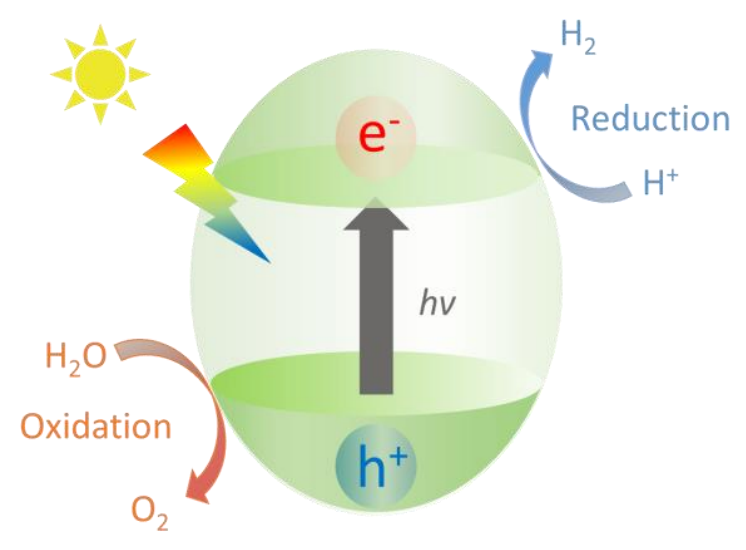

Figure 1.2 Principle of water splitting using semiconductor photocatalysts taken from[12] 
In summary, the water-splitting process happening on a semiconductor can be summarized into four steps: (1) When the photocatalyst absorbs light with energy enough to drive photocatalytic reaction, electron-hole pairs will be produced; (2) Charge separation and then the their movement from bulk towards the surface of the semiconductor; (3) Surface chemical reactions, including photo-generated holes involved in the oxidation reaction and electrons in the reduction reaction; (4) If no reactions occur (i.e., kinetic barriers), the photo-generated electrons and holes will recombine followed by the energy released in the form of light and heat [13].

\subsection{The Principles of Photoelectrocatalysis}

In the previous section, a typical process of photocatalysis is presented, which is usually carried out using aqueous suspensions of semiconductor powder. However, there are two distinct problems in the research and application of photocatalysis. First, in the suspension system with a powdered photocatalyst, the catalyst has to be separated from the solution after use [14]. Second, the accumulation of the photo-generated electrons and holes in the catalyst are much easier to recombine with each other [14-17]. Hence, the efficiency of the light utilization is significantly reduced. Also, the resulting gas produced will be a mixture of $\mathrm{O}_{2}$ and $\mathrm{H}_{2}$, which poses a hazard due to its inherent explosive nature $[18,19]$. And also, more processes are necessary to separate $\mathrm{O}_{2}$ and $\mathrm{H}_{2}$.

Different from electrocatalysis, photoelectrocatalysis is more effective by applying a biased voltage to the reaction system. This change improves the separation of photogenerated electrons and holes because the extra power applied to the system forces the electrons to move to the external 
circuit. In this way, the probability of recombination for electrons and holes is greatly decreased [14-17].

Figure 1.3 shows the overall photoelectrochemical water splitting process on a semiconductor electrode. When irradiated by the light with energy enough to drive the photoelectrochemical reaction, electrons are excited from $\mathrm{VB}$ to $\mathrm{CB}$, and holes will be left in the $\mathrm{VB}$. Most of these electrons combine with $\mathrm{H}^{+}$to generate hydrogen on a counter electrode as holes combined with $\mathrm{H}_{2} \mathrm{O}$ on the surface of the working electrode to produce oxygen. The half-reactions in acid solution can be described as follows [20,21]:

$$
\begin{gathered}
2 \mathrm{H}^{+}+2 e^{-} \rightarrow H_{2} \\
2 \mathrm{H}_{2} \mathrm{O} \rightarrow \mathrm{O}_{2}+4 \mathrm{H}^{+}+4 e^{-}
\end{gathered}
$$

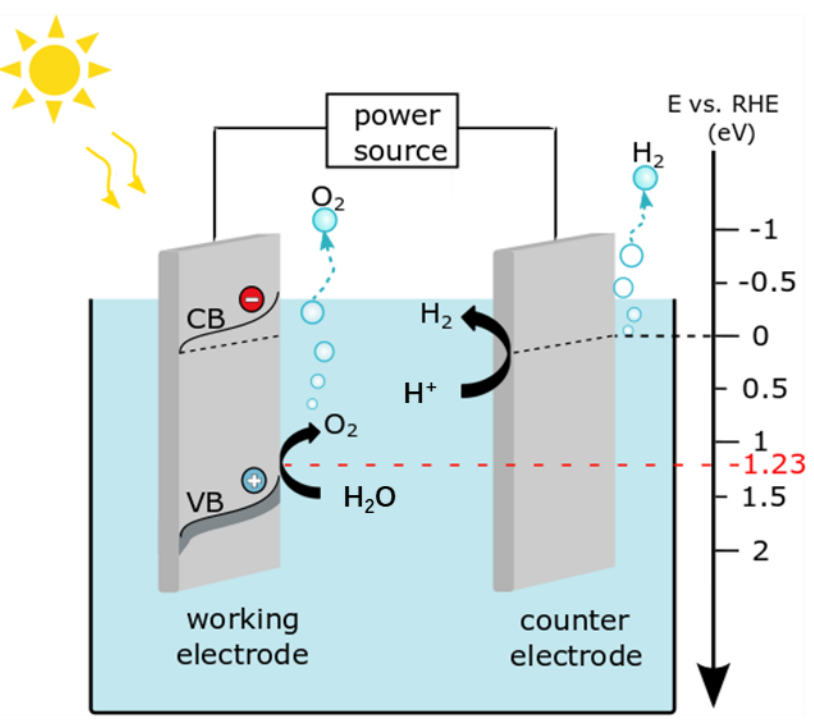

Figure 1.3 Mechanism of photoelectrochemical water splitting for hydrogen production

The required Gibbs free energy for water splitting is $237.2 \mathrm{~kJ} / \mathrm{mol}$ (Eqn 3). This means that the minimum voltage and photocatalyst bandgap is $1.23 \mathrm{~V}$ based on Eqn 4 : 


$$
\begin{gathered}
2 \mathrm{H}_{2} \mathrm{O} \rightarrow \mathrm{O}_{2}+2 \mathrm{H}_{2} \quad \Delta G_{0}=237.2 \mathrm{~kJ} / \mathrm{mol} \\
\Delta G_{0}=-n F E_{0}
\end{gathered}
$$

where $n$ stands for the number of electrons transferred during the reaction. $F$ stands for the Faraday constant $[8,12,21-26]$. The required cell potential should be $1.6 \mathrm{~V} \sim 2.4 \mathrm{~V}$ for reaching the optimal operating current density [26-30].

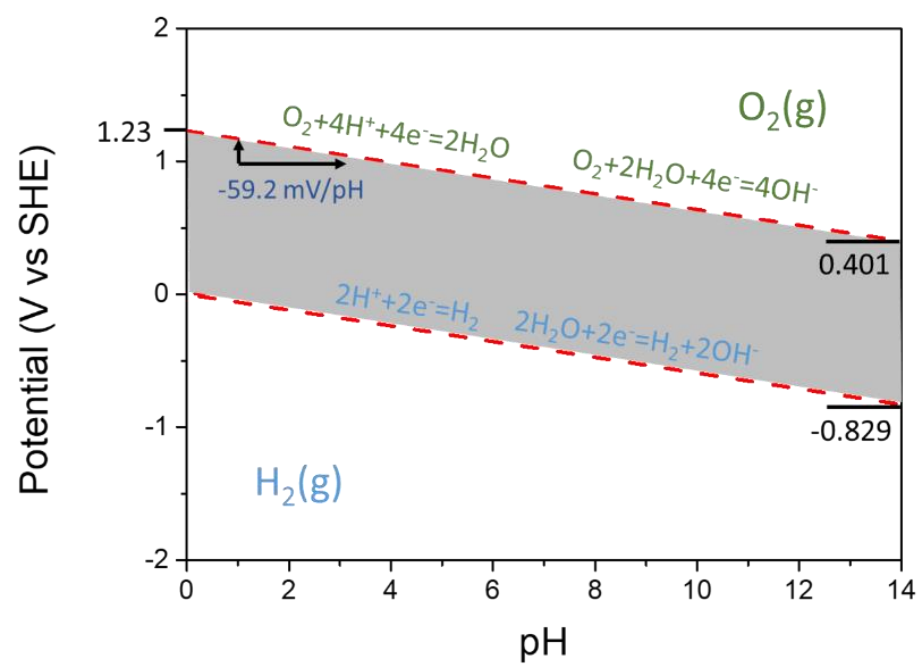

Figure 1.4 Pourbaix diagram of water at $25{ }^{\circ} \mathrm{C}$ taken from[31, 32]

Figure 1.4 shows the Pourbaix diagram for water at standard conditions for temperature and pressure $(273.15 \mathrm{~K}, 101.3 \mathrm{kPa})$. The $\mathrm{Y}$-axis shows the electrode potential referred to a standard hydrogen electrode (SHE). The X-axis represents the $\mathrm{pH}$ of the electrolyte. The stable potential window for water (without being reduced to $\mathrm{H}_{2}$ ) is related to the $\mathrm{pH}$ of the electrolyte following the equation,

$$
E_{H}=-0.0591 \times p H
$$


where $E_{\mathrm{H}}$ is the potential for hydrogen evolution. If the applied potential is more negative than the thermodynamic reduction potential for water, hydrogen will be evolved. This plot shows that the thermodynamic conditions to induce the evolution of water is strongly related to the $\mathrm{pH}$ [31-35].

\subsection{Fundamentals of Photoelectrocatalytic Semiconductors}

Not all semiconductors with bandgap above $1.23 \mathrm{~V}$ can split water in the solar-to-hydrogen (STH) conversion system. The capacity of the electrode in driving the photoelectrochemical reaction is dictated not only by the width of bandgap but the position of CB and VB. Semiconductor electrodes immersed in the electrolyte require a minimum energy (from the photons) to separate the charge carriers. This minimum energy is determined by the Fermi energy level of the semiconductor's band edge when contacting with the liquid. This may be different because of the different surface states in the semiconductor, and the composition of the electrolyte [21]. In other words, even if the width of the band gap of a semiconductor electrode is thermodynamically favorable to a photoelectrochemical reaction, the position of the conduction and valence band may be not suitable for the drive the reaction. To achieve the entire water splitting process, the width of bandgap should be more than $1.23 \mathrm{~V}$, with the $\mathrm{VB}$ energy level more positive than the potential of $\mathrm{O}_{2} / \mathrm{H}_{2} \mathrm{O}$, and the $\mathrm{CB}$ energy level more negative than that of $\mathrm{H}^{+} / \mathrm{H}_{2}$. [23, 36]. Figure 1.5 shows that many semiconductors have suitable bandgaps to catalyze the water-splitting reaction, like $\mathrm{TiO}_{2}, \mathrm{ZnO}, \mathrm{Nb}_{2} \mathrm{O}_{5}, \mathrm{CdS}$, and $\mathrm{BiTiO}_{3}$. However, for some of those materials, toxicity and corrosion remain challenges for their commercial application [37, 38]. 


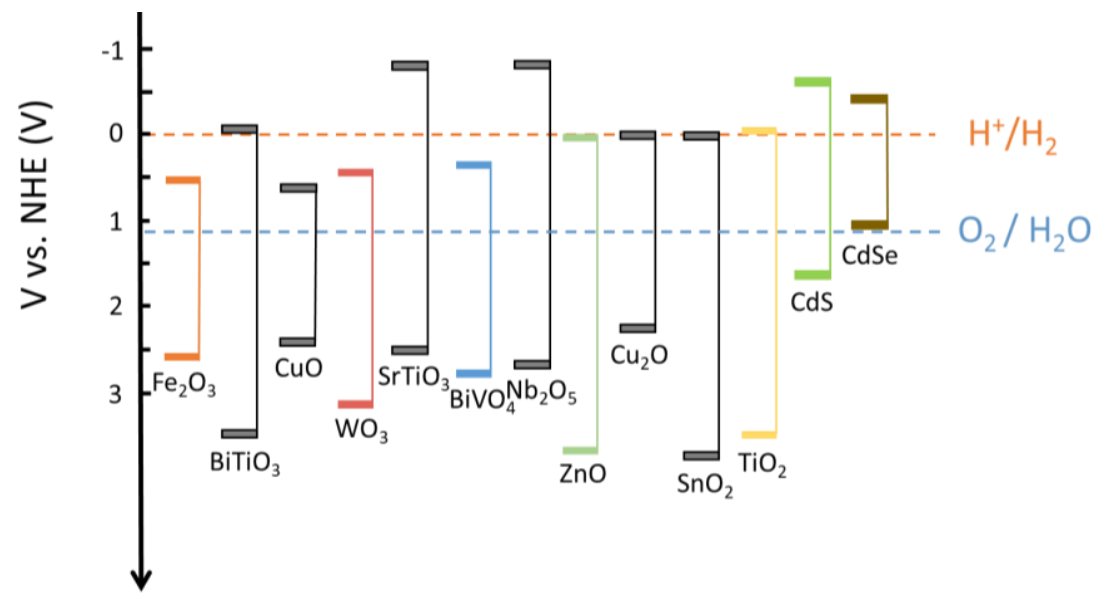

Figure 1.5 Band positions of several semiconductors in contact with aqueous electrolyte at $\mathrm{pH}=0$ taken from[39]

Titanium dioxide $\left(\mathrm{TiO}_{2}\right)$ is widely used as a functional photoanode material due to its chemical stability, nontoxicity and bandgap position suitable for photoelectrocatalytic reactions under ultraviolet (UV) light [40-43]. It commonly exists either in anatase $\left(E_{g}=3.2 \mathrm{eV}\right)$ or rutile $\left(E_{g}=3.0\right.$ eV) phase [44]. However, because of its large band gap, the photons used to excite $\mathrm{TiO}_{2}$ should be in the range of UV light [45-47]. Also, the photoelectrocatalytic (PEC) efficiency of $\mathrm{TiO}_{2}$ electrode is still limited due to the high recombination rate of photo-generated electrons with holes [48-52]. Hiroaki Tada proposed $\mathrm{CdS}-\mathrm{Au}-\mathrm{TiO}_{2}$ nanojunction, which had a higher photoelectrocatalytic activity compared with $\mathrm{TiO}_{2}$ films, due that the Z-scheme formed by $\mathrm{CdS}-\mathrm{Au}-\mathrm{TiO}_{2}$ greatly improved charge-separation efficiency [53]. Tamura et al. used $\mathrm{p}-\mathrm{GaP} / \mathrm{n}-\mathrm{TiO}_{2}$ as a tandem combination. GaP has band gap energy of $2.25 \mathrm{eV}$ and absorbs visible part of solar emission. However, a tandem combination of the $\mathrm{p}-\mathrm{GaP} / \mathrm{n}-\mathrm{TiO}_{2}$ had a low efficiency $(<1 \%)$ due to the degradation of the p-GaP electrode [54].

$\mathrm{ZnO}$ is another widely studied metal oxide in photoelectrochemistry. $\mathrm{ZnO}$ has a bandgap position similar to that of $\mathrm{TiO}_{2}$, which makes it a good substitute when $\mathrm{TiO}_{2}$ cannot be used. To improve 
the performance of $\mathrm{ZnO}$, many synthesis methods have been developed to create different morphologies, like nanorods, nanoneedles, nanobranches, etc.

In addition to $\mathrm{TiO}_{2}$ and $\mathrm{ZnO}, \mathrm{WO}_{3}$ is among the most studied oxides due to its good stability against photo-corrosion during photoelectrochemical water oxidation process [55]. Although $\mathrm{WO}_{3}$ has a lower bottom edge of the conduction band than $\mathrm{TiO}_{2}$ [56], its smaller bandgap (2.4-2.8 eV) when compared with that of $\mathrm{TiO}_{2}$ makes it a preferable alternative as the catalyst [57-63]. However, the photoelectrocatalytic efficiency of pure $\mathrm{WO}_{3}$ is very limited, due to the fast recombination of electron-hole pairs [57-60]. Bin Yang et al. reported a photocurrent density of $2.3 \mathrm{~mA} / \mathrm{cm}^{2}$ using a photoelectrode of interconnected spherical nanoparticle $\mathrm{WO}_{3}$ (produced by sol-gel method) in the solution of $1 \mathrm{M} \mathrm{H}_{2} \mathrm{SO}_{4}$, and $4.0 \mathrm{~mA} / \mathrm{cm}^{2}$ with the addition of $0.1 \mathrm{M}$ methanol, under light irradiation at $86 \mathrm{~mW} / \mathrm{cm}^{2}$ [64]. Other methods to generate efficient $\mathrm{WO}_{3}$ include magnetron sputtering $\left(2.68 \mathrm{~mA} / \mathrm{cm}^{2}\right)$ [65], doping with $\mathrm{C}\left(2.6 \mathrm{~mA} / \mathrm{cm}^{2}\right.$ in presence of $20 \%$ (v/v) methanol in $1 \mathrm{M} \mathrm{HCl)} \mathrm{[66],} \mathrm{etc.}$

\subsection{The Factors Influencing Efficiency of Photoelectrocatalytic Process}

According to the principle of photoelectrocatalysis described in section 1.2, the factors that affect the efficiency of energy conversion are listed below:

(1) The optical absorption coefficient of materials. From section 1.2, we know that the first step of the photoelectrocatalytic process is that the semiconductor electrode is stimulated by light, generating electron-hole pairs, followed by a redox reaction. Therefore, the ideal semiconductor electrode should have $100 \%$ absorption of photons that have a wavelength shorter than the 
theoretical absorption edge for the material. However, the actual situation is not the case. In an extrinsic semiconductor, poor absorption and utilization efficiency of photons at short wavelengths are typically expected. In contrast, the intrinsic semiconductor has a much higher absorption rate of light [67]. When light is irradiated to the semiconductor, the light penetration depth is expected to be longer for an extrinsic semiconductor before being facing a decay event (i.e. recombination, scavenging, etc.). Therefore, for the intrinsic semiconductor, a relatively thin thickness is favorable for the transmission and reaction of the optical carrier [68].

(2) The separation efficiency of photogenerated carriers. After the semiconductor photoelectrode is activated through light, the photogenerated carriers are produced. Typically, photogenerated carriers will follow one of the three following pathways. The first is the emission of light via irradiative recombination of photogenerated electrons and holes. The second is the energy dissipation in the form of heat energy due to radiative recombination $[69,70]$. The third pathway is the separation of electrons and holes followed by the redox reaction. The charge carrier is consumed by the ways mentioned above, among which the separation of electrons and holes will significantly influence the energy conversion efficiency.

(3) The migration efficiency of the photogenerated carrier. From section 1.2, we know that for a photoelectrochemical reaction, the electrons excited at the semiconductor electrode will move through the external circuit to the surface of the counter electrode. The holes left in VB will migrate to the interface between the semiconductor and electrolyte, followed by the water oxidation reaction. If the lifetime of photogenerated charge carries is not enough to support their migration to their collection site (in the case of the electrons) or the reaction site (for the holes), the excitons 
will recombine. Therefore, the conductivity and mobility efficiency of these species are important factors affecting the performance of the photoelectrocatalytic process.

(4) The kinetics of the charge carrier reactions. The final process, in photoelectrocatalytic water splitting, takes place at the interface between electrode and electrolyte. According to kinetics of the reactions mentioned in equations 1 and 2, the oxidation reaction is much slower, and thus it is the limiting step for the entire process. However, if the oxidation reaction is merely considered, the whole reaction process can be accelerated by adding the hole consumption agent (sacrificial agent) [13].

\subsection{State of the Art in Photoelectrocatalysis}

The materials used in these technologies are semiconductors, which often have reduced conversion efficiencies, limited light absorption spectra, and slow charge transfer kinetics. Nevertheless, it is possible to modulate the properties by promoting the growth of preferential crystalline phases, increasing their surface area, or by generating dopants in the semiconductors.

A typical activation route for oxide semiconductor materials is through non-metal doping, which enhances their conversion efficiencies and expands the absorption spectrum, by introducing intra bandgap states or reducing the bandgap. The standard approaches for oxide semiconductor doping include the addition of the dopants during the synthesis process (via wet chemistry), or posttreatment in reactive environments such as $\mathrm{H}_{2}$ atmosphere, which requires higher processing complexity. Recently, Zhou's group reported an electrochemical treatment that activated $\mathrm{TiO}_{2}$ by a constant polarization of nanotubular morphologies [71]. By applying this potential, the partial 
reduction of the $\mathrm{Ti}^{4+}$ to $\mathrm{Ti}^{3+}$ on the surface of the electrode took place and created a chemical gradient in the outmost layer of the $\mathrm{TiO}_{2}$, i.e., self-doping. This chemical gradient influenced the electric properties of the $\mathrm{TiO}_{2}$, as the processes related to the charge separation were governed by the thermodynamics. The potential used in these experiments was in the region of water reduction, e.g., hydrogen evolution. Such constant polarization leads to the damage of the nanotube arrays by fracturing the tubes, and their detachment from the electrode and loss of active areas. The latter was explained due to the gas accumulation in the gaps between the nanotubes that contributed to the cracking of the nanotubes.

\subsection{Hypothesis and Objective}

In this work, a dynamic polarization via cyclic voltammetry was used to induce the partial reduction on the $\mathrm{TiO}_{2}$ nanotube, $\mathrm{WO}_{3}$ nanoparticle, and $\mathrm{ZnO}$ nanorod to enhance the conversion efficiencies and expand the absorption spectrum of the semiconductor. By improving the charge transfer process and modifying the charge carrier separation kinetics through the self-doping process, the incident-photon-to-current conversion efficiency of these materials should be improved. Meanwhile, this approach modulated the charge carrier separation process while preventing the accumulation of $\mathrm{H}_{2}$ and preserving the morphological structure. Furthermore, a comparison with a similar system, $\mathrm{TiO}_{2}$ nanorod, was used to compare these properties to understand the role of the morphology and the crystallinity in the self-doping process. 


\section{Experimental Systems and Experimental Methods}

\subsection{Semiconductor Thin Film Deposition Methods}

Many preparation methods of semiconductor electrode have been developed, such as spray pyrolysis process, hydrothermal method, spin coating, chemical vapor deposition, physical vapor deposition, continuous ion layer adsorption, electrostatic spraying, screen printing method, etc. The choice of the methodology is based on different considerations according to the characteristics of the material, the difficulty of the preparation process, and the particular application of the thin film. The following methods described below are the ones that were used to synthesize the materials investigated in this thesis.

\subsubsection{Preparation of $\mathrm{TiO}_{2}$ Nanotube Film}

$\mathrm{TiO}_{2}$ nanotubes were synthesized using an electrochemical anodization process [72]. Briefly, a solution was prepared consisting of $0.1 \mathrm{~mol} \mathrm{~L}^{-1} \mathrm{NH}_{4} \mathrm{~F}$ (Alfa Aesar, 98.0\%), 2\% wt $\mathrm{H}_{2} \mathrm{O}$, and ethylene glycol (Sigma-Aldrich, $99 \%)$ as the solvent. A Ti foil $(1.5 \mathrm{~cm} \times 1.5 \mathrm{~cm})$ and a steel plate served as anode and cathode, respectively. The anodization was performed at $60 \mathrm{~V}$ for 30 mins using a fixed distance between both electrodes of $2.5 \mathrm{~cm}$. Subsequently, the pristine electrode was immersed firstly in ethyl alcohol for 10 mins, then submerged in deionized water for 10 mins to remove the remaining electrolyte. Then, the anodized electrode was annealed at $450{ }^{\circ} \mathrm{C}$ for 2 hours in a muffle furnace (JZ-4-1200) under atmospheric condition.

\subsubsection{Preparation of $\mathrm{TiO}_{2}$ Nanorod Film}

The $\mathrm{TiO}_{2}$ and $\mathrm{ZnO}$ nanorods were prepared through the hydrothermal process. In a typical hydrothermal synthesis, the reactants solubilized in an aqueous solution react with each other to 
form the corresponding production in a closed container under a condition where temperature and pressure were much higher than the ambient (reaction temperatures $<300{ }^{\circ} \mathrm{C}$ and pressure pressures $<1.5 \mathrm{MPa}$ ). A typical design of an autoclave is shown in Figure 2.2, where the reactor is usually made of stainless steel while the lining is made of polytetrafluoroethylene.

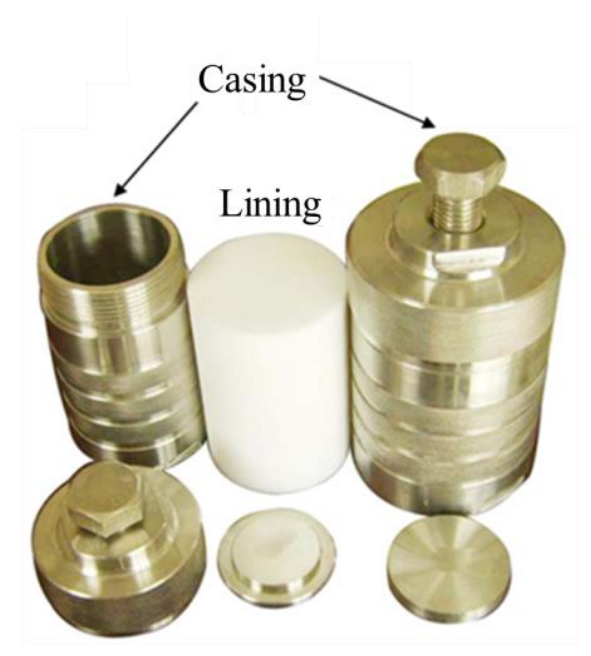

Figure 2.1 Picture of the autoclave

The $\mathrm{TiO}_{2}$ nanorods were deposited on fluorine-doped tin oxide (FTO) (TEC 15, $15 \Omega / \mathrm{cm}$, Hartford Glass) glass in the experiment by a hydrothermal method [73]. The FTO glass was introduced into an ultrasonic bath for cleaning in acetone, ethanol, and deionized water for 30 mins respectively, followed by being dried with the $\mathrm{N}_{2}$ flow. The glass was placed at an angle against the wall with the conducting side facing down, inside the Teflon-lined autoclave. The autoclave was filled with a $0.05 \mathrm{M}$ tetrabutyl titanate (Sinopharm Chemical Reagent Co., Ltd, AR) solution where the solvent was a 1:1 (v/v) mixture of $\mathrm{HCl}$ (Sinopharm Chemical Reagent Co., Ltd, 36.5\%-38\%) and deionized (DI) water. The autoclave was placed in an electric oven at $160{ }^{\circ} \mathrm{C}$ for 2 hours, followed by a cooling process down to the room temperature. After that, the prepared FTO glass was moved from the autoclave and rinsed with deionized water to remove the remaining electrolyte. Finally, 
the sample was annealed at $400{ }^{\circ} \mathrm{C}$ in a muffle furnace (JZ-4-1200) for 0.5 hours to improve crystallinity.

\subsubsection{Preparation of $\mathrm{WO}_{3}$ Nanoparticle Film}

The $\mathrm{WO}_{3}$ nanoparticle film used in the experiment was prepared by the spin coating method [74]. As previously described, the FTO used for the deposition of $\mathrm{WO}_{3}$ nanoparticle was washed by acetone, deionized water, as well as ethanol ultrasonically for 30 mins respectively, followed by drying in a stream of $\mathrm{N}_{2}$. The solution was prepared by dissolving $1 \mathrm{~g}$ ammonium wolframate $\left(\mathrm{H}_{40} \mathrm{~N}_{10} \mathrm{O}_{41} \mathrm{~W}_{12} \cdot \mathrm{xH}_{2} \mathrm{O}\right)$ solution in $9 \mathrm{~g}$ lactic acid and $90 \mathrm{~g}$ ethanol under the temperature of $70{ }^{\circ} \mathrm{C}$ to accelerate its dissolution. After that, the $5 \mathrm{ml}$ precursor solution was dropped on the FTO that is attached to the disk of the spin coater. The spinning process was set as $3000 \mathrm{rpm}$ for $30 \mathrm{~s}$. After repeating this process for 3 times, the substrate was removed and transferred to the muffle furnace to be annealed at $500{ }^{\circ} \mathrm{C}$ for 3 hours.

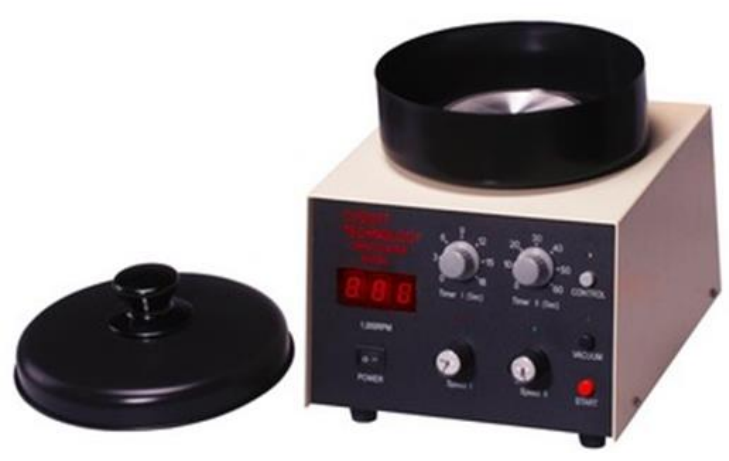

Figure 2.2 Picture of the spin coater

\subsubsection{Preparation of ZnO Nanorod Film}

$\mathrm{ZnO}$ nanorod arrays were prepared via the spin coating process followed by the hydrothermal method [75]. The substrate for the deposition of $\mathrm{ZnO}$ is also FTO which follows the same washing process mentioned before. Before the hydrothermal process, a seed layer of $\mathrm{ZnO}$ was prepared by 
spinning coating process to improve the growth of $\mathrm{ZnO}$ nanorod. A precursor solution of $0.1 \mathrm{M}$ zinc acetate $\left(\mathrm{Zn}\left(\mathrm{CH}_{3} \mathrm{COO}\right)_{2} \cdot 2 \mathrm{H}_{2} \mathrm{O}\right)$ dispersed in methanol was used to apply the seed layer. The layer was applied while the electrode spinned at a speed of $2000 \mathrm{rpm}$ during $25 \mathrm{~s}$. After repeating it for 8 times, the substrate was detached and then thermally treated in a muffle furnace. The conditions for the annealing were $350{ }^{\circ} \mathrm{C}$, with a ramping rate of $5{ }^{\circ} \mathrm{C} / \mathrm{min}$ and a dwell period of 30 min under air. When cooled to the room temperature, the electrode was put into an autoclave with a solution mixture of zinc nitrate $\left(\mathrm{Zn}\left(\mathrm{NO}_{3}\right)_{2} \cdot 6 \mathrm{H}_{2} \mathrm{O}\right)$ and hexamethylenetetramine $\left(\mathrm{C}_{6} \mathrm{H}_{12} \mathrm{~N}_{4}\right)$ at the concentration of $0.05 \mathrm{~mol} \mathrm{~L}^{-1}$. After maintaining at $90{ }^{\circ} \mathrm{C}$ for 24 hours, the electrode was taken out of the autoclave and into a secondary annealing treatment to improve the crystallinity. The conditions for this last step were $450{ }^{\circ} \mathrm{C}$ with a ramping rate of $5{ }^{\circ} \mathrm{C} / \mathrm{min}$, with a dwell time of $30 \mathrm{~min}$.

\subsubsection{Preparation of Thin Film Electrode}

In the film preparation, a part of the conductive glass was usually left uncovered by the catalyst. The part uncovered was used to make the ohmic contact using a copper wire which was connected with a conductive silver glue. Then the electrical connection was covered with epoxy resin adhesive to make sure the film was firmly connected to the wire, and no extra substrate was exposed to electrolyte except the deposited material.

Due to the encapsulation of the electrode with an epoxy resin adhesive, the shape of the exposed part of the film is often irregular, so it is difficult to measure the area directly. In our experiment, we determined the effective area from a digital image through the ImageJ software to calculate the effective area accurately. 


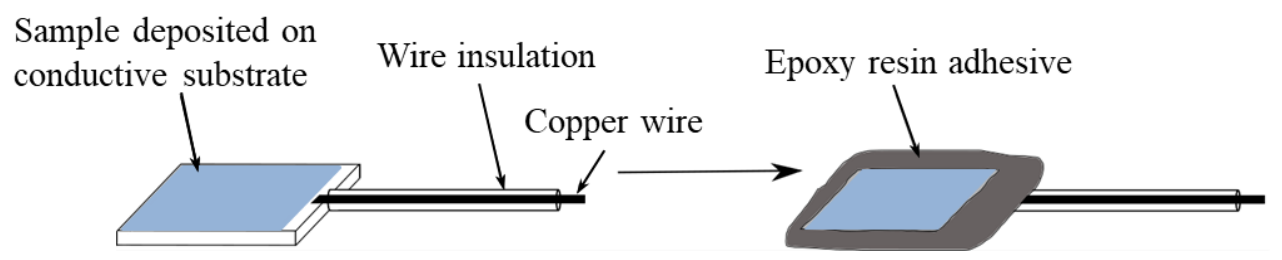

Figure 2.3 Schematic illustration of electrode preparation

\subsubsection{Preparation of Self-doped Thin Film Electrode}

The modification of the electrodes was carried out by an electrochemical reduction technique according to the Pourbaix diagram. Based on Zhou's research, an electrochemical reduction method is a suitable process to induce oxygen vacancy into the material so that the energy states of the material can be modified [71]. The modification potential range should have two important considerations. The upper potential should not induce $\mathrm{O}_{2}$ evolution and lower potential should be lower enough to partially reduce the material. Depending on the Pourbaix diagram of each material (Figures 2.4 and 2.5), the modification potential range for $\mathrm{TiO}_{2}$ should be around -1 to $1 \mathrm{~V}$ vs. $\mathrm{Ag} \mid \mathrm{AgCl}$ in $0.5 \mathrm{M} \mathrm{H}_{2} \mathrm{SO}_{4}(\mathrm{pH}=0.3)$ solution and -1.8 to $0.2 \mathrm{~V}$ vs. $\mathrm{Ag} \mid \mathrm{AgCl}$ in $1 \mathrm{M} \mathrm{NaOH}(\mathrm{pH}=$ 14) in order to induce particle reduction to the film. For $\mathrm{WO}_{3}$, the potential range should be around -1.0 to $1.0 \mathrm{~V}$ vs. $\mathrm{Ag} \mid \mathrm{AgCl}$ in $0.5 \mathrm{M} \mathrm{H}_{2} \mathrm{SO}_{4}$ solution $(\mathrm{pH}=0.3)$ while -1.0 to $1.0 \mathrm{~V}$ vs. $\mathrm{Ag} \mid \mathrm{AgCl}$ for $\mathrm{ZnO}$ in $0.5 \mathrm{M} \mathrm{Na}_{2} \mathrm{SO}_{4}(\mathrm{pH}=7)$.

During the modification process, the reaction takes place at the interface between the electrode and electrolyte. During the potential scan, the semiconductor will be partially reduced resulting in the inclusion of donors at the interface through the reaction between the semiconductor and the electrolyte. This change can be assessed through the Mott-Schottky plots obtained from potentiostatic impedance measurements. 
For the electrochemical experiments, the previously prepared semiconductor electrodes served as the working electrode, with a graphite rod as the counter electrode, as well as a saturated $\mathrm{Ag} \mid \mathrm{AgCl}$ as the reference electrode. A $0.5 \mathrm{M} \mathrm{H}_{2} \mathrm{SO}_{4}(\mathrm{pH}=0.3)$ solution was used as the supporting electrolyte. A cyclic potential scan from -1 to $1 \mathrm{~V}$ vs. $\mathrm{Ag} \mid \mathrm{AgCl}$ (for the $\mathrm{TiO}_{2} \mathrm{NR}$ and $\mathrm{NT}$ ) at a scanning rate of $500 \mathrm{mV} / \mathrm{s}$ was performed for 100 cycles at room temperature to modify the sample. The electrochemical characterization of the electrodes (before and after modification) was performed in the same electrolyte within the potential range of -0.2 to $1 \mathrm{~V}$ vs. $\mathrm{Ag} \mid \mathrm{AgCl}$. In addition, $1 \mathrm{M} \mathrm{NaOH}(\mathrm{pH}=14)$ was also used as the electrolyte to modify $\mathrm{TiO}_{2}$ within the potential range of -1.8 to $0.2 \mathrm{~V}$ vs. $\mathrm{Ag} \mid \mathrm{AgCl}$, and -1.0 to $0.2 \mathrm{~V}$ for electrochemical characterization.

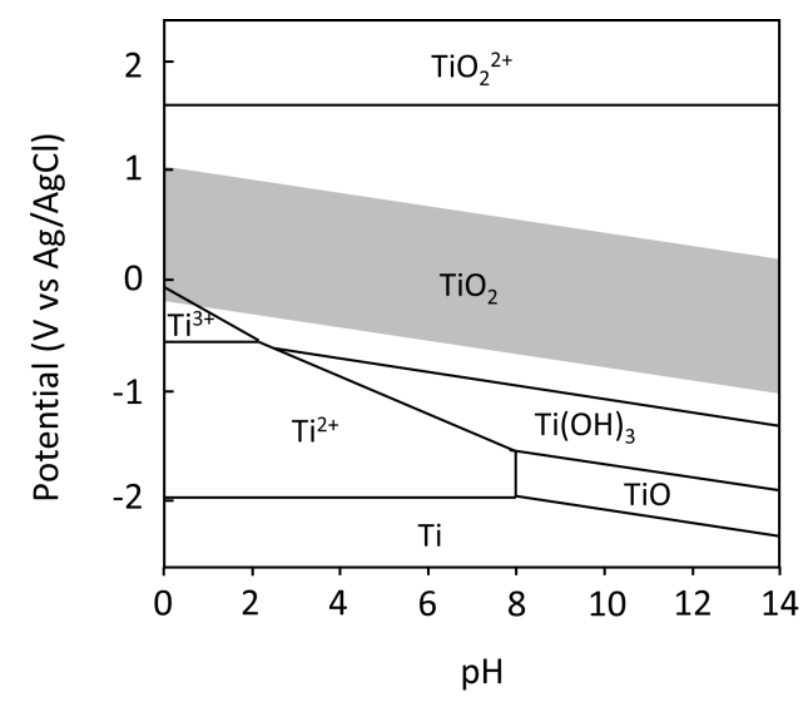

Figure 2.4 Pourbaix diagram of titanium taken from[76]

The modification of other materials was performed using the same electrochemical reduction method by just changing the working electrode to the corresponding material. For the $\mathrm{WO}_{3}$ nanorod electrode, the modification potential range is -1.0 to $1.0 \mathrm{~V}$, at the scanning rate of 500 
$\mathrm{mV} / \mathrm{s}$ for 100 cycles in $0.5 \mathrm{M} \mathrm{H}_{2} \mathrm{SO}_{4}$ solution $(\mathrm{pH}=0.3)$. While for $\mathrm{ZnO}$, we used the same potential range as $\mathrm{WO}_{3}$, but in $0.5 \mathrm{M} \mathrm{Na}_{2} \mathrm{SO}_{4}(\mathrm{pH}=7)$ to keep the stability.
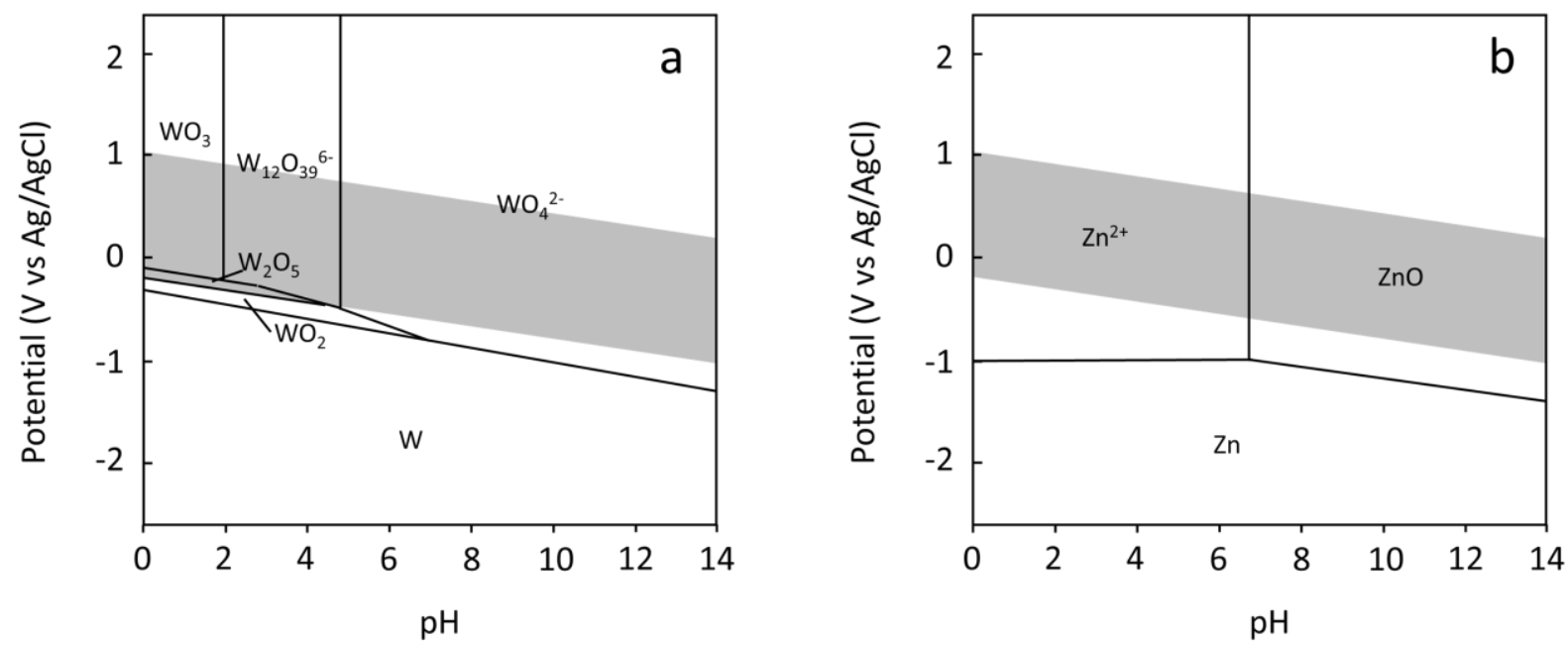

Figure 2.5 Pourbaix diagram of a) $\mathrm{W}-\mathrm{H}_{2} \mathrm{O}$ taken from [77] and b) $\mathrm{Zn}-\mathrm{H}_{2} \mathrm{O}$ taken from [78] system

\subsubsection{Physical Characterization of Thin Film}

X-ray diffractograms were obtained with a Bruker D8-Advance X-ray diffractometer with Copper $\mathrm{K}_{\alpha 1} \& \mathrm{~K}_{\alpha 2}$ irradiation $(\lambda=1.54 \AA)$, scanning from $5^{\circ}$ to $90^{\circ}$ with a step size of $0.03^{\circ}$. Scanning electron microscopy (SEM) was attained with a field emission electron microscope (FEI Helios NanoLab 650 SEM) at the accelerating voltage of $1.0 \mathrm{KV}$, with the secondary electron (SE) mode. Raman spectra were conducted on a Horiba Lab RAM HR Raman microscope using a HeNe laser with $633 \mathrm{~nm}$ irradiation at $2 \mathrm{~mW}$. X-ray photoelectron spectroscopy (XPS) measurements were used to obtain the surface chemical composition, as well as the film states. This process was performed with a Kratos spectrometer (Axis UltraDLD), coupled with monochromatic Al $\mathrm{K}_{\alpha}$ radiation $(h v=1486.69 \mathrm{eV})$. 


\subsubsection{Electrochemical and Photoelectrochemical Characterization of Thin Film}

Photoelectrochemical and electrochemical characterization of the electrodes was carried out in the same experimental platform as that used for electrode modification in addition to a $150 \mathrm{~W}$ xenon lamp. This experimental setup consisted of the semiconductor electrode, a graphite rod, and a saturated $\mathrm{Ag} \mid \mathrm{AgCl}$ electrode respectively used as the working, counter and reference electrode. All electrodes were connected to a potentiostat (Bio-Logic, SP-150) (shown in Figure 2.7).

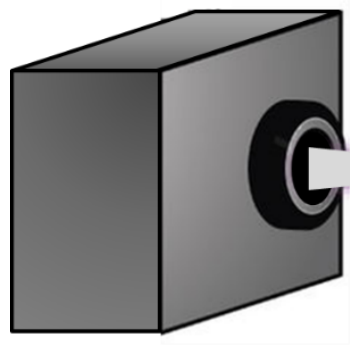

Xe lamp

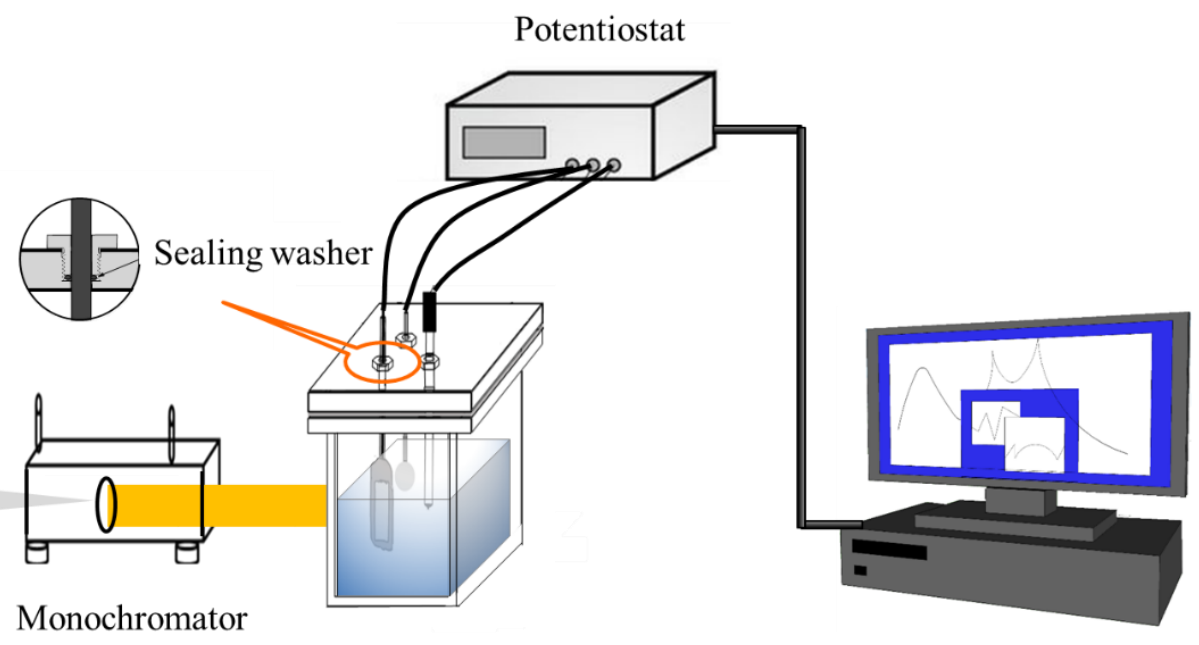

Figure 2.6 Schematic of electrochemical characterization platform

Cyclic voltammograms (CV) were recorded at a scanning rate of $50 \mathrm{mV} / \mathrm{s}$, while Linear Sweep voltammograms (LSV) at a scanning rate of $10 \mathrm{mV} / \mathrm{s}$. The chronoamperometric responses were recorded under a constant potential by turning on and off the lamp. Mott-Schottky plots were measured at different frequencies in the same potential range as that in the CV test. Incidentphoton-to-current conversion efficiency (IPCE) spectra were calculated with the following equation shown below $[79,80]$, 


$$
I P C E=\left(\frac{h c}{e}\right)\left(\frac{J_{p h(\lambda)}}{P_{(\lambda)} \lambda}\right)
$$

where $j_{\mathrm{ph}(\lambda)}$ is the photocurrent density in $\mathrm{mA} / \mathrm{cm}^{2}$ and $P(\lambda)$ denotes the incident irradiance in $\mathrm{mW} / \mathrm{cm}^{2}$ at a specific wavelength $\lambda . h$ is the Planck constant $\left(6.62 \times 10^{-34} \mathrm{~m}^{2} \mathrm{~kg} / \mathrm{s}\right), c$ represents the speed of light $\left(3.0 \times 10^{8} \mathrm{~m} / \mathrm{s}\right)$, and $e$ is the elementary charge $\left(1.602 \times 10^{-19} \mathrm{C}\right)$. Based on the statement above, the equation for IPCE can be simplified as,

$$
I P C E=1240\left(\frac{J_{p h(\lambda)}}{P_{(\lambda)} \lambda}\right)
$$

The semiconductor band gap can be deducted by the formula below,

$$
E_{g}=\frac{1240}{\lambda}
$$

where $\lambda$ is the corresponding wavelength of the absorption edge shown in IPCE plots [83]. It is easy to get the conclusion that the change in the absorption edge of the sample can reflect the change of its bandgap.

To further investigate the changes in the capacitance of the space-charge region in the materials after the self-doping treatment, Mott-Schottky plots were recorded. Based on the Mott-Schottky equation, the capacitance developed inside of semiconductors follows the relationship [84],

$$
C_{S C}^{-2}=\frac{2}{\varepsilon \varepsilon_{0} A^{2} e N_{d}}\left(V-V_{f b}-\frac{k_{B} T}{e}\right)
$$

where $C_{\mathrm{sc}}$ is the differential capacitance of the space-charge region, $\varepsilon$ stands for the dielectric constant of the materials, $\varepsilon_{0}$ represents the permittivity of free space, $A$ is the area of the sample that is in contact with electrolyte, $e$ is the elementary charge, $N_{\mathrm{d}}$ is the density of donors, $V$ denotes the applied potential, $V_{\mathrm{fb}}$ is the flatband potential, $k_{B}$ stands for the Boltzmann constant, and $T$ is the absolute temperature. 
The Mott-Schottky equation is based on many assumptions as follows,

(1) The resistance of the electrolyte and electrode should be zero; (2) the surface of the electrode should be flat enough; (3) interfacial layers should be absent; (4) the dielectric constant of the material is independent on the frequency; (5) the defect can be only donor or acceptor and it must be homogeneously distributed [84]. 


\section{Characterization Results of $\mathrm{TiO}_{2}$ Nanotube/Nanorod Arrays Film}

\subsection{Physical Characterization Results of $\mathrm{TiO}_{2}$ Nanotube/Nanorod Arrays Film}

X-ray diffraction in Bragg-Brentano geometry was used to determine the crystalline phases in $\mathrm{TiO}_{2}$ NT and NR photoanodes. As shown in Figure 3.1, the characteristic diffraction peaks of the planes (101), (103), (102) correspond to the phase of metallic Ti which is the substrate for NT's growth. Except for the peaks of $\mathrm{Ti}$ foil, the crystal structure of $\mathrm{TiO}_{2} \mathrm{NT}$ before and after modification was consistent with anatase phase since the peaks found at $25.367^{\circ}, 37.909^{\circ}$, and $54.051^{\circ}$ correspond to (101), (004), and (105). These peaks attributed to the anatase phase with the standard card (JCPDS 01-073-1764), which allowed us to discard the presence of rutile or other phases. The preferential growth in the [001] direction for the NT sample could be observed from the peak at $37.9^{\circ}$ which assigned to the plane (004). The lattice plane has been reported to be present in other titania materials with enhanced photoactive behavior [85].

Similarly, the crystallinity was induced on the $\mathrm{TiO}_{2} \mathrm{NR}$ films after being annealed at $400{ }^{\circ} \mathrm{C}$ in $\mathrm{N}_{2}$ for 0.5 hours. The diffractograms from $\mathrm{TiO}_{2} \mathrm{NR}$ samples before modification showed identical peak positions and the presence of rutile phase (JCPDS 00-021-1276). Diffraction peaks from the FTO can be detected with the peaks of (110), (200), (211) and (310) which occur at $26.57^{\circ}, 37.75^{\circ}$, $51.47^{\circ}$, and $61.59^{\circ}$ respectively (JCPDS 046-1088). For both $\mathrm{TiO}_{2} \mathrm{NT}$ and NR, there was not an appreciable change in the position of the peaks. However, a small decrease of the intensity appeared in the peaks, which could be attributed to the loss of crystallinity on the surface of the samples as a result of the electrochemical treatment. It is important to remember that the nature of the electrochemical experiments is simply confined in the electrode/electrolyte interface. 
Therefore, such subtle changes would not be appreciated in measurements of the bulk of the material, as observed in the diffractograms.
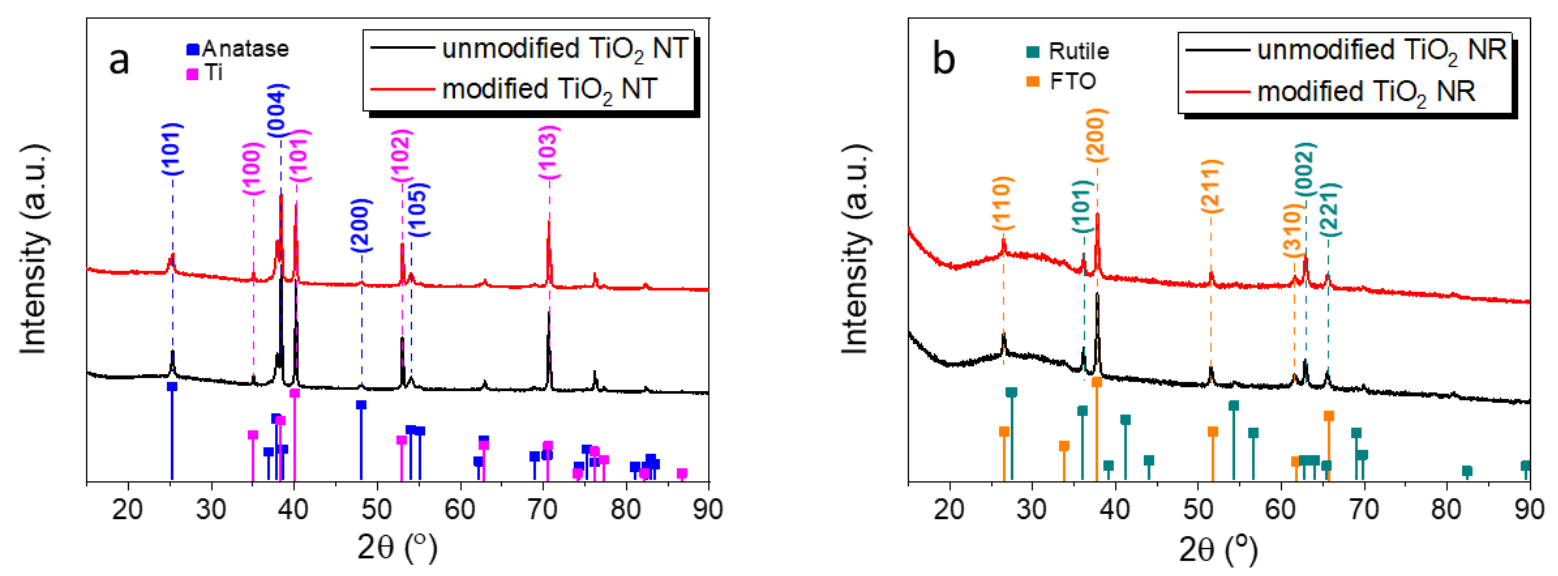

Figure 3. 1 XRD spectra for the $\mathrm{TiO}_{2}$ a) NT and b) NR before and after modification

The surface morphology of $\mathrm{TiO}_{2}$ arrays was investigated by SEM, and Figure 3.2 shows the obtained micrographs. Figure 3.2a is the top view of the $\mathrm{TiO}_{2} \mathrm{NT}$ surface with an ordered array after being annealed. The NTs were self-aligned and grew epitaxially from the metallic Ti substrate, with a higher ordering degree than the NR. Before modification, it was observed that the top side of the NTs was connected with a thin layer of $\mathrm{TiO}_{2}$. This is usually regarded in the literature as the initiation layer, a passive compact layer that arises from the polishing quality of the metallic Ti [86]. The gap distance between the individual NTs was not possible to determine through the images. After the electrochemical modification, there was a higher surface area exposed to the electrolyte because part of the initiation layer was removed. This will, in turn, generate a larger surface exposed to the electrolyte, fully wetting the tubes by overcoming the initial capillary resistance to go inside of the NTs. From Figure 3.2b, it was observed that the NRs were almost vertically aligned to the surface of FTO and almost no joints between each other. The as-prepared rutile $\mathrm{TiO}_{2} \mathrm{NRs}$ used in this material system had a narrow size distribution of 100-150 
$\mathrm{nm}$ in length. Similar to the NTs, no significant morphological differences were observed in the NRs after the self-doping modification.
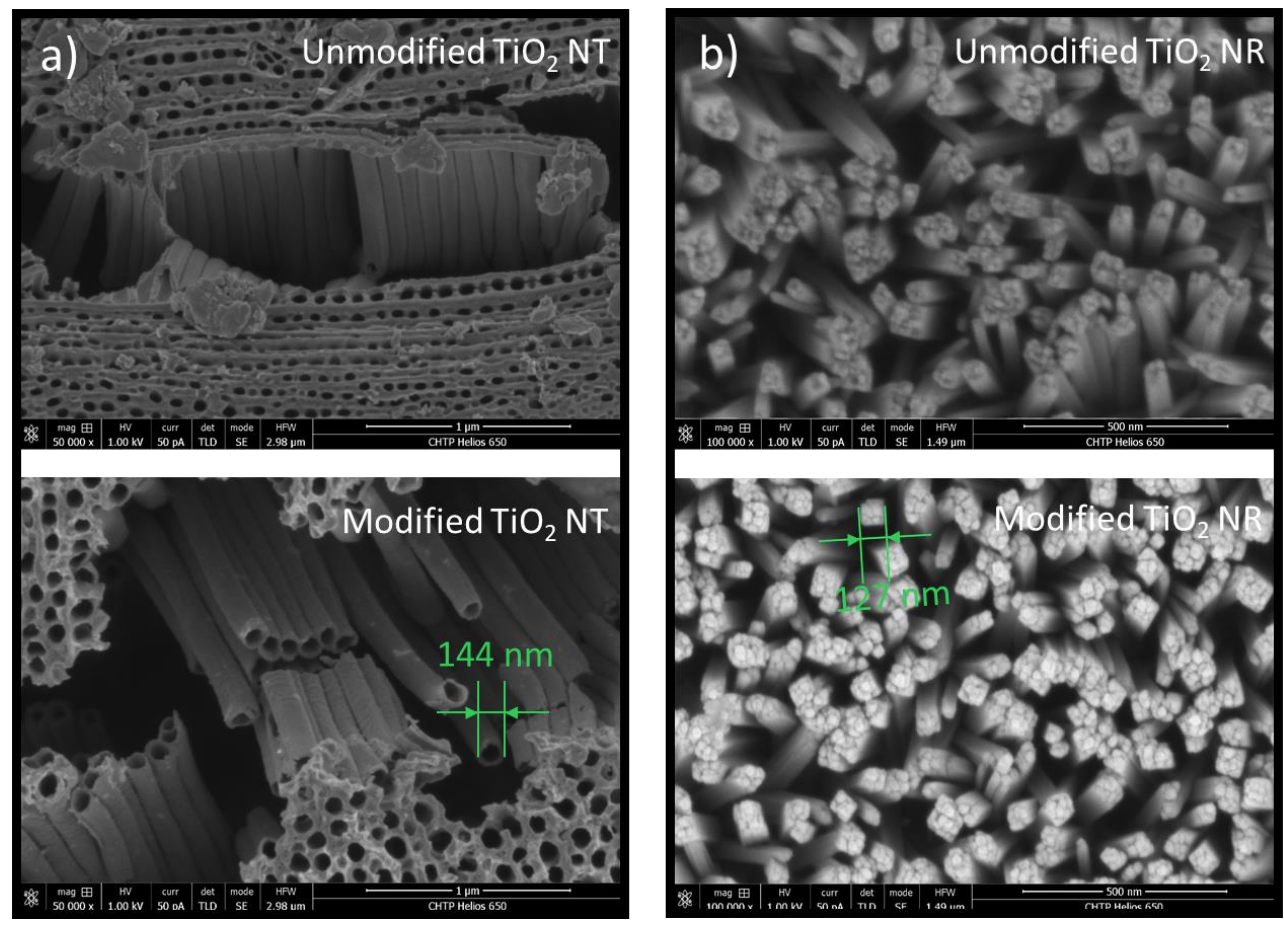

Figure 3.2 SEM for the $\mathrm{TiO}_{2}$ a) $\mathrm{NT}$ and b) $\mathrm{NR}$ before and after modification

Raman spectra were recorded to confirm the crystallinity of the nanostructured materials and were presented in Figure 3.3. As illustrated in Figure 3.3a, anatase $\mathrm{TiO}_{2} \mathrm{NT}$ showed a prominently sharp peak at $145 \mathrm{~cm}^{-1}$ [87]. Such a high intensity of the low-energy line is characteristic of the anatase Raman spectrum. This is an $E_{g}$ mode related to an O-Ti-O bending. Additionally, the three bands in $404,525,646 \mathrm{~cm}^{-1}$ also fitted in good agreement with the reported pure anatase spectrum [88]. Figure $3.3 \mathrm{~b}$ shows the spectrum of pure $\mathrm{TiO}_{2} \mathrm{NR}$. The well-defined peaks at 443 and $610 \mathrm{~cm}^{-1}$ showed both of the $\mathrm{TiO}_{2}$ before and after modification with pure rutile phase [89]. It is reasonable to conclude from Figure 3.3 that electrochemical treatment does not affect the Raman signals of any of the samples, which agrees well with the XRD results. The shift in intensity gives 
information about the vibrational modes in the system. For the NT, the intensity decreased while for the NR it increased after modification. This maybe because NT lost sensitivity on the surface while NR seems to had a clean surface, or its surface became more responsive to this kind of molecular relaxation.
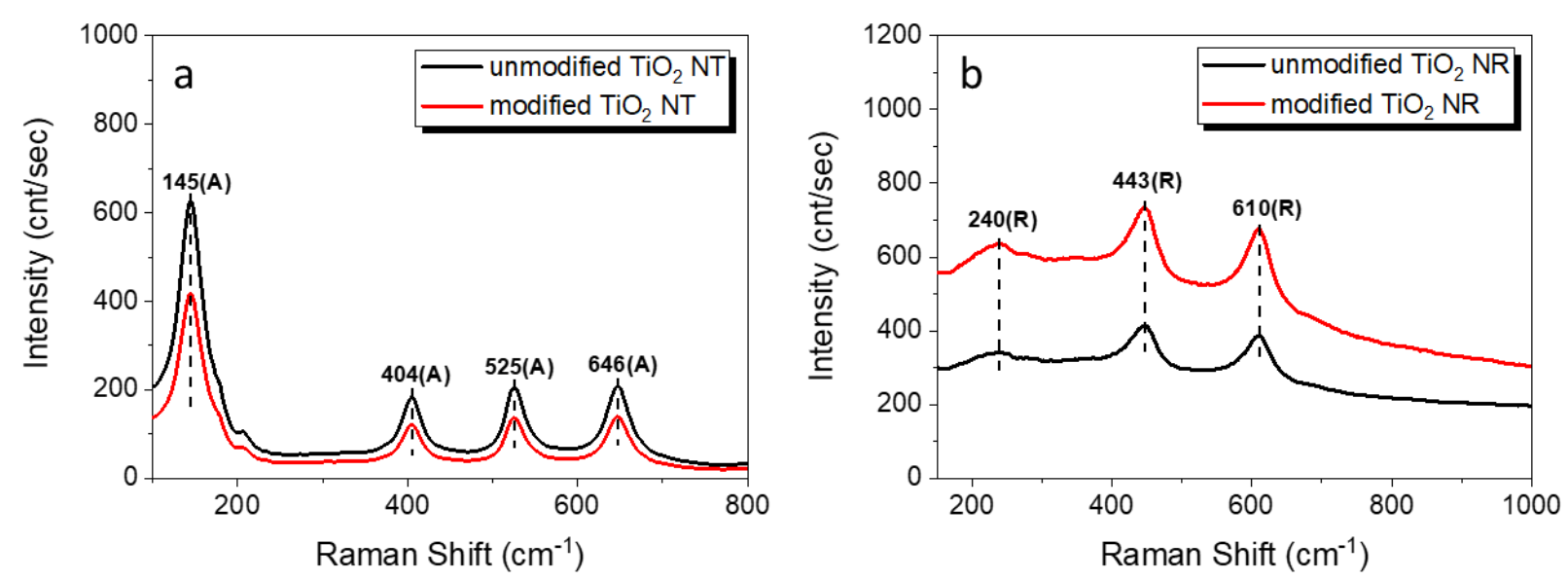

Figure 3.3 Raman spectra of the $\mathrm{TiO}_{2}$ a) $\mathrm{NT}$ and b) $\mathrm{NR}$ before and after modification

The SEM observations revealed that the partial reduction treatment used in this study does not create any significant morphological alteration on the $\mathrm{TiO}_{2}$ surface. However, any change in the surface chemical state cannot be ruled out by such observations. XPS was used to investigate the impact of modification on the surface chemical composition of $\mathrm{TiO}_{2}$. Figure 3.4 shows the highresolution XPS profiles of $\mathrm{O} 1 \mathrm{~s}$ and Ti $3 p$ as the major two elements at the surface of the pristine versus modified samples.

Figure $3.4 \mathrm{a}$ and $\mathrm{b}$ show the Ti $2 \mathrm{p}$ profile for the $\mathrm{TiO}_{2} \mathrm{NTs}$ characterized by a doublet at $458.9 \mathrm{eV}$ and $464.6 \mathrm{eV}$. According to Tien Khoa Le et al.'s report, these energy states correspond to the signals of the Ti 2p/2 and Ti 2p $\mathrm{p}_{1 / 2}$. [90]. A slight shift was observed for the modified sample (Fig 3.4c) while preserving the same gap in the peak splitting $(5.7 \mathrm{eV})$, which could be ascribed to the 
electrochemical reduction of the surface groups. To verify the latter, the high-resolution spectra of the core $\mathrm{O}$ 1s peaks for the pristine and modified sample are presented in Figure $3.4 \mathrm{~d}$-f. At first glance, the signals showed an asymmetric peak, typical of a convoluted response of different type of oxygen bonds. The deconvolution of the peak allowed us to ascribe the signals to the oxygen atoms in the lattice of the $\mathrm{TiO}_{2}$ and surface $-\mathrm{OH}$ groups, centered at about 530 and $531.7 \mathrm{eV}$, respectively [90]. A third broad peak near the high binding energies of $532.8 \mathrm{eV}$ was also obtained only in the modified sample and was associated with adsorbed water [90]. In this same sample, the component related to the - $\mathrm{OH}$ groups decreased simultaneously to the water adsorption, suggesting a prior dehydrogenation step. This is supported by the nature of the electrochemical reduction that in turn reduces the $\mathrm{Ti}$ following the reaction $\mathrm{TiO}_{2}+\mathrm{H}^{+}+\mathrm{e}^{-} \rightarrow \mathrm{TiO}(\mathrm{OH})$. Thus, the partially reduced surface could absorb water molecules via electrostatic forces.

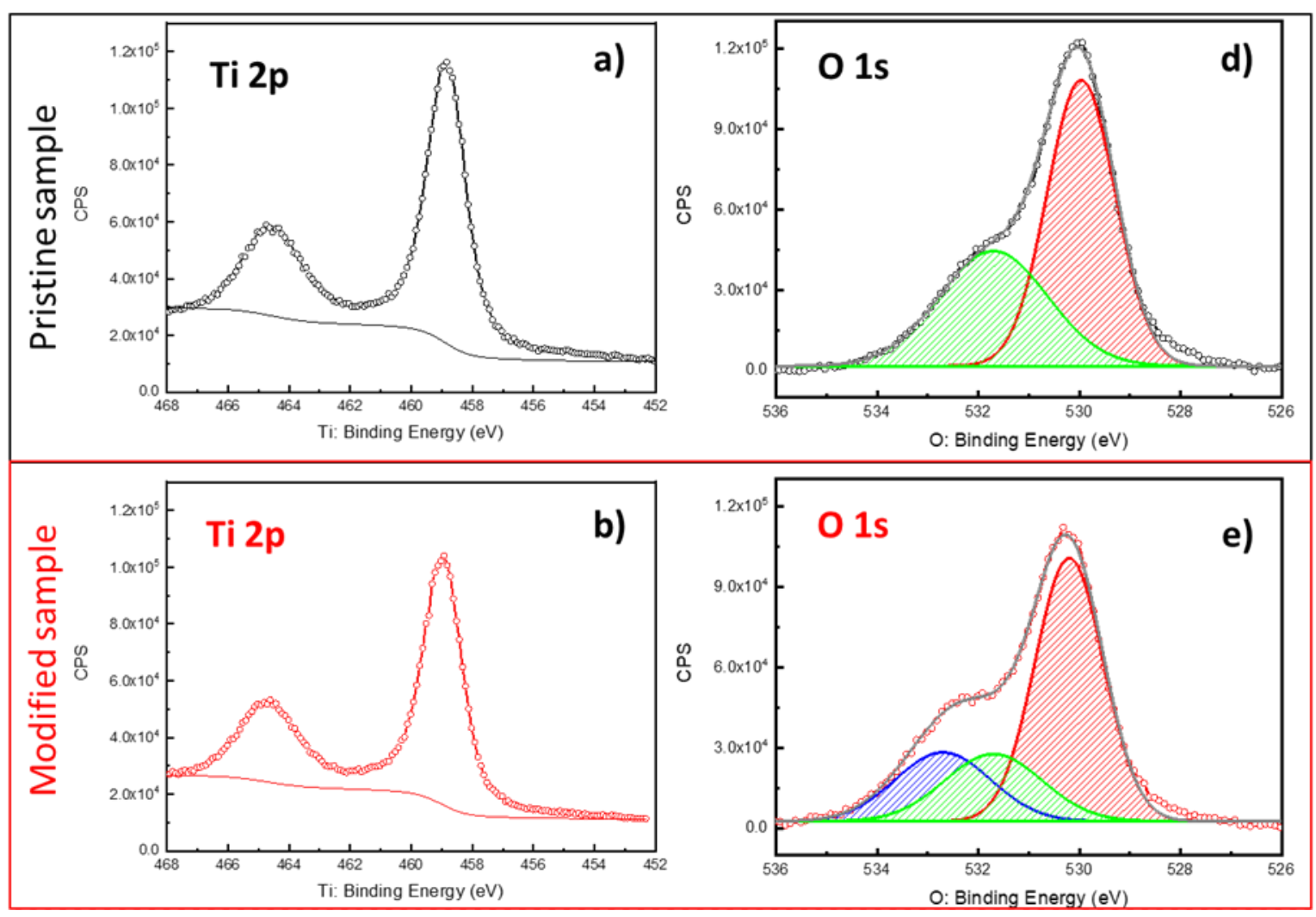




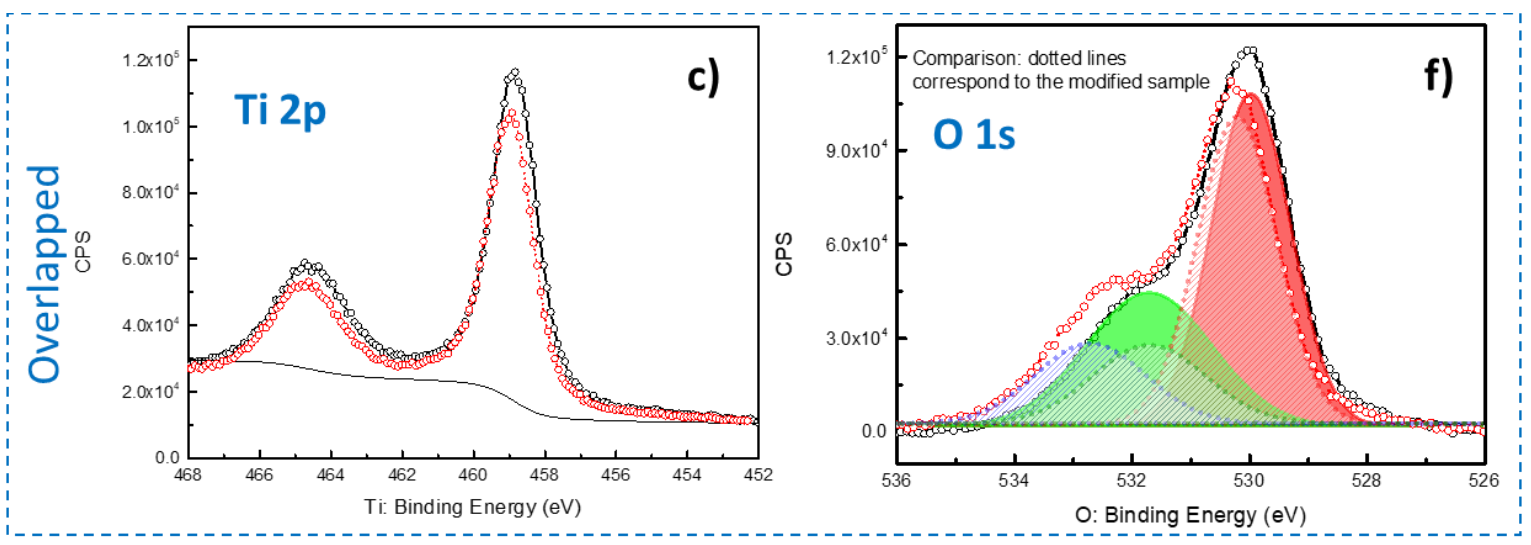

Figure 3.4 High-resolution XPS spectra of the Ti $2 \mathrm{p}\left(\mathrm{a}, \mathrm{b}\right.$, and c), and $\mathrm{O} 1 \mathrm{~s}(\mathrm{~d}, \mathrm{e}$, and $\mathrm{f})$ of the $\mathrm{TiO}_{2}-\mathrm{NT}$ samples before and after the electrochemical reduction

In the case of the NR sample, the XPS information was compiled and presented in Figure 3.5. In Figure $3.5 \mathrm{a}$ and $\mathrm{b}$, the spectra for the Ti $2 \mathrm{p}$ show a similar trend compared to the NT sample. However, the O 1s spectra (in Figure 3.5 c-f) show an increase in the -OH surface groups; which suggests that the rutile NRs are prone to increase the hydroxylation state while inducing water uptake at the same time. This could have implications that are directly related to the processes that occur in the interface (i.e., charge transfer reactions), as such processes highly depend on the composition of this zone. Therefore, the hydroxylation state of the surface will be an aspect of consideration for the discussion of the electrochemical results in the following sections.

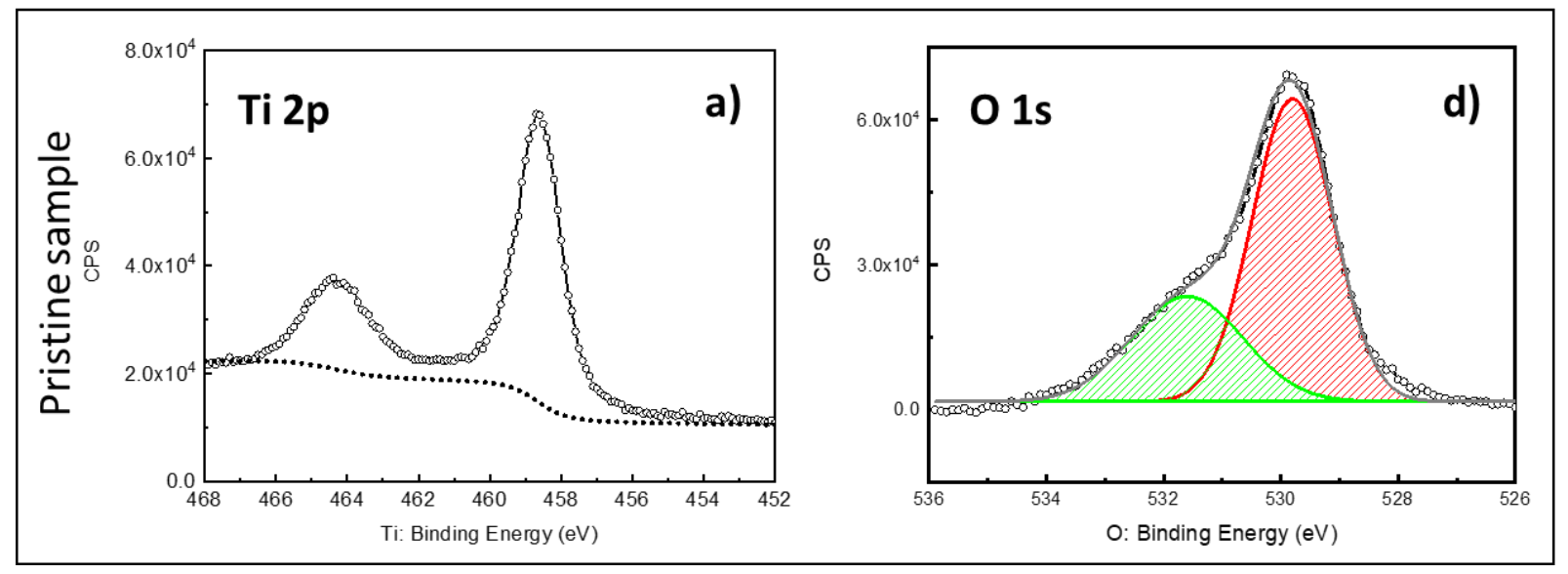




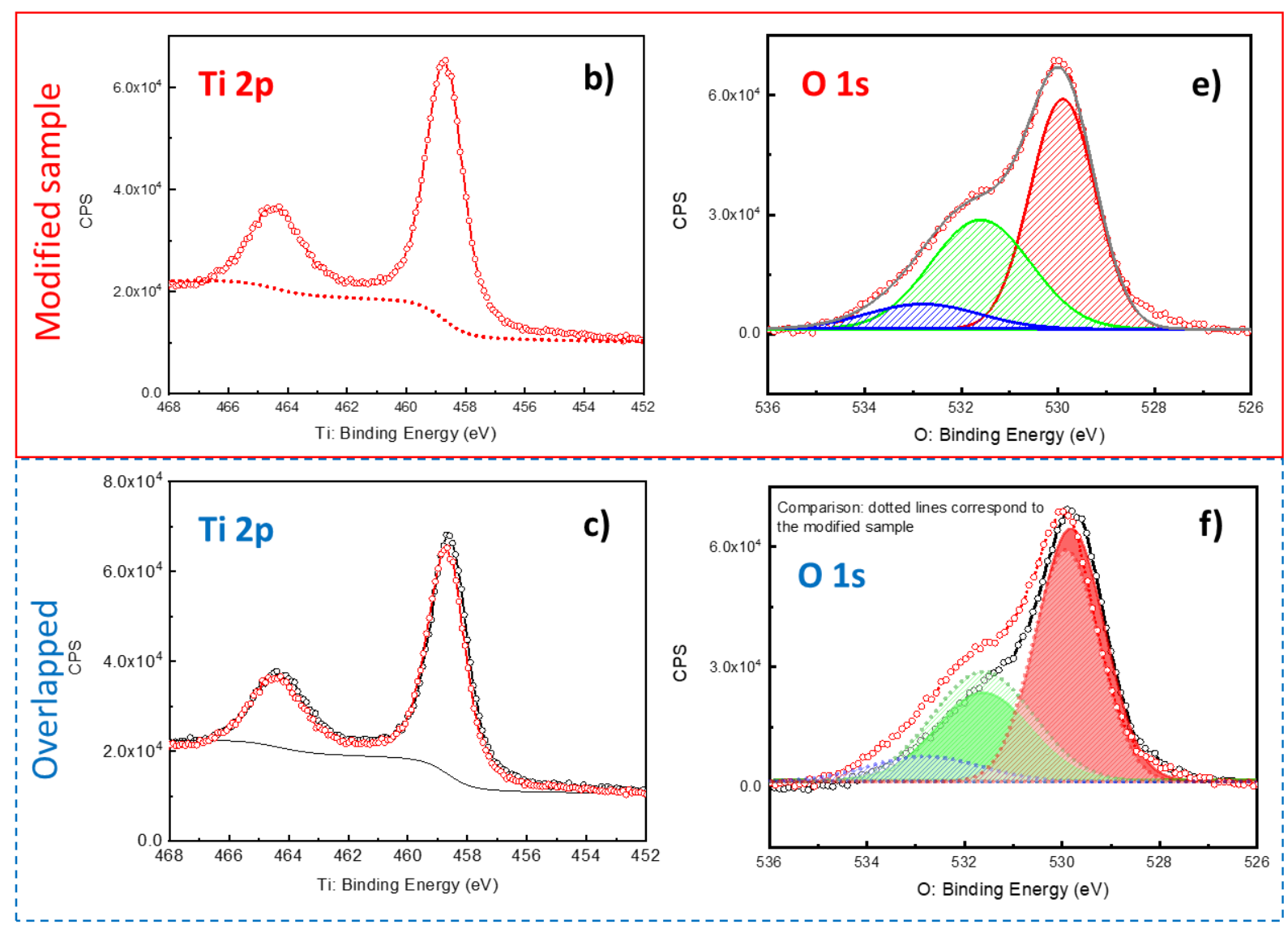

Figure 3.5 High-resolution XPS spectra of the Ti $2 \mathrm{p}(\mathrm{a}, \mathrm{b}$, and $\mathrm{c})$, and $\mathrm{O} 1 \mathrm{~s}\left(\mathrm{~d}, \mathrm{e}\right.$, and f) of the $\mathrm{TiO}_{2}-\mathrm{NR}$ samples before and after the electrochemical reduction

\subsection{Photoelectrochemical Characterization Results of $\mathrm{TiO}_{2}$ Nanotube/Nanorod Arrays \\ Evaluation in $\mathrm{H}_{2} \mathrm{SO}_{4}$ Electrolyte}

To assess systematically the materials, an electrochemical characterization was conducted. Figure 3.6a and b show a Cyclic Voltammogram (CV) of the $\mathrm{TiO}_{2}$ electrodes recorded in $0.5 \mathrm{M} \mathrm{H}_{2} \mathrm{SO}_{4}$ aqueous solution $(\mathrm{pH}=0.3)$. Figure $3.6 \mathrm{c}$ and $\mathrm{d}$ shows the corresponding modification processes. Due to the reduction of $\mathrm{Ti}^{4+}$ to $\mathrm{Ti}^{3+}$, a peak was appeared in the cathodic scan at nearly $-0.2 \mathrm{~V}$ vs. $\mathrm{Ag} \mid \mathrm{AgCl}$ for $\mathrm{TiO}_{2} \mathrm{NT}$. This reaction can be described as $\mathrm{TiO}_{2}+\mathrm{H}^{+}+\mathrm{e}^{-} \rightarrow \mathrm{TiO}(\mathrm{OH})$, indicating the presence of the reduced states [91]. This particular potential value indicated an electrochromic reaction, also accompanied by the color change of the electrode from light gray to dark blue, which 
is frequently ascribed to the formation of oxygen vacancies [71]. Zhou et al. proposed that the oxygen vacancies generated at low potentials, where the $\mathrm{H}_{2}$ evolution takes place, accounts for an expansion of the crystalline lattice in $\mathrm{TiO}_{2}$ derived from proton intercalation [71]. Oxygen vacancies will provide more electrons during the reaction, which is the reason for the conductivity increase of the material after modification. According to the theory, the n-type semiconductor will increase its resistivity when polarized at a more positive potential. This is evident from the lower current densities in the cyclic voltammetry $(\mathrm{CV})$ curve at the potential around $1 \mathrm{~V}$. Compared with the pristine $\mathrm{TiO}_{2}$, the CV curves of the self-modified $\mathrm{TiO}_{2} \mathrm{NT}$ exhibited a closely rectangular shape, revealing a greatly enhanced capacitive behavior after modification. Such changes have been discussed in the literature as a result of small ion intercalation (e.g., proton intercalation) [91].

Figure 3.6b shows the electrochemical responses for the NR samples. The peaks of $\mathrm{TiO}_{2} \mathrm{NR}$ between $0.1 \mathrm{~V}$ and $0.3 \mathrm{~V}$ existed both before and after modification, which is associated with the trap states that already existed on the pristine samples. Based on such peaks compared with that of the $\mathrm{TiO}_{2} \mathrm{NT}$, the trap states seemed to be more significant in the $\mathrm{TiO}_{2} \mathrm{NR}$, which will improve the recombination of electrons and holes. The $\mathrm{CV}$ peak firstly located at $0.2 \mathrm{~V}$ moved to the positive potential and became wider after the electrochemical modification. This might be indicative of slower kinetics induced by the $\mathrm{Ti}^{3+}$ sites formed due to a partial reduction of the surface. Also, the improved photocurrent of NR after modification seemed to indicate an improvement of NR's response to light; while this is hard for us to distinguish for NT. 

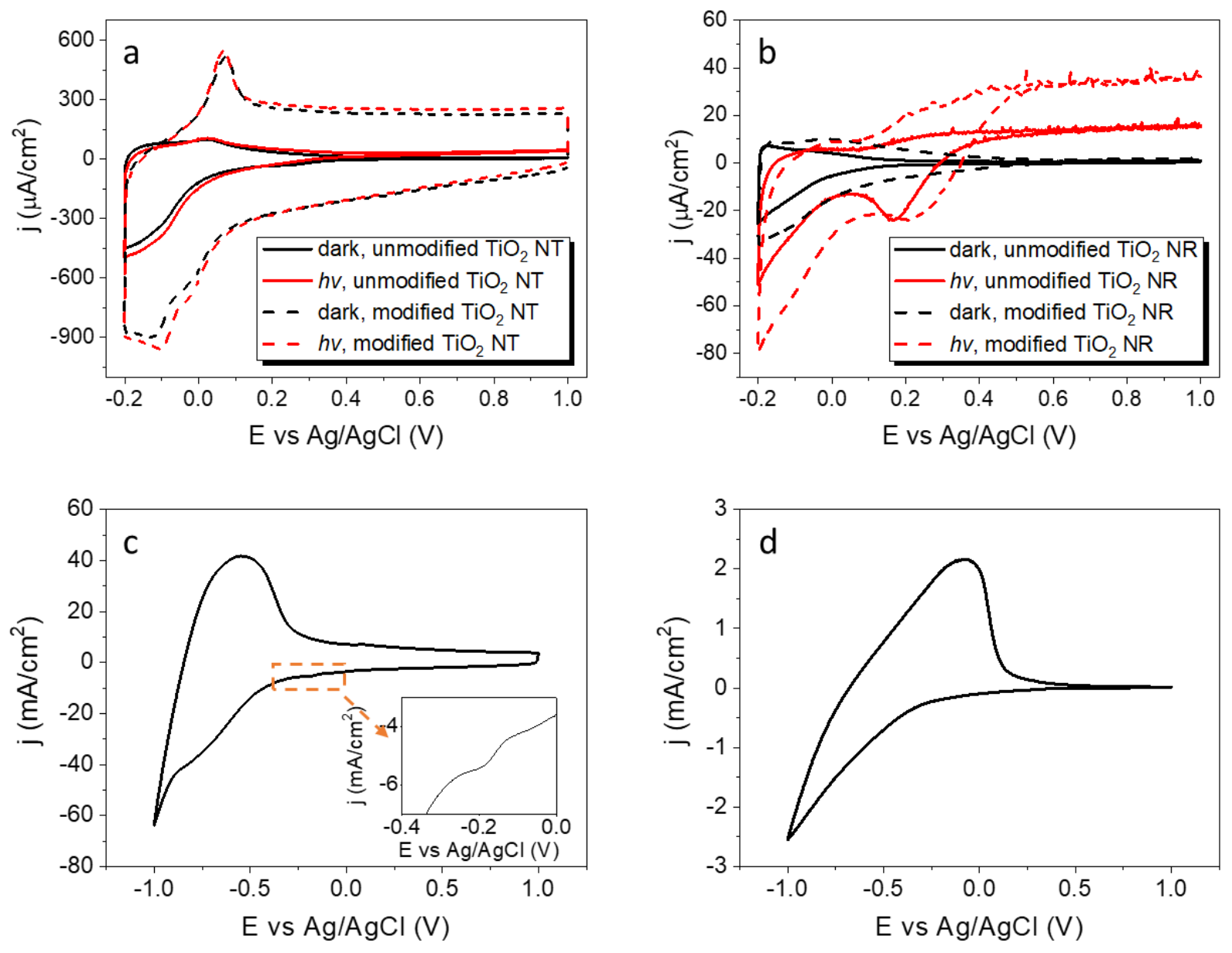

Figure 3.6 Cyclic voltammograms (CV) of the $\mathrm{TiO}_{2}$ a) NT and b) NR before and after modification; modification process of the $\mathrm{TiO}_{2}$ c) $\mathrm{NT}$ and d) $\mathrm{NR}$ in $0.5 \mathrm{M} \mathrm{H}_{2} \mathrm{SO}_{4}$ solution

Linear sweep voltammograms (LSV) were recorded with a scanning rate of $10 \mathrm{mV} / \mathrm{s}$ to minimize the contribution of the charging current and account for a better comparison of the $j_{\text {ph. }}$. Figures $3.7 \mathrm{a}$ and $\mathrm{b}$ show the comparative LSVs of the samples in the same potential range under darkness and white light irradiation. At first glance, the photocurrent of the $\mathrm{TiO}_{2} \mathrm{NTs}$ decreased slightly after modification. This can be explained by a change in the kinetics, either due to the slower separation, or the faster recombination of the electron-hole pairs. It is also possible that some electron scavengers (dissolved oxygen from previous experiments) in the vicinity of the electrode might 
consume the electrons and reduce the $j_{\mathrm{ph}}$. It is noteworthy that, for the $\mathrm{TiO}_{2} \mathrm{NT}$, the dark current density also increased after modification, which dramatically changed the shape of the voltammogram. Based on the XPS observations, it seemed that the reduction of the $-\mathrm{OH}$ surface groups could have induced a greater number of traps (from Fig 3.6a), which can improve the separation of the charge carriers. As a plateau in the LSV was not observed in the evaluated potential range. It may be associated with the fact that the potential bias was not large enough to overcome the recombination processes. In the meantime, for $\mathrm{TiO}_{2} \mathrm{NRs}$ electrode, the $j_{\mathrm{ph}}$ improved by more than two times after modification. For this case, it seemed that a more hydroxylated surface tended to favor the generation of the photocurrent. These data proved our assumption that the partial reduction modification has improved the photoelectrochemical properties of $\mathrm{TiO}_{2}$.
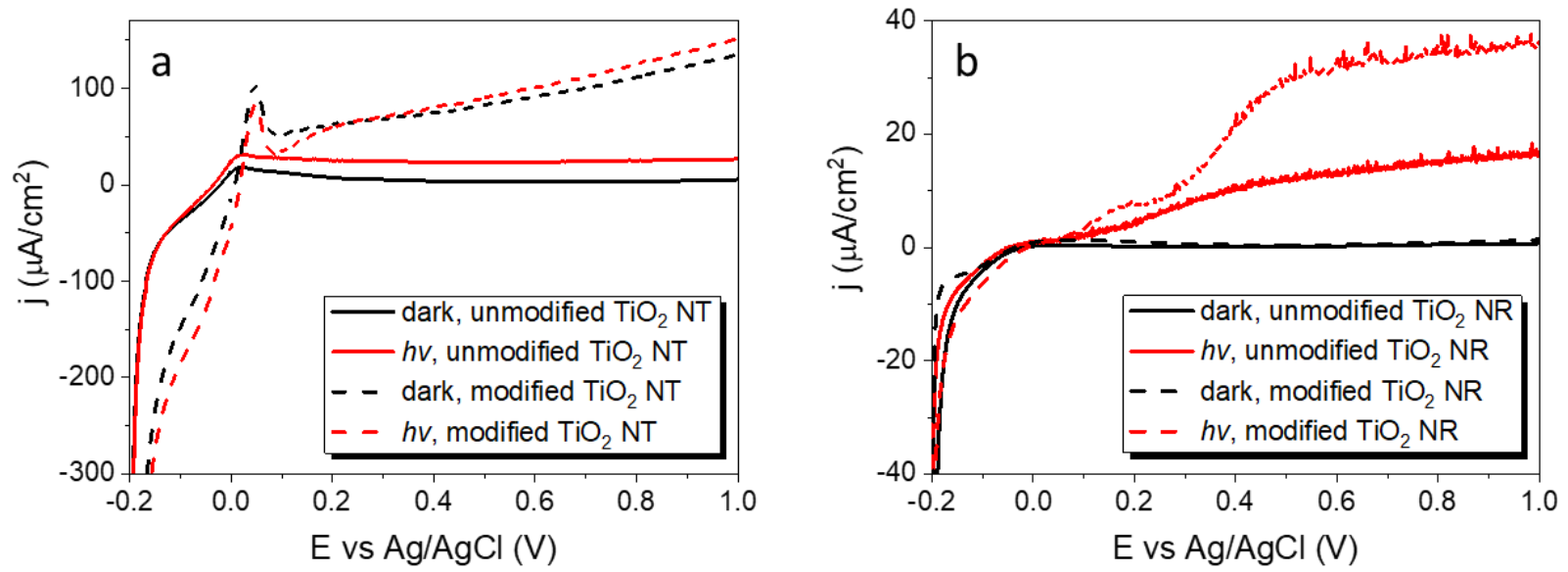

Figure 3.7 Linear sweep voltammograms ( $\mathrm{LSV}$ ) of the $\mathrm{TiO}_{2}$ a) $\mathrm{NT}$ and b) NR before and after modification in

\section{$0.5 \mathrm{M} \mathrm{H}_{2} \mathrm{SO}_{4}$ solution}

To further minimize the effect of the charging current, the chronoamperometric response of the electrodes was recorded, and the curves are presented in Figure 3.8. A step potential of $1 \mathrm{~V}$ vs. $\mathrm{Ag} \mid \mathrm{AgCl}$ was applied to minimize the charging current and obtain the value of the dark current. The applied potential shifted the energy of the interface to more positive potentials from the 
equilibrium (open circuit potential), and the relaxation of the interface occurred rapidly by minimizing the current density value and achieving a constant value (at nearly 60 s) referred as the dark current. Then, the light was irradiated to the surface of the electrode to induce the separation of charge carriers, and a plateau was developed as a result of water oxidation and limited by deactivation processes (recombination, surface traps states, etc.) [92]. The photon excitation was interrupted after $60 \mathrm{~s}$, and then the current density recovered to the dark current value, as no more charge carriers were generated. For both samples, there was an improvement of the current density after the self-doping process, especially for the NR with the photocurrent density improved by more than twice. The different response in the development of current between $\mathrm{TiO}_{2} \mathrm{NT}$ and NR indicated the differences in their kinetics. As observed from the plots, the charging process for the NT seemed to have been improved after the electrochemical modification, since a faster response and higher photocurrent density were obtained. However, small initial spikes were observed in the photocurrent when the light was turned on for $\mathrm{TiO}_{2} \mathrm{NR}$. This spikes are usually attributed to a larger number of trap sites (oxygen vacancies, surface traps, etc.) which are equally fast filled, and the corresponding photo-current density stabilizes to the plateau value [92]. They may also arise from electron recombination with photooxidation intermediates, which hinders the charging and discharging process [93]. For both cases, the noise in the signal of the current plateau denoted the competition of different processes which could be related to water oxidation and/or re-oxidation of the $\mathrm{Ti}^{3+}$ sites. For the NT sample, the reduced charging and stabilization time was reflected as the sharper feature of the plateau. In a smaller proportion, the similar phenomenon was appreciated in the NR electrode. 

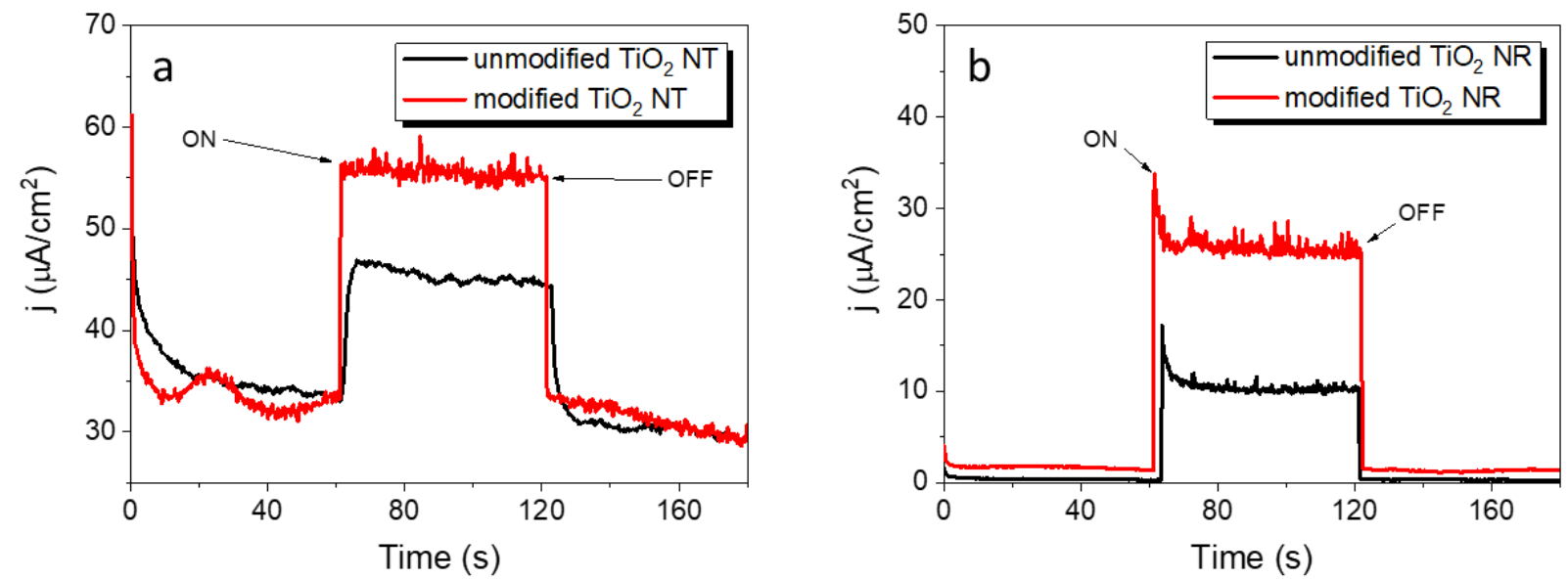

Figure 3.8 Chronoamperometric (CA) response of the $\mathrm{TiO}_{2}$ a) $\mathrm{NT}$ and b) $\mathrm{NR}$ before and after modification in $0.5 \mathrm{M} \mathrm{H}_{2} \mathrm{SO}_{4}$ solution

To understand the contribution of the individual wavelengths to the $j_{\mathrm{ph}}$ generation, action spectra were recorded under monochromatic illumination, scanning from lower to higher energies (from longer to shorter wavelengths) and the dark current was subtracted from the signal. IPCE of $\mathrm{TiO}_{2}$ was calculated from the action spectra and is shown in Figure 3.9a and b. Because of the different crystallinity and morphology of anatase and rutile, the onset was observed at 390-400 $\mathrm{nm}$ for $\mathrm{TiO}_{2}$ NT and 410-420 nm for the NR electrode, which was consistent with the onset of the UV-Vis absorption spectrum [94]. The absorption edge refers to the maximum wavelength (minimum energy of the photons) that can excite the material. For both of the samples, there was no change in their absorption edge after modification. The $\mathrm{TiO}_{2} \mathrm{NT}$ arrays exhibited an IPCE of up to 3.3\% at $360 \mathrm{~nm}$. For the NR, there was an improvement of IPCE from 1.5\% to 3\%. The improved IPCE for NT and NR maybe result from the higher immigration rate of photo-generated electrons from the valence band ( $2 \mathrm{p}$ orbitals for oxygen) to the conduction band (populated by $3 \mathrm{~d}$ orbitals from Ti) and/or reduced recombination with holes, which can significantly improve the number of photo-generated carriers. 
Figure 3.9c and d show the Tauc plots of $\mathrm{TiO}_{2}$ films. As many publications suggested, $\mathrm{TiO}_{2}$ is a material with direct optical transitions, and $\mathrm{n}$ should be $1 / 2$ [95]. Although there was the $\mathrm{Ti}^{3+}$ injection after modification, the bandgaps were not significantly modified, which was $3.18 \mathrm{eV}$ for $\mathrm{TiO}_{2} \mathrm{NT}$, and $3.02 \mathrm{eV}$ for $\mathrm{TiO}_{2} \mathrm{NR}$. This maybe because the partial reduction took place on the surface of our sample, and the extension of this modification was solely limited to the outmost layer of the material. In this way, the generation of oxygen vacancies was not enough to impact the bandgap $\left(E_{\mathrm{g}}\right)$ value.
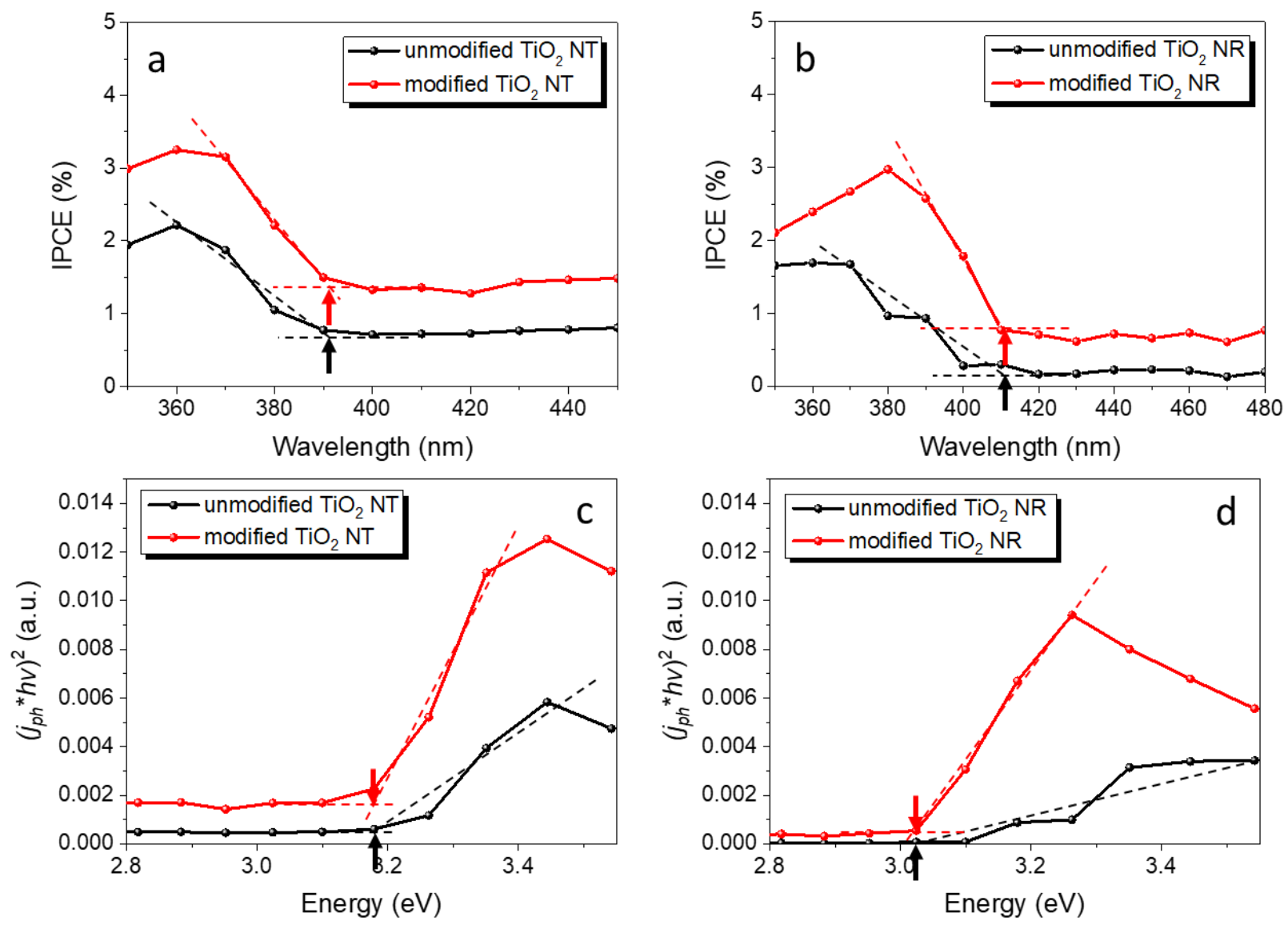

Figure 3.9 Incident Photon-to-Current Efficiency and Tauc plots of the $\mathrm{TiO}_{2} \mathrm{a}, \mathrm{c}$ ) NT and b, d) NR before and after modification in $0.5 \mathrm{M} \mathrm{H}_{2} \mathrm{SO}_{4}$ solution

To further investigate the changes of the capacitance in the space-charge region of the materials after the self-doping treatment, Mott-Schottky plots were recorded and presented in Figure 3.10. The dielectric constant for the $\mathrm{TiO}_{2} \mathrm{NT}$ is 42 [96], and the frequency we chose is $135 \mathrm{~Hz}$, while 
the dielectric constant is 170 for the $\mathrm{TiO}_{2} \mathrm{NR}$ [97] recorded at a frequency of $332 \mathrm{mHz}$. The M-S plots allow us to distinguish clearly the impact of the electrochemical reduction as the condition used for these experiments relied on a pseudo-steady-state where oxygen was not generated since the tests were conducted in darkness [93]. According to the theory of bands for an n-type semiconductor, introducing new levels of energy (e.g., surface states or dopants) will result in the change of Fermi level position. On the basis that the bottom of the conduction band could be approximated from the calculation of the flatband potential, the Mott-Schottky (regarded as M-S onwards) equation was applied to obtain such value [98]. From our experiments, the $V_{\mathrm{fb}}$ showed a change from $0.16 \mathrm{~V}$ to $-0.44 \mathrm{~V}$ vs. $\mathrm{Ag} \mid \mathrm{AgCl}$ for self-doped $\mathrm{TiO}_{2} \mathrm{NT}$. The negative shift can be ascribed to the oxygen vacancies $\left(\mathrm{Ti}^{3+}\right)$ induced to the material during modification, which provide more electrons in the PEC reaction. In principle, this can also be appreciated from the LSV curves (Figure 3.7), where the $E_{\text {onset }}$ usually shifted to more negative potential values. However, in our experiments, this has not been possible to observe due to the scavenging action of dissolved oxygen.

Furthermore, from the M-S equation, it is possible to obtain a value of the donor density that shows a remarkable enhancement from $11 \times 10^{21}$ to $25 \times 10^{22}$ donors $/ \mathrm{cm}^{3}$ for $\mathrm{TiO}_{2} \mathrm{NT}$. This result agrees well with its increased capacitance property because of the oxygen vacancy $\left(\mathrm{Ti}^{3+}\right)$ or proton intercalation. While for the NR sample, the modification enhanced the $N_{\mathrm{d}}$ from 1.2 to $1.7 \times 10^{21}$ donors $/ \mathrm{cm}^{3}$. This slight enhancement supports well with its shape in the CV which does not show significantly different features after modification as compared to that obtained in the NT sample. A positive shift in the $V_{\mathrm{fb}}$, as observed for the NR from $0.11 \mathrm{~V}$ to $0.17 \mathrm{~V}$, could be interpreted as adsorption of cations or solvent dipoles oriented with their positive end towards NR [99]. It is 
noteworthy to mention the high dopant density of $\mathrm{TiO}_{2} \mathrm{NT}$ after modification, which is almost in the same order with that of a metallic material. This is because the application of M-S equation is based on some assumptions, among which is the electrochemical area. We assumed that the surface of the film should be totally flat. In this case, the electrochemical area will be the same as the geometric area. However, in reality, the surface is not flat enough because of the nanostructures grown on the surface. Finally, the use of the geometric area as the electrochemical area will yield a relatively higher dopant density. Nevertheless, we emphasized the qualitative changes of dopant density that is consistent in these two cases.
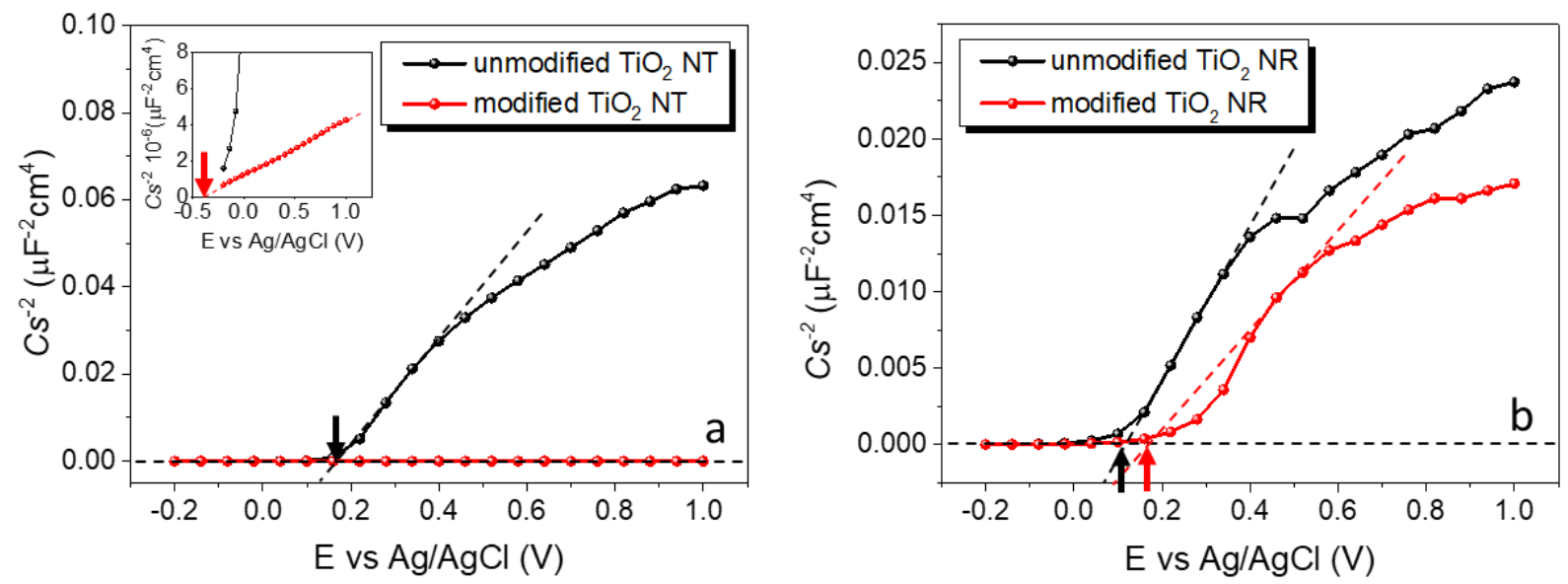

Figure 3.10 Mott-Schottky plots of the $\mathrm{TiO}_{2}$ a) NT and b) NR before and after modification in $0.5 \mathrm{M} \mathrm{H}_{2} \mathrm{SO}_{4}$ solution

The bandgap structure of $\mathrm{TiO}_{2}$ before and after modification is presented in Figure 3.11. From these plots, it is clear that the partial reduction process did not modify the bandgap of the material, but the position of the CB and VB. For the NT, there was a negative shift for the $V_{\mathrm{fb}}$ while positive for the NR. Such differences have been discussed in the previous sections. 


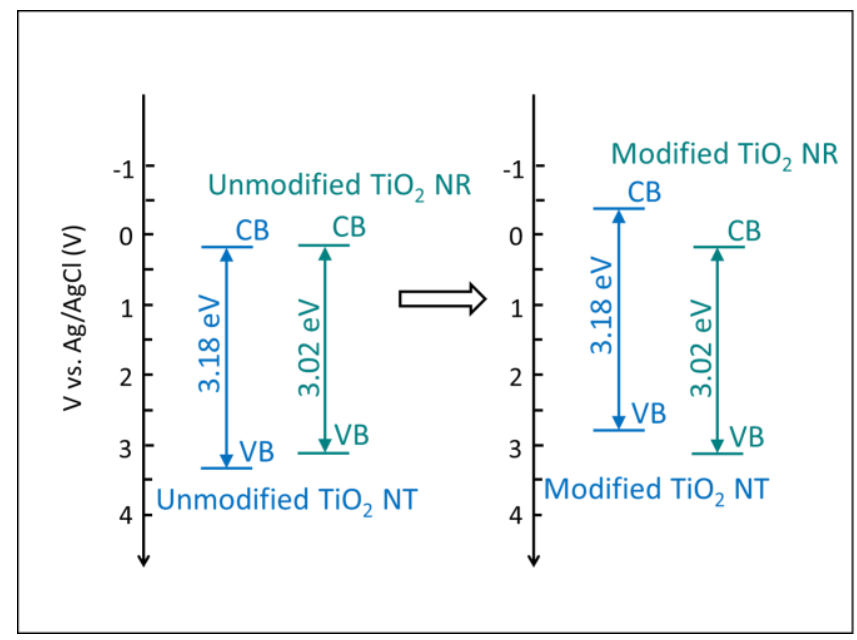

Figure 3.11 Bandgap structure of the $\mathrm{TiO}_{2} \mathrm{NT}$ and $\mathrm{NR}$ before and after modification in $0.5 \mathrm{M} \mathrm{H}_{2} \mathrm{SO}_{4}$ Solution

\subsection{Photoelectrochemical Characterization Results of $\mathrm{TiO}_{2}$ Nanotube/Nanorod Arrays Evaluation in $\mathrm{NaOH}$ Electrolyte}

Figure 3.12 shows cyclic voltammetry $(\mathrm{CV})$ curves of the $\mathrm{TiO}_{2}$ electrodes recorded in $1 \mathrm{M} \mathrm{NaOH}$ aqueous solution $(\mathrm{pH}=14)$. As the potential goes more negative, the current density increases as a result of the $\mathrm{H}_{2}$ generation $\left(2 \mathrm{H}^{+}+2 \mathrm{e}^{-} \rightarrow \mathrm{H}_{2}\right)$. Moreover, the formation of oxygen vacancies $\left(\mathrm{Ti}^{3+}\right)$ in the self-doped $\mathrm{TiO}_{2}$ NT follows the reaction $\mathrm{TiO}_{2}+\mathrm{H}_{2} \mathrm{O}+\mathrm{e}^{-} \rightarrow \mathrm{TiO}(\mathrm{OH})+\mathrm{OH}^{-}$. Due to the reduction of $\mathrm{Ti}^{4+}$ to $\mathrm{Ti}^{3+}$, a peak became conspicuous at $-0.9 \mathrm{~V} / \mathrm{Ag} \mid \mathrm{AgCl}$, (Fig. 3.12c). This reaction is evidenced by the corresponding color change of the electrode from light gray to dark blue. At near $-0.6 \mathrm{~V}$ vs. $\mathrm{Ag} \mid \mathrm{AgCl}$ (Fig. 3.12a), there were a couple of shoulders that are usually associated to the occurrence of surface states [99], suggesting the presence of either crystalline defects or dopants. The cyclic voltammogram in red depicted the behavior of $\mathrm{TiO}_{2}$ in the presence of white light, demonstrating its charge separation properties. Some filling of the trap states took place, as the potential shoulders almost disappeared. Compared with the pristine sample, the self-doped $\mathrm{TiO}_{2} \mathrm{NT}$ showed a dramatic change to a closely rectangular-shaped cyclic voltammogram, which 
was associated with its more capacitive behavior. It is noteworthy to mention that the CV did not return to the original shape, even after the storage under environmental conditions for 4 weeks, which means the charge separation feature was still preserved.

In contrast, the $\mathrm{CV}$ of the NR (Figure 3.12b) showed a very different behavior with a diminished capacitance and an almost absence of surface states features. At lower polarization potentials, the current density increased when it approximated to the hydrogen evolution range, but no signals related to the partial reduction of $\mathrm{Ti}$ were observed. The photocurrent $\left(j_{\mathrm{ph}}\right)$ seemed to be affected by the self-doping process and was observed as a higher current density. On the other hand, the $j_{\mathrm{ph}}$ plateau was shifted to slightly higher potentials, which could be influenced by the sweep rate.
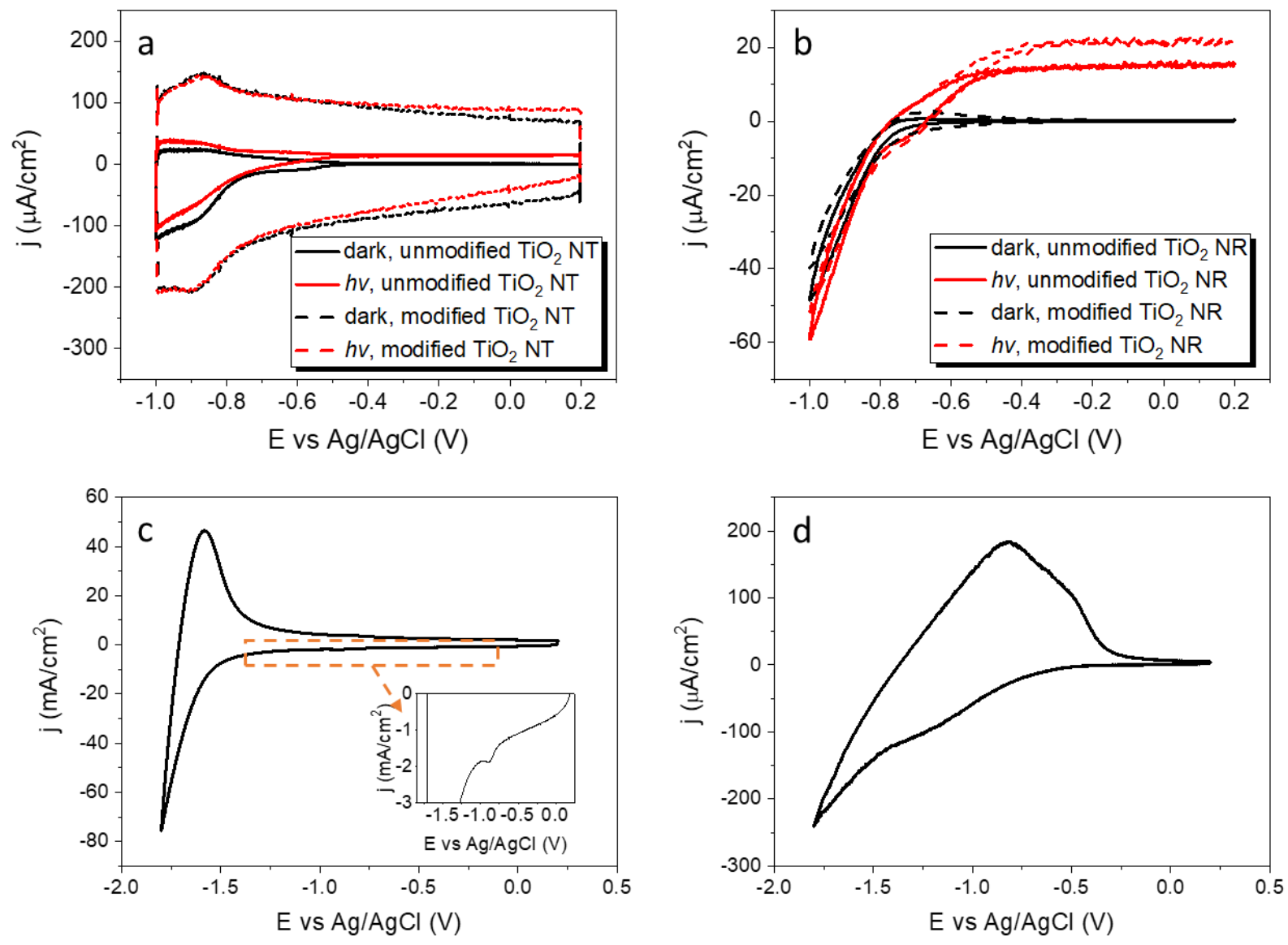

Figure 3.12 Cyclic voltammograms (CV) of the $\mathrm{TiO}_{2}$ a) NT and b) NR before and after modification; modification process of the $\mathrm{TiO}_{2} \mathrm{c}$ ) $\mathrm{NT}$ and d) $\mathrm{NR}$ in $1 \mathrm{M} \mathrm{NaOH}$ solution 
Figure 3.13 shows a comparative linear sweep study performed between the $\mathrm{TiO}_{2} \mathrm{NT}$ and $\mathrm{TiO}_{2}$ $\mathrm{NR}$ samples recorded in the potential range of $-1 \mathrm{~V}$ to $0.2 \mathrm{~V}$ (vs. $\mathrm{Ag} \mid \mathrm{AgCl}$ ) with a scanning rate of $10 \mathrm{mV} / \mathrm{s}$. The $j_{\text {ph }}$ of the NT showed an onset potential ( $\left.E_{\text {onset }}\right)$ at very low values in the evaluated range of c.a. $-0.95 \mathrm{~V}$ vs. $\mathrm{Ag} \mid \mathrm{AgCl}$, for both unmodified and modified samples. While the $j_{\text {ph }}$ plateau was achieved for the unmodified NT, after the self-doping this event was not observed, but the $j_{\mathrm{ph}}$ increased continuously with higher potential. The latter suggested a change in the kinetics of the charge carrier separation. Such behavior could be understood as increased recombination aroused by the formation of surface traps during the self-doping process [100]. Nevertheless, a two-fold increase at the anodic end of the voltammograms was observed for this sample. Similarly, the modified NR sample showed a $50 \%$ increase in the $j_{\mathrm{ph}}$ compared to the unmodified initial condition. Moreover, the $j_{\text {ph }}$ plateau was developed, confirming the overcoming of the recombination of the electrons and holes.
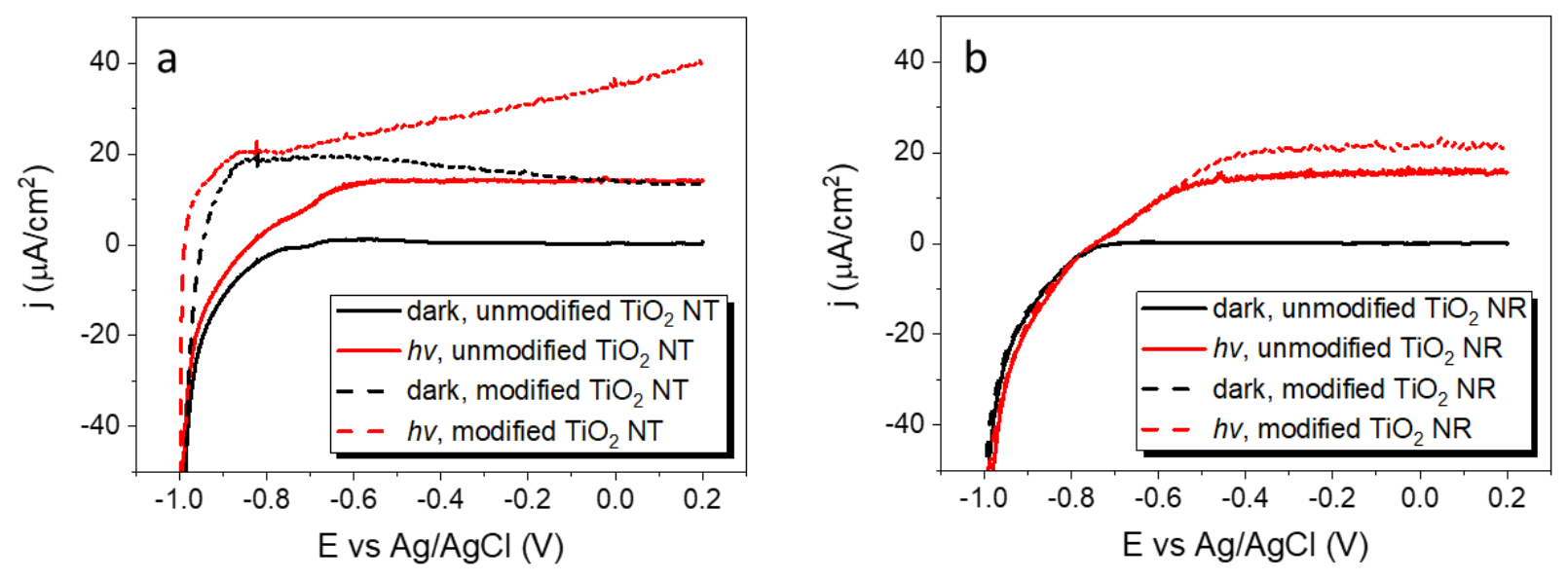

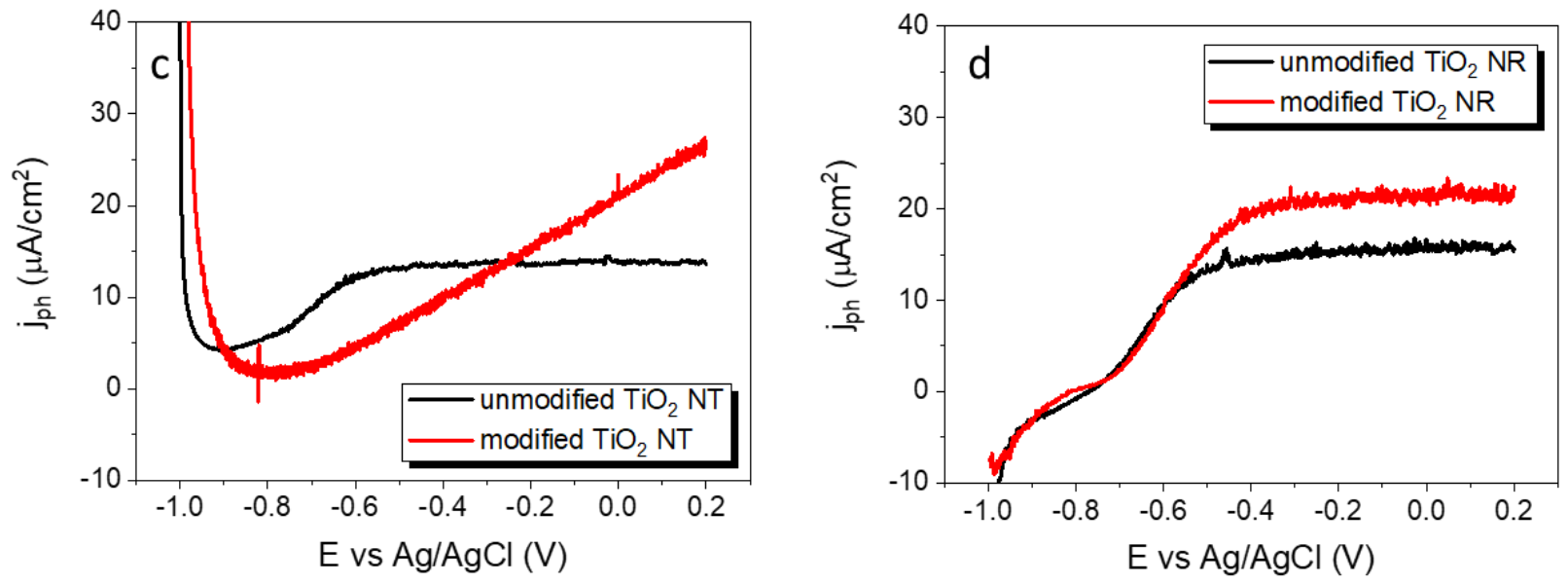

Figure 3.13 Linear sweep voltammograms (LSV) of the $\mathrm{TiO}_{2}$ a) NT and b) NR; and photocurrent density $\left(j_{\mathrm{ph}}\right)$ for the $\mathrm{TiO}_{2}$ c) $\mathrm{NT}$ and d) $\mathrm{NR}$ before and after modification in $1 \mathrm{M} \mathrm{NaOH}$ solution

To investigate the photoelectrochemical performance of the self-doped sample, chronoamperograms were recorded. The potential was set at $0.2 \mathrm{~V}$ vs. $\mathrm{Ag} \mid \mathrm{AgCl}$ to minimize the effect of the charging current. From the CAs, we can confirm the enhancement of the $j_{\mathrm{ph}}$ for both materials after the self-doping process, as well as the differences in the charging and discharging kinetics. Fast charging and discharging of the $j_{\mathrm{ph}}$ for the NR was obtained, leading to conclude that the recombination events are not compromising the collection of the photogenerated electrons at such potential bias. Conversely, in the NT, an overshoot was observed when the light was turned on. The spike developed just after the irradiation of the electrode is indicative of recombination of the electron-hole pairs. However, the maximum $j_{\text {ph }}$ was higher in the NT modified sample, and the stabilization process could be explained by the electron scavenging from surface states. 

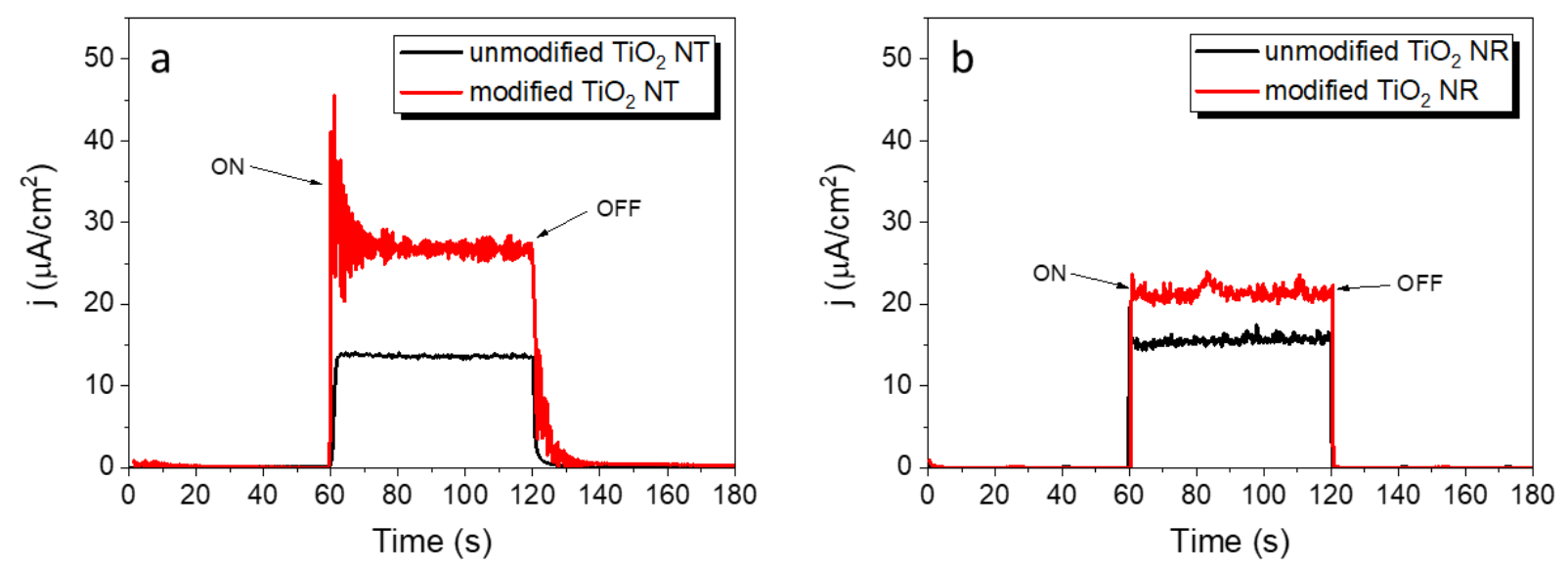

Figure 3.14 Chronoamperometric (CA) response to light irradiation of the $\mathrm{TiO}_{2}$ a) $\mathrm{NT}$ and b) $\mathrm{NR}$ before and after modification in $1 \mathrm{M} \mathrm{NaOH}$ solution

IPCE was obtained from action spectra under monochromatic illumination in a steady-state condition as shown in Figure 3.15. After the self-doping, there was no change in the absorption edge for both $\mathrm{TiO}_{2} \mathrm{NT}$ and NR, which is $393 \mathrm{~nm}$ and $414 \mathrm{~nm}$, respectively. This suggests that the electrochemical modification does not change the minimum energy used to excite the materials. No apparent photosensitization in the visible part of the spectrum was observed. Nonetheless, the IPCE values showed enhancement in the UV range, demonstrating an increased separation of photoexcited electrons and holes. The attribution of these responses could be due to the $\mathrm{Ti}$ reduction after the promotion of oxygen vacancies that would induce a higher local electron density. For the $\mathrm{TiO}_{2} \mathrm{NR}$, there was an almost homogeneous increase in the UV part, which improved from $18 \%$ to $23 \%$. In the case of the NT, a particular wavelength was benefited after the modification, where the IPCE reached $25 \%$ when it was irradiated with a wavelength of $360 \mathrm{~nm}$. Similar as the Tauc plots of $\mathrm{TiO}_{2}$ modified in $\mathrm{H}_{2} \mathrm{SO}_{4}$ solution, the bandgap remained $3.21 \mathrm{eV}$ in $\mathrm{NT}$ and $3.03 \mathrm{eV}$ in NR after self-modification, as shown in Figure 3.15c and d. 

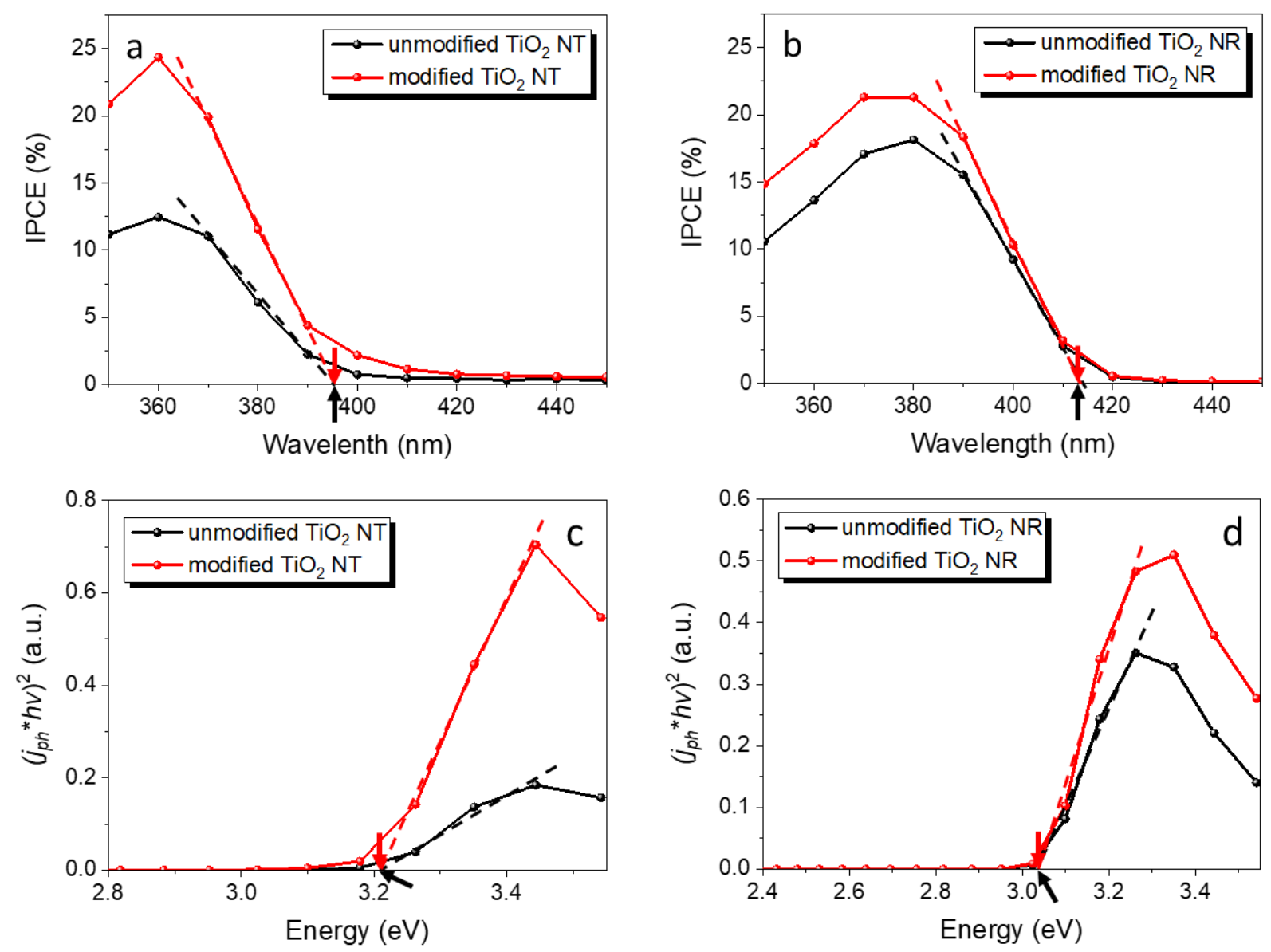

Figure 3.15 Incident Photon-to-Current Efficiency and Tauc plots of the $\mathrm{TiO}_{2} \mathrm{a}, \mathrm{c}$ ) NT and b, d) NR before and after modification in $1 \mathrm{M} \mathrm{NaOH}$ solution

Figure 3.16 shows the Mott-Schottky plots of $\mathrm{TiO}_{2} \mathrm{NT}$ and NR in $\mathrm{NaOH}$ solution. Based on the Mott-Schottky equation, the donor density can be derived from the slope of the plot, where a remarkable enhancement of almost 4 orders of magnitude was obtained from $67 \times 10^{19}$ to $23 \times 10^{23}$ donors $/ \mathrm{cm}^{3}$. This observation was in good agreement with those from the CVs, where the capacitance increased due to the oxygen vacancies $\mathrm{Ti}^{3+}$ sites. For the NR sample, the modification enhanced the $N_{\mathrm{d}}$ from 1.6 to $1.9 \times 10^{18}$ donors $/ \mathrm{cm}^{3}$. These observations were at the underlying mechanisms that provided the different responses at the CAs, where the recombination was increased in the NT sample due to a higher number of vacancies present. The filling of such surface 
states did not occur at the same rate as for the NR, where the density of donors was slightly modified and lead to a decreased electron trapping. From the extrapolation of the slope to the limit of the $C_{\mathrm{sc}}{ }^{-2}$, the $V_{\mathrm{fb}}$ can be approximated. The changes in the $V_{\mathrm{fb}}$ were observed as a result from the self-doping treatment, from -0.58 to $-1.02 \mathrm{~V}$ vs. $\mathrm{Ag} \mid \mathrm{AgCl}$ and from -0.70 to $-0.60 \mathrm{~V}$ vs. $\mathrm{Ag} \mid \mathrm{AgCl}$ for the NT and NR, respectively. The negative shift in the NT sample agrees with the idea of the self-doping and generation of $\mathrm{Ti}^{3+}$ sites. A positive shift in the $V_{\mathrm{fb}}$, as observed for the NR, shows a similar conclusion as the NR modified in $\mathrm{H}_{2} \mathrm{SO}_{4}$ solution, which could be explained as the adsorption of cations or solvent dipoles oriented with their positive end towards the NR [99]. Therefore, the idea of proton intercalation on the surface of the NR sample was supported.
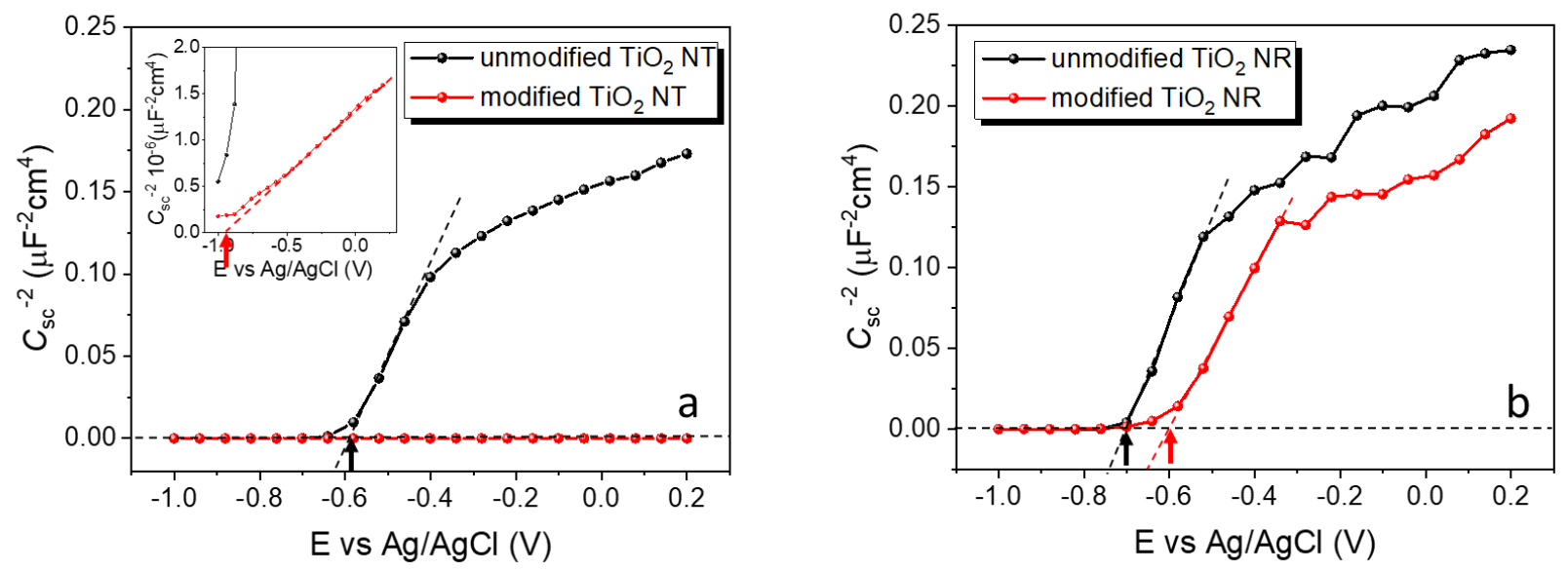

Figure 3.16 Mott-Schottky plots of the $\mathrm{TiO}_{2}$ a) NT and b) NR before and after modification in $1 \mathrm{M} \mathrm{NaOH}$ solution

Based on the analysis of Tauc plots and Mott-Schottky plots, the band gap structure is shown in Figure 3.17. This is straight-forward to see the influence of the partial reduction on the energy level of $\mathrm{TiO}_{2}$. For both samples, the $\mathrm{Ti}^{3+}$ formed on the interface of the electrode did not change the bandgap. However, the new energy level introduced between CB and VB will shift the position of bandgap (negative shift for NT and positive for NR) and improve the separation of photogenerated electrons and holes. 


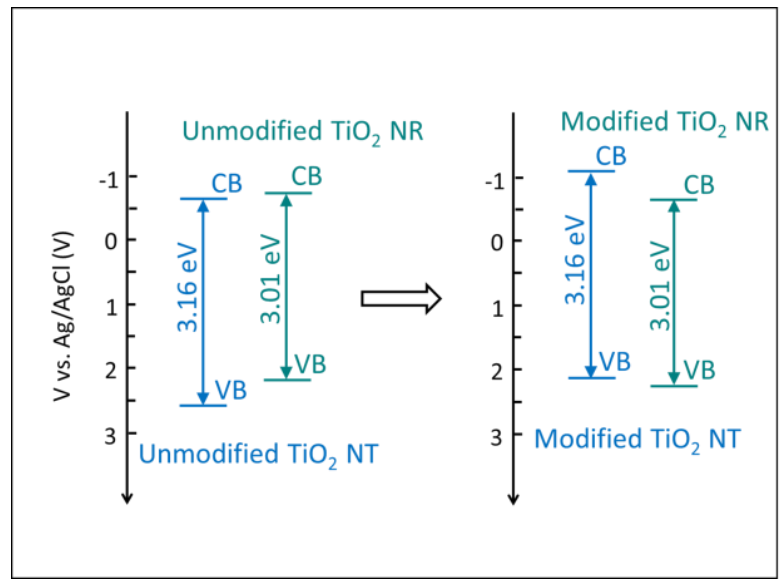

Figure 3.17 Bandgap structure of the $\mathrm{TiO}_{2} \mathrm{NT}$ and $\mathrm{NR}$ before and after modification in $1 \mathrm{M} \mathrm{NaOH}$ solution 


\section{Characterization Results of $\mathrm{WO}_{3}$ Arrays Film}

\subsection{Physical Characterization Results of $\mathrm{WO}_{3}$ Arrays Film}

The $\mathrm{WO}_{3}$ morphology was characterized by SEM. As shown in Figure 4.1, the $\mathrm{WO}_{3}$ nanoparticles did not have a well-defined geometry but structures with an average diameter of around $100 \mathrm{~nm}$. It is obvious to notice that the morphology was well preserved and there was almost no change in the nanostructure of $\mathrm{WO}_{3}$ after the electrochemical modification. Since the hydrogen evolution took place during the modification process, gas bubbles near the vicinity of the electrode were produced. However, the morphology did not seem to be altered, and for such reason, we can conclude that the parameters used during the electrochemical reduction did not damage the original $\mathrm{WO}_{3}$ nanostructures.
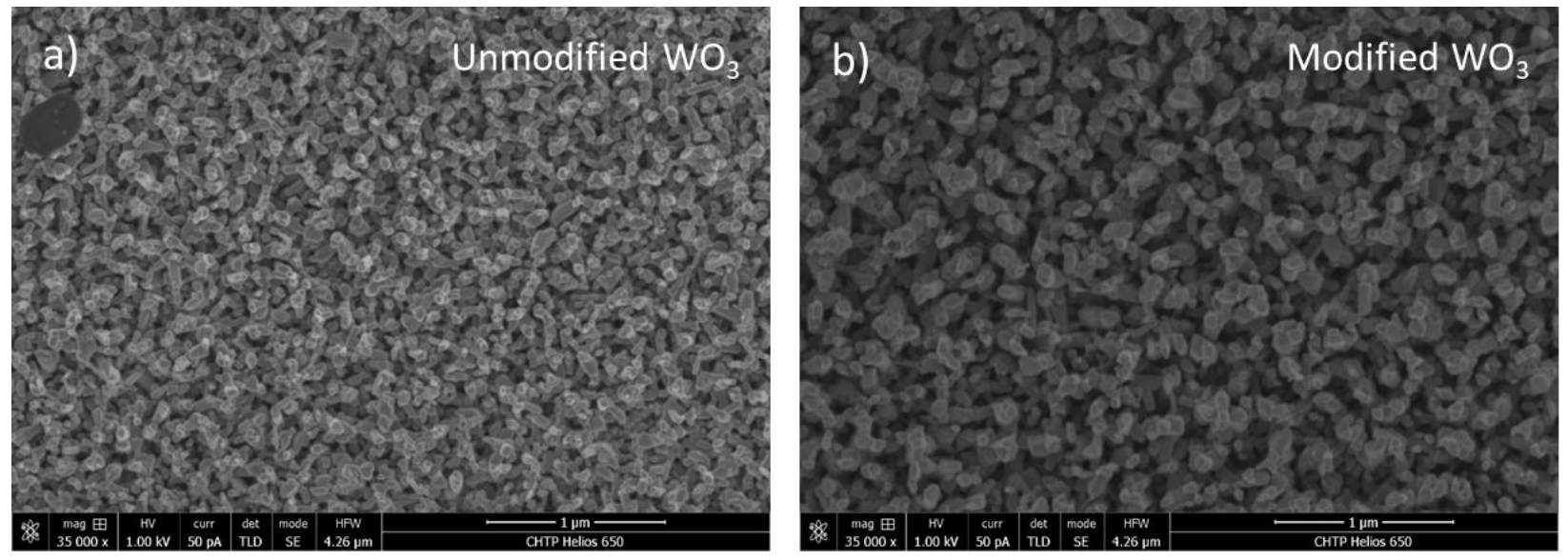

Figure 4.1 SEM images of the $\mathrm{WO}_{3}$ before and after modification

The crystallinity analysis of $\mathrm{WO}_{3}$ was performed by XRD patterns shown in Figure 4.2. The electrodes were thermally annealed at $500{ }^{\circ} \mathrm{C}$ in $\mathrm{N}_{2}$ for 3 hours to induce its crystallinity. Because the peaks at $23.14,23.61,24.37,49.94^{\circ}$ correspond to the (002), (020), (200) and (400) with no other peaks, the crystal structures of $\mathrm{WO}_{3}$ nanoparticle arrays both before and after modification were consistent with the monoclinic phase (01-072-1465). However, it is obvious from the XRD 
patterns that compared with the untreated $\mathrm{WO}_{3}$, a siginificant increase in the intensity of the principal peaks was obtained for our sample after the electrochemical reduction process. Meanwhile, (020) diffraction peak had a higher intensity which was attributed to the high orientation of the particles in [010] direction in the self-doped $\mathrm{WO}_{3}$.
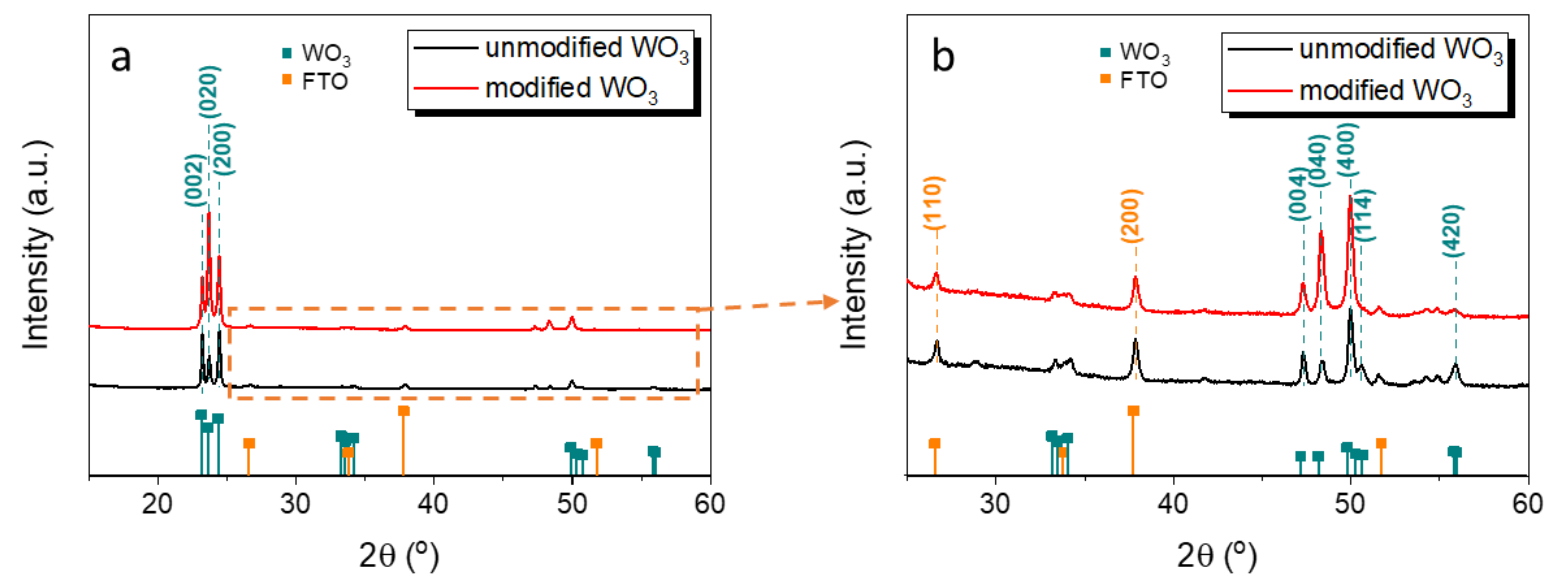

Figure 4.2 a) XRD spectra and b) detailed spectra of the $\mathrm{WO}_{3}$ before and after modification

Figure 4.3 shows the Raman signal of $\mathrm{WO}_{3}$ before and after modification. The Raman data showed the peaks at $720 \mathrm{~cm}^{-1}$ and $813.5 \mathrm{~cm}^{-1}$, which are associated with $[v(\mathrm{O}-\mathrm{W}-\mathrm{O})]$. The Raman spectroscopy in red depicted the structural fingerprint of self-doped $\mathrm{WO}_{3}$, with the peaks in the same position as the un-modified sample demonstrating the no change of crystallinity for $\mathrm{WO}_{3}$. It is reasonable to conclude from Figure 4.3 that the electrochemical treatment does not affect the Raman signals of $\mathrm{WO}_{3}$, which means there is no change in the crystallinity of this material. This agrees well with the XRD results. 


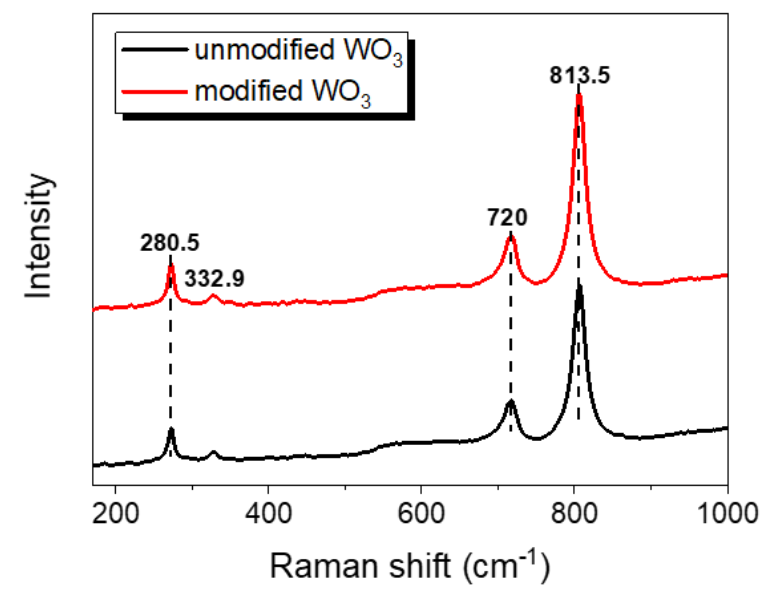

Figure 4.3 Raman spectra of the $\mathrm{WO}_{3}$ before and after modification

The changes in the surface chemistry were evaluated using XPS, and the high-resolution spectra results were summarized in Figure 4.4. The responses for the $\mathrm{W} 4 \mathrm{f}$ of the electrode before (pristine) and after the electrochemical modification are presented in Figures 4.4a, b and c. The typical primary signal was found at $35.7 \mathrm{eV}$ and with a doublet separated by $2.1 \mathrm{eV}$, agreeing with the literature reports [101]. A small shift towards lower energies was observed which could usually be ascribed to $\mathrm{W}^{5+}$ signals [102]. However, the fitting was not conclusive, and for such reason, the signals related to the $\mathrm{O} 1 \mathrm{~s}$ were also obtained and presented in Figure 4.4d-f. The deconvolution of the $\mathrm{O} 1 \mathrm{~s}$ signals revealed a major peak of $530.6 \mathrm{eV}$ which is characteristic of metal oxides. Two smaller contributions were found present in both samples at $531.1 \mathrm{eV}$ and $532 \mathrm{eV}$. The first corresponds to $\mathrm{OH}$ surface groups which were also present in the $\mathrm{TiO}_{2}$ materials and are known for their importance in the water oxidation process [102]. It is noteworthy to mention that the binding energies for the $\mathrm{W}-\mathrm{O}$ and $\mathrm{OH}$ signals were fixed during the fitting process. For such reason, the signal at $\sim 532.5 \mathrm{eV}$ was not fixed as it could be attributed to weakly adsorbed species or $\mathrm{H}_{2} \mathrm{O}$ molecules. Based on our observations for the $\mathrm{TiO}_{2}$ samples, it seems reasonable to conclude that water was absorbed in the higher binding energies in the $\mathrm{O} 1 \mathrm{~s}$ spectra. This also 
supports the idea that the hydroxylation extent of the surface is critical for the charge transfer processes.

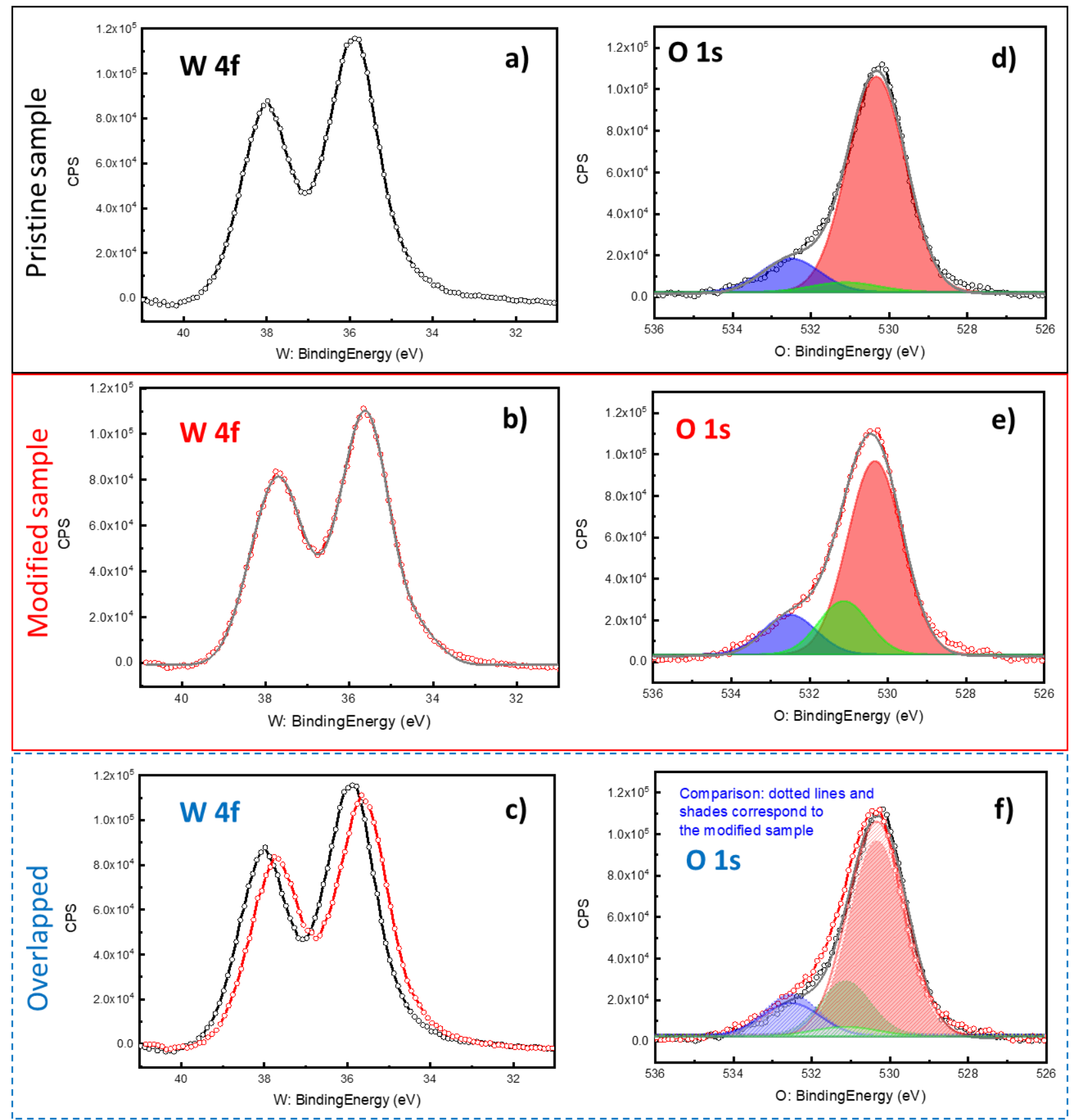

Figure 4.4 High-resolution XPS spectra of the $\mathrm{WO}_{3}$ before and after modification 


\subsection{Photoelectrochemical Characterization Results of $\mathrm{WO}_{3}$ Arrays Film}

The effect of the modification process on the electrochemical properties of $\mathrm{WO}_{3}$ was systematically studied. Figure 4.5 shows the $\mathrm{CV}$ curves of the $\mathrm{WO}_{3}$ samples recorded at a scanning rate of $50 \mathrm{mV} / \mathrm{s}$ from $-0.2 \mathrm{~V}$ to $1.0 \mathrm{~V}$ in $0.5 \mathrm{M} \mathrm{H}_{2} \mathrm{SO}_{4}$ solution $(\mathrm{pH}=0.3)$. It should be noted that the anodic current peak (under illumination conditions) underwent a slight shift to cathodic potentials after the electrochemical reduction process. This could be associated with an enhanced oxidation process of $\mathrm{H}_{2}$. On the other hand, there was a slight increase in the current density of the modified $\mathrm{WO}_{3}$ under illumination, from $50 \mu \mathrm{A}$ to $75 \mu \mathrm{A}$ at a potential of $\sim 1 \mathrm{~V}$ vs. $\mathrm{Ag} \mid \mathrm{AgCl}$. A similar observation can be done for the capacitance at the same potential range for the CV under darkness. As noted in Figure 4.5b, it is evident that the modification process has slightly improved the capacitance of $\mathrm{WO}_{3}$, which is the reason for the higher current density obtained at the positive potential after modification.
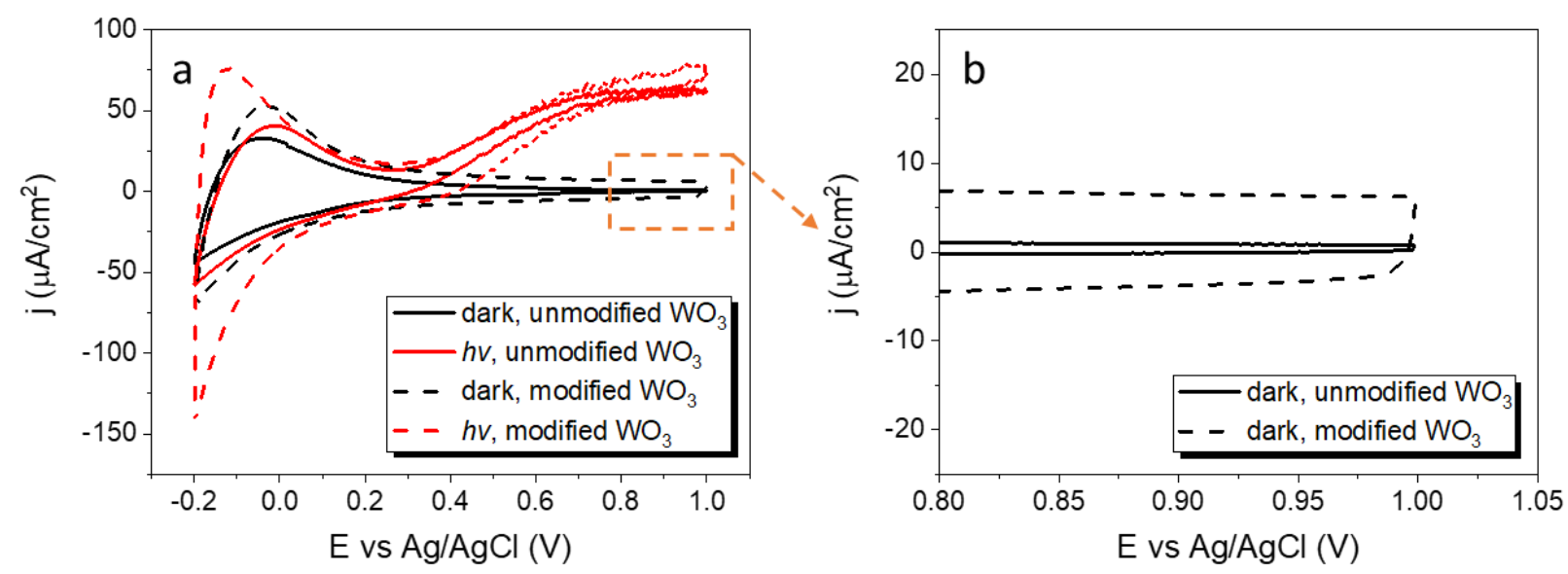


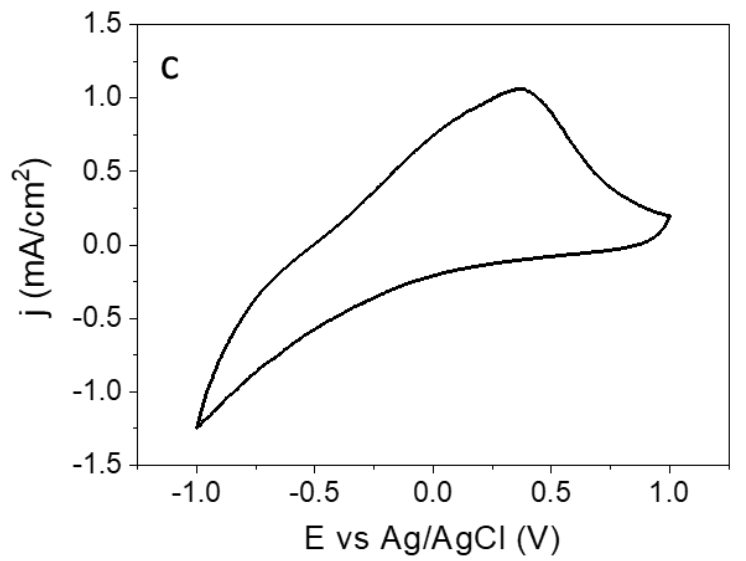

Figure 4.5 a) Original and b) zoomed-in cyclic voltammograms (CV) of the $\mathrm{WO}_{3}$ before and after modification; c) modification process of $\mathrm{WO}_{3}$

Figure 4.6 shows the plots of $\mathrm{LSV}$ for $\mathrm{WO}_{3}$ photoanodes recorded at a scanning rate of $10 \mathrm{mV} / \mathrm{s}$. The photoelectroactivity of these films slightly increased which resulted in a photocurrent density of $73 \mu \mathrm{A} / \mathrm{cm}^{2}$ at $1.0 \mathrm{~V}$ vs. $\mathrm{Ag} \mid \mathrm{AgCl}$. The onset potential $(0.2 \mathrm{~V}$ vs. $\mathrm{Ag} \mid \mathrm{AgCl})$ did not change significantly after the electrochemical modification. Furthermore, the photocurrent density of pristine $\mathrm{WO}_{3}$ reached a plateau at around $0.8 \mathrm{~V}$ vs. $\mathrm{Ag} \mid \mathrm{AgCl}$. However, after the partial reduction process, it was hard to see the plateau which could be associated to oxygen vacancies induced to the pristine $\mathrm{WO}_{3}$ and, thus, affecting the kinetics of the separation of photo-generated charge carriers [103].
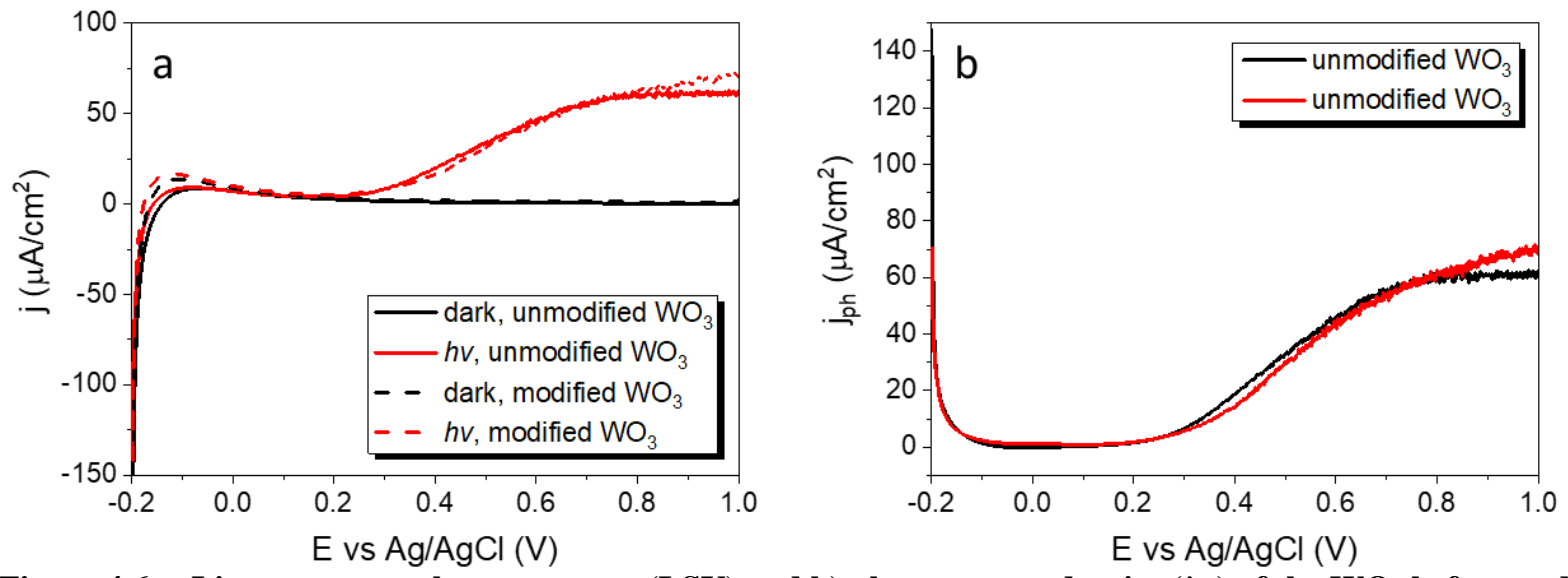

Figure 4.6 a) Linear sweep voltammograms $(\mathrm{LSV})$ and b) photocurrent density $\left(j_{\mathrm{ph}}\right)$ of the $\mathrm{WO}_{3}$ before and after modification 
The chronoamperometric (CA) responses of the electrodes were recorded to evaluate the change of the photocurrent at a constant potential bias $(1 \mathrm{~V}$ vs. $\mathrm{Ag} \mid \mathrm{AgCl})$. After the dark current was obtained, the light irradiated to the photoanode, and a $j_{\mathrm{ph}}$ of around $55 \mu \mathrm{A} / \mathrm{cm}^{2}$ was obtained for the pristine electrode. An enhancement was observed for the modified sample, reaching $j_{\mathrm{ph}}=80$ $\mu \mathrm{A} / \mathrm{cm}^{2}$, but with an initial spike that was not present in the pristine sample. Such a spike may arise from the recombination between electrons and holes at surface states. In other words, the photocurrent rose when the carriers separated quickly, followed by a sudden drop due to the recombination of those carriers. This is also reflected as a negative overshoot at the moment when the illumination is interrupted, which suggests the fast recombination rate because of the oxygen vacancies' generation.

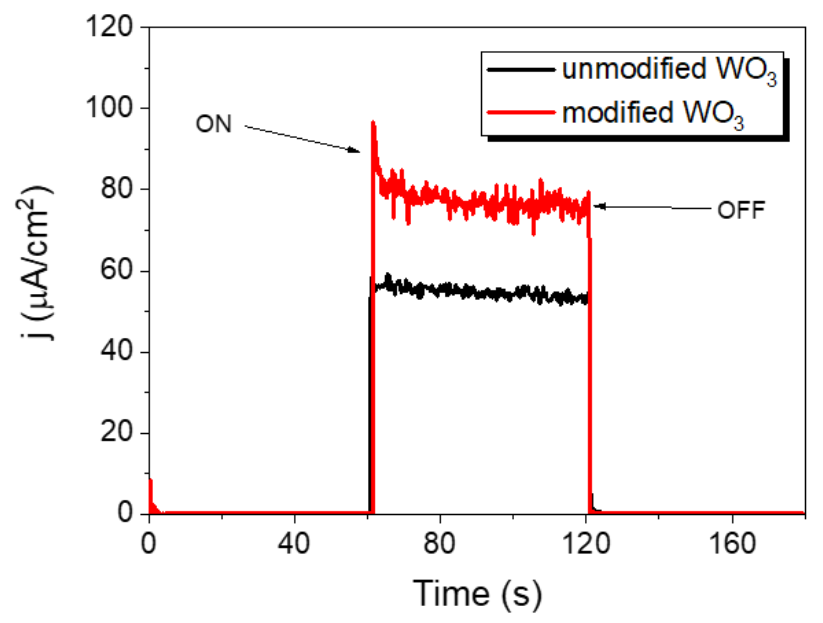

Figure 4.7 Chronoamperometric (CA) response to light irradiation of the $\mathrm{WO}_{3}$ before and after modification

Figure 4.8a shows the incident photon-to-current efficiency for the bare and modified $\mathrm{WO}_{3}$. The $\mathrm{WO}_{3}$ exhibited a broad visible light absorption, whereas pure $\mathrm{TiO}_{2}$ did not. It is clearly shown in Figure 4.8a that, for $\mathrm{WO}_{3}$, the introduction of oxygen vacancy did not increase the IPCE significantly and almost no change in the absorption edge. In Tauc plots (Figure 4.8b), the bandgap can be approximated from the extrapolated slope on the transition part of the curve to the energy 
axis. The unchanged bandgap of $2.81 \mathrm{eV}$ was consistent with the unchanged absorption edge shown in Figure 4.8a. This reflects the fact that the optical properties of $\mathrm{WO}_{3}$ did not show any substantial changes.
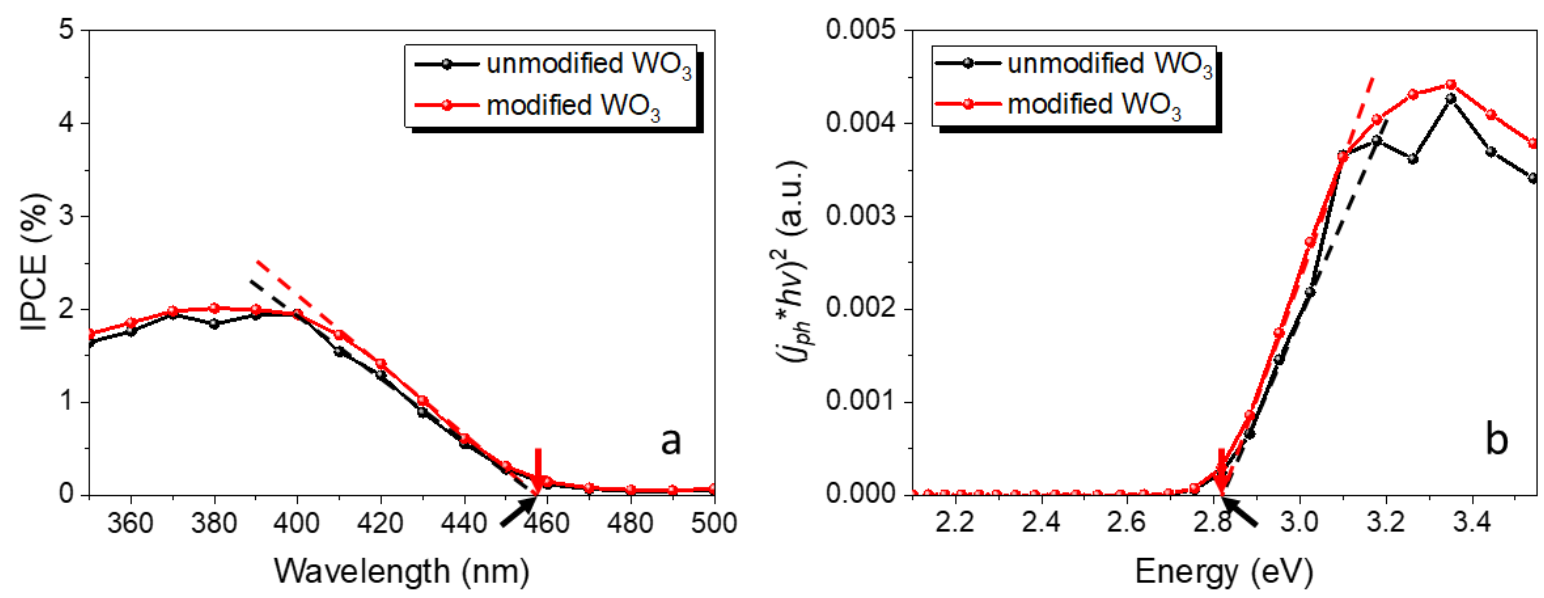

Figure 4.8 a) Incident Photon-to-Current Efficiency and b) Tauc plots of the $\mathrm{WO}_{3}$ before and after modification

To study the influence of partial reduction modification on the capacitance property of $\mathrm{WO}_{3}$, the Mott- Schottky plots were tested for pristine $\mathrm{WO}_{3}$ and self-doped $\mathrm{WO}_{3}$ samples, as shown in Figure 4.9. The differential capacitance of the space-charge region $C_{\mathrm{s}}$ was obtained from the electrochemical impedance spectroscopy (EIS) obtained at constant polarization in the same potential region as that in the CVs. The frequency selected to evaluate the $C_{\mathrm{s}}$ is $800 \mathrm{~Hz}$, and the dielectric constant of $\mathrm{WO}_{3}$ is 20 [104]. There was a decrease in the slope of modified samples compared with that of the unmodified sample, because of the increased donor density in the material. Based on the Mott-Schottky equation, the donor density of $\mathrm{WO}_{3}$ before and after modification is $3.78 \times 10^{21} \mathrm{~cm}^{-3}$ and $9.17 \times 10^{21} \mathrm{~cm}^{-3}$, respectively. This demonstrated the generation of oxygen vacancies during the modification process [105], which will improve the conductivity of the material and charge transfer in PEC reaction [106-108]. Moreover, there was a positive shift 
of flatband potential for $\mathrm{WO}_{3}$ from $0.18 \mathrm{eV}$ to $0.56 \mathrm{eV}$. It could be due to the adsorption of cations or solvent dipoles oriented with their positive end towards the $\mathrm{WO}_{3}$ nanoparticles.

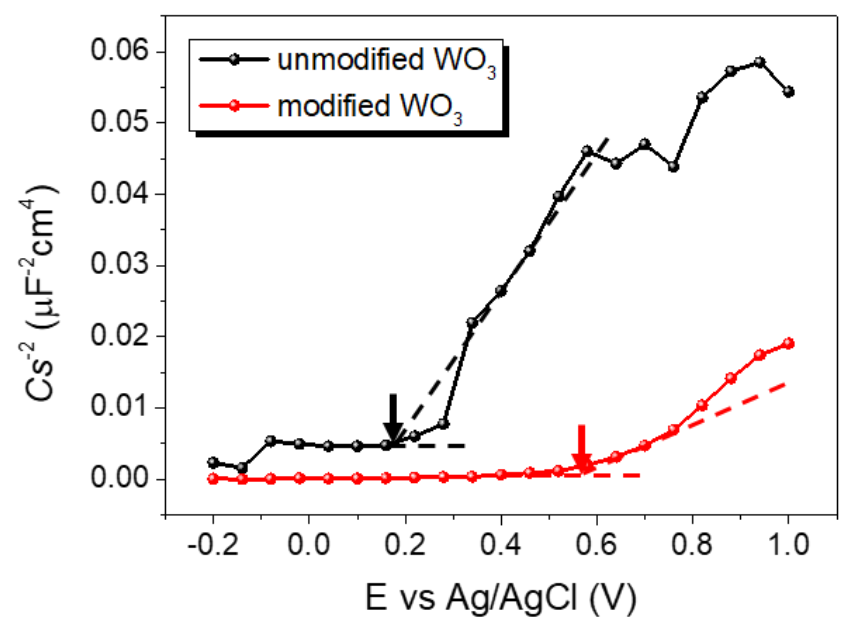

Figure 4.9 Mott-Schottky plots of the $\mathrm{WO}_{3}$ before and after modification

The bandgap structures of $\mathrm{WO}_{3}$ before and after modification are shown in Figure 4.10. There was no change in the bandgap of $\mathrm{WO}_{3}$. However, after modification, a positive shift of bandgap position could be observed, as a higher charge density for proton intercalation was achieved in $\mathrm{H}_{2} \mathrm{SO}_{4}$ solution [109].

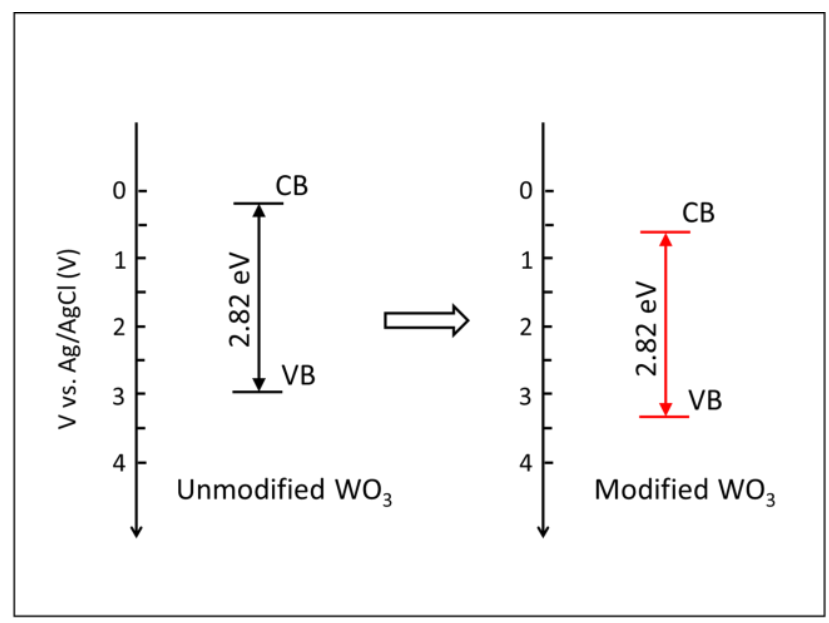

Figure 4.10 Bandgap structure of the $\mathrm{WO}_{3}$ before and after modification 


\section{Characterization Results of $\mathrm{ZnO}$ Arrays Film}

\subsection{Physical Characterization Results of $\mathrm{ZnO}$ Arrays Film}

To study the impact of the electrochemical modification on the nanostructure of the nanorods, FESEM images were shown in Figure 5.1. Before modification, the $\mathrm{ZnO}$ nanorods presented a hexagonal/columnar shape with diameters around 100-200 nm and flat surface on the top. After modification, the nanorods showed a pyramidal mophology, with a base width of around $100 \mathrm{~nm}$ that tapered to a tip of around $25 \mathrm{~nm}$. As is reported before, the dopants induced into the material can have great influence on the size and morphology of the nanorods [110, 111]. According to that, the formation of the nanoneedle structure could be due to the $\mathrm{ZnO}$ dissolved from the top part, resulting in a morphological modification. This phenomenon suggested already a change in the surface chemistry of the material.
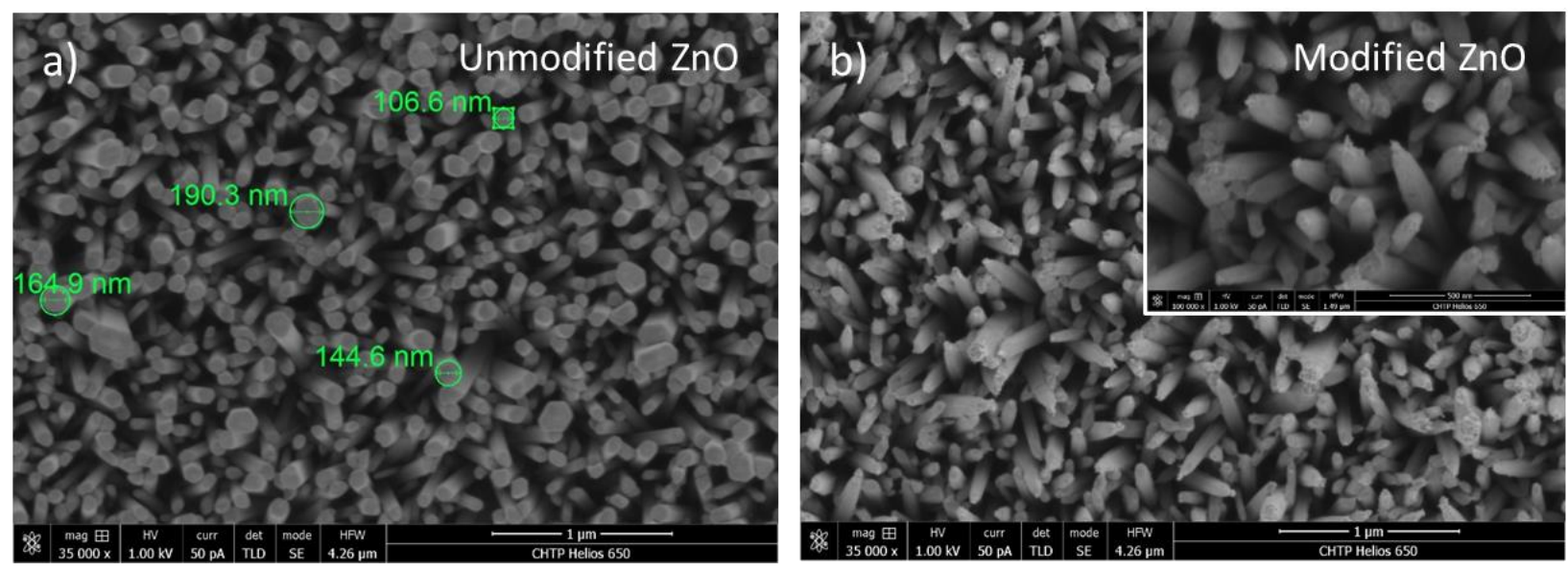

Figure 5.1 SEM images of the $\mathrm{ZnO}$ a) before and b) after modification

The crystallinity of the $\mathrm{ZnO}$ arrays was characterized using XRD. As shown in the diffractograms in Figure 5.2, the samples presented sharp and narrow peaks evidencing a highly crystalline material. For either bare or self-doped $\mathrm{ZnO}$, five peaks appeared at $34.4^{\circ}, 36.3^{\circ}, 47.6^{\circ}, 62.9^{\circ}$ and 72.59 which could be assigned to (002), (101), (102), (103) and (004) planes of wurtzite $\mathrm{ZnO}$ (01- 
089-0510). Beside the FTO, no other peaks were detected in the diffractograms. The sharp peak at $35^{\circ}$ corresponding to the (002) plane for the unmodified sample, indicates the highly oriented growth of the nanorods $[113,114]$. However, the peak significantly decreased its intensity from 97634 to 34026 units by a factor of 0.35 after modification, while almost no change of the intensity for other peaks. This supports the observations in the SEM images, which could be associated with chemical changes in the surface as a partial reduction of the surface [115].

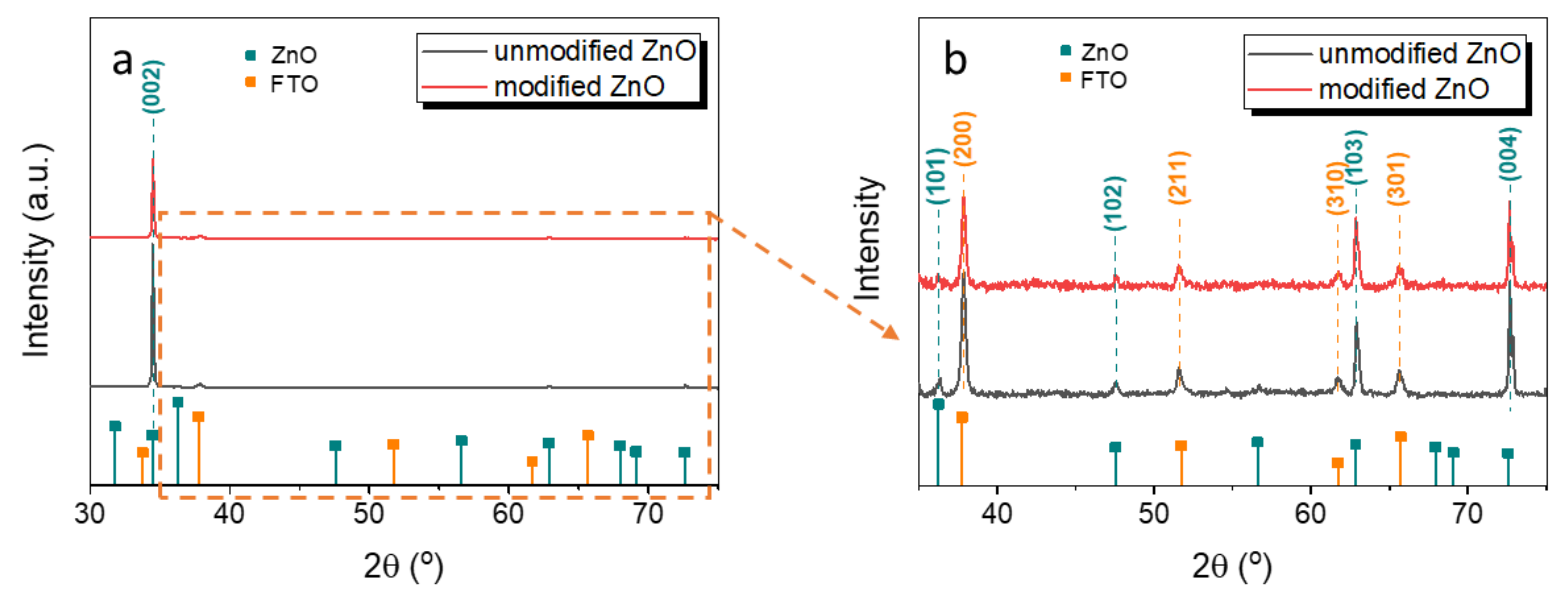

Figure 5.2 a) XRD spectra and b) detailed spectra of the ZnO before and after modification

Figure 5.3 shows the Raman spectra of $\mathrm{ZnO}$ sample to analyze the change of its crystallinity. It is obvious to see that the Raman signal in $439 \mathrm{~cm}^{-1}$ dominated in the Raman scattering spectra (Figure 5.3), which is attributed to $\mathrm{E}_{2}$ mode. This is typical for the wurtzite $\mathrm{ZnO}$ phase [116]. There was nearly no change for the Raman signal after the partial reduction modification. However, compared to the Raman spectra of $\mathrm{ZnO}$ reported by Zhang [117], the Raman spectrum of our samples presented a sharp peak, which may be attributed to the well-orientated crystallinity as observed in XRD analysis before [118]. 


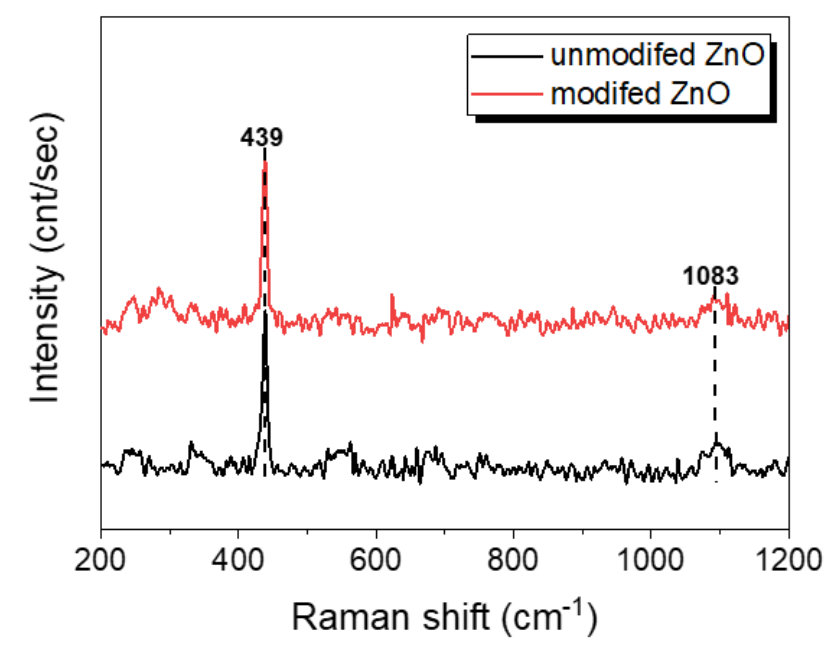

Figure 5.3 Raman spectra of the $\mathrm{ZnO}$ before and after modification

The surface chemistry for the $\mathrm{ZnO}$ samples was studied by using XPS, and the high-resolution spectra are presented in Figure 5.4. The expected signals related to the $\mathrm{Zn} 2 \mathrm{p}_{3 / 2}$ appeared at 1021 $\mathrm{eV}$ and its corresponding doublet $\left(\mathrm{Zn} 2 \mathrm{p}_{1 / 2}\right)$ at $1044 \mathrm{eV}$, agreeing with the literature reports [101]. A slight shift towards higher binding energies was observed for the sample modified electrochemically (Figure 5.4c). This observation was in contrast with the spectra associated with the $\mathrm{O} 1 \mathrm{~s}$ signals that occurred at $\sim 530 \mathrm{eV}$. From Figure 5.4d, the deconvolution of the signal showed two peaks which accounted for the oxygen in the lattice $(530.2 \mathrm{eV})$ and $\mathrm{OH}$ groups (531.5 $\mathrm{eV}$ ) on the surface. As observed in the previous cases, the peak associated with the hydroxylated surface increased after the modification of the electrode, supporting the observations found in $\mathrm{XRD}$ and SEM. This is also consistent with what was observed in $\mathrm{TiO}_{2}$ and $\mathrm{WO}_{3}$, where the hydroxylated surface favored the charge transfer reactions for water oxidation. 


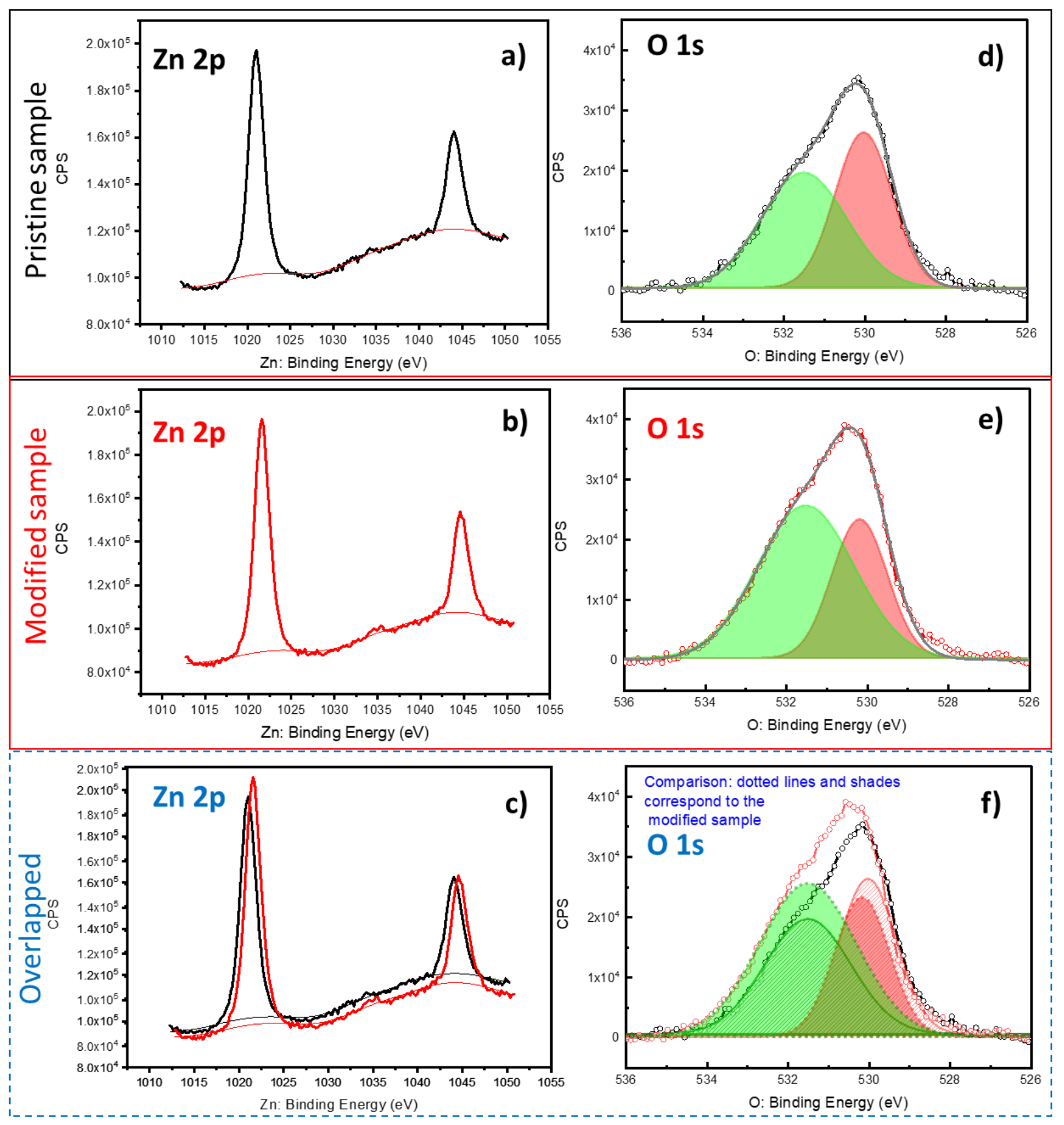

Figure 5.4 High-resolution XPS spectra of the ZnO before and after modification

\subsection{Photoelectrochemical Characterization Results of $\mathrm{ZnO}$ Arrays Film}

Figure 5.5 shows the cyclic voltammograms $(\mathrm{CV})$ of bare $\mathrm{ZnO}$ in $0.5 \mathrm{Na}_{2} \mathrm{SO}_{4}$ at a scanning rate of $50 \mathrm{mV} / \mathrm{s}$. The absence of the peaks in the voltammograms suggested a lower trap states density in 
this material. Unlike $\mathrm{TiO}_{2} \mathrm{NT}$ we discussed before, the $\mathrm{CV}$ curves of $\mathrm{ZnO}$ revealed a triangle shape, which is typical for semiconducting materials. From Figure $5.5 b$ we can observe that the partial reduction does not modify the characteristic curves significantly under darkness.
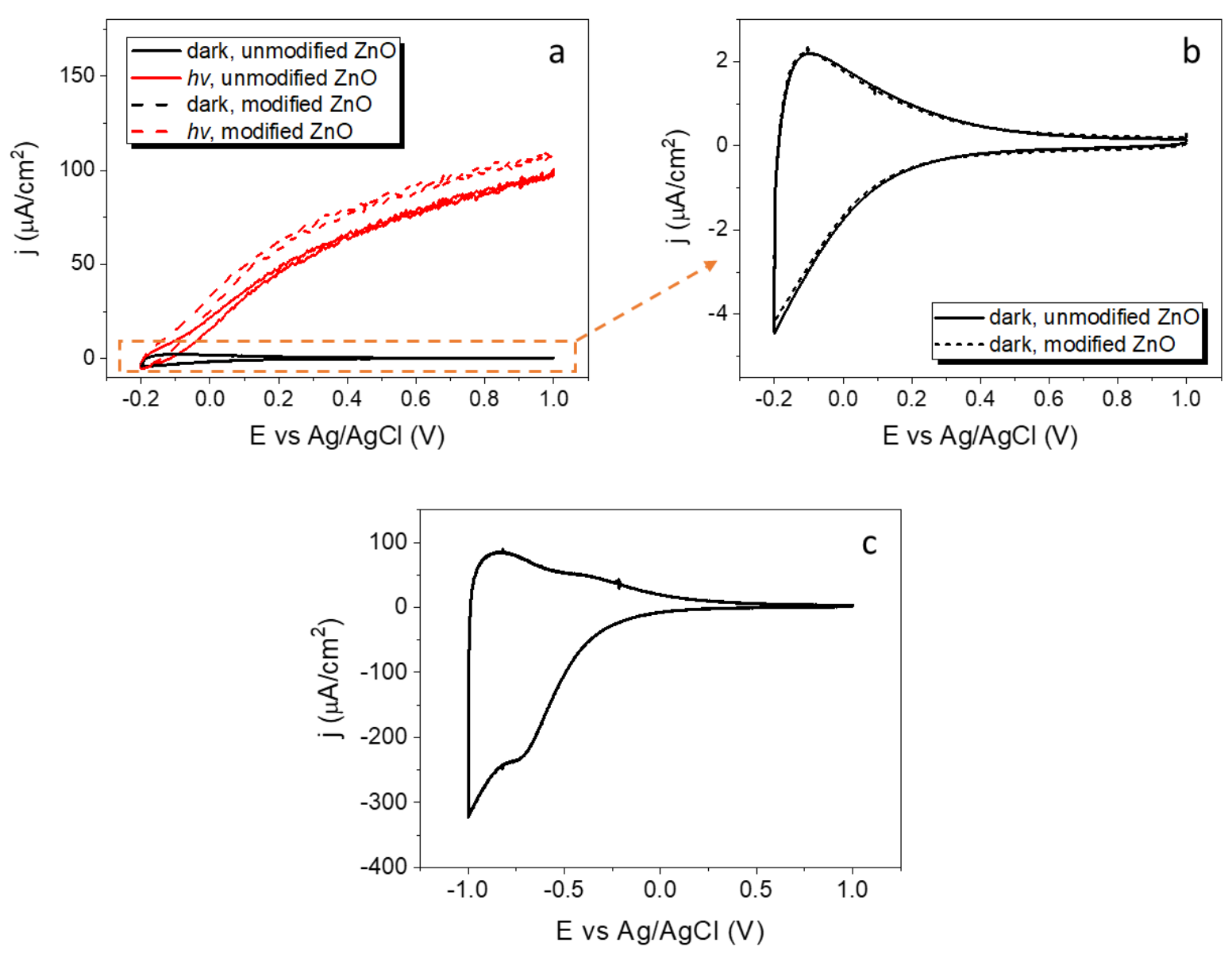

Figure 5.5 a) Original and b) zoomed-in cyclic voltammograms (CV) of the $\mathrm{ZnO}$ before and after modification; c) modification process of the $\mathrm{ZnO}$

A slower scanning rate of $10 \mathrm{mV} / \mathrm{s}$ was set to record the Linear sweep voltammograms (LSV) of the $\mathrm{ZnO}$ to minimize the influence of charging current. Meanwhile, the dark current (joff) was subtracted from the illumination current $\left(j_{\text {on }}\right)$ to more accurately assess the photogenerated current $\left(j_{\mathrm{ph}}\right)$ (shown in Figure 5.6b). There was a homogeneous improvement of the photocurrent density around -0.2 to $1.0 \mathrm{~V}$ vs. $\mathrm{Ag} \mid \mathrm{AgCl}$ for self-doped $\mathrm{ZnO}$. This phenomenon may be attributed to oxygen vacancies $(\mathrm{Zn})$ produced in the $\mathrm{ZnO}$ lattice, which shall introduce localized charge located 
below the conduction band. Hence, the energy needed for electron immigration to CB in the bulk region will be smaller as a result from the localized charge. Because of this, the charge separation between electrons and holes was enhanced [122].
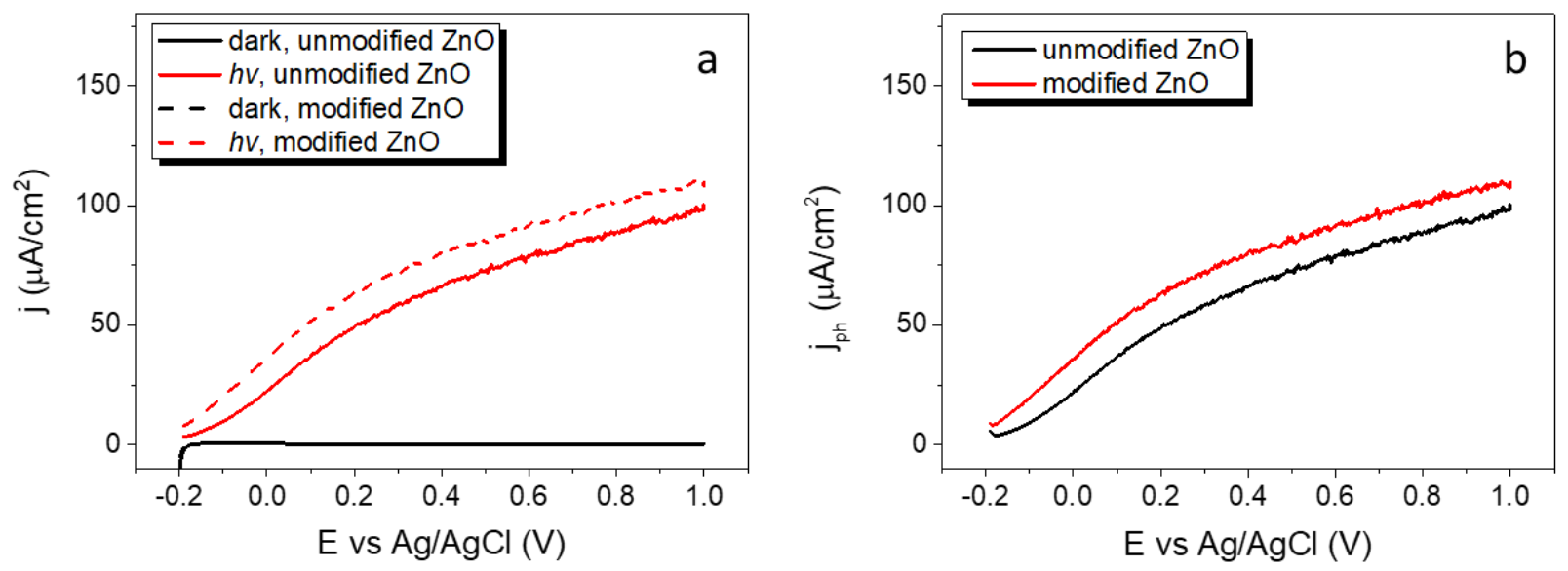

Figure 5.6 a) Linear sweep voltammograms (LSV) and b) photocurrent density $\left(j_{\text {ph}}\right)$ of the $\mathrm{ZnO}$ before and after modification

In Figure 5.7 the chronoamperometric $(\mathrm{CA})$ response to light irradiation of the $\mathrm{ZnO}$ is presented. The pristine $\mathrm{ZnO}$ electrode presented a current density of around $100 \mu \mathrm{A} / \mathrm{cm}^{2}$ and a slight improvement after modification. This can be explained that oxygen vacancies were produced on the surface of our material. The modified $\mathrm{ZnO}$ nanoneedles could generate an enhanced separation of photoinduced electron-hole pairs on the partially reduced sites (oxygen vacancies) with the energy level between CB and VB. This will lead to a higher number of photoexcited electrons transported to the conduction band. However, the kinetics did not show a significant difference, as evidenced by the onset and decay of $j_{\mathrm{ph}}$. Since the overshoot presented when the $j_{\mathrm{ph}}$ was just generated appeared in both conditions (unmodified and modified), agreeing with such an idea. 


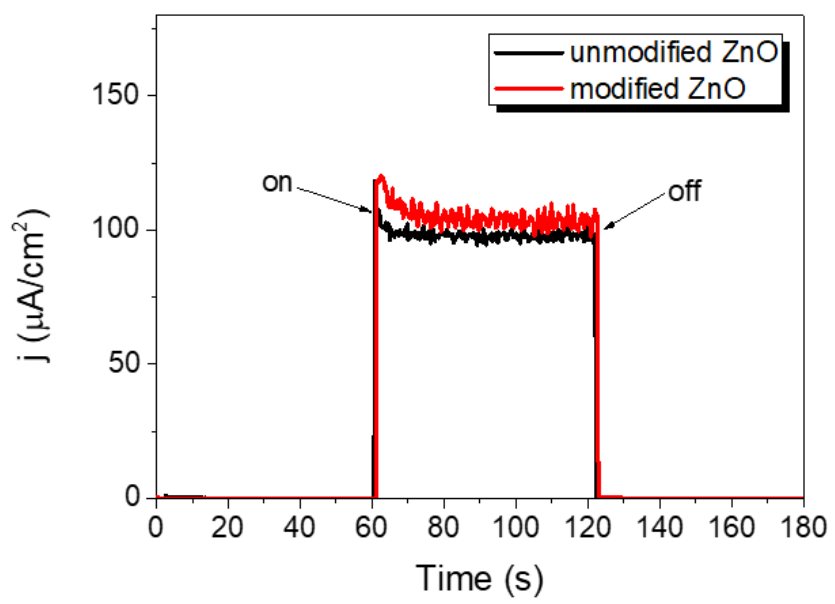

Figure 5.7 Chronoamperometric (CA) response to light irradiation of the $\mathrm{ZnO}$ before and after modification

The Incident Photon-to-Current Efficiency and Tauc plots of $\mathrm{ZnO}$ are shown in Figure 5.8. For the modified samples, a slight increase in the IPCE was recorded in the UV region from 5\% to 5.6\% with the absorption edge of around $390 \mathrm{~nm}$. This absorption edge corresponds to the band gap of $3.18 \mathrm{eV}$ that has been previously reported and no substantial difference with that before partial reduction. The IPCE increase was consistent with the improved photocurrent as observed from CA analysis, which may be due to the dopants induced into $\mathrm{ZnO}$ during the modification process.
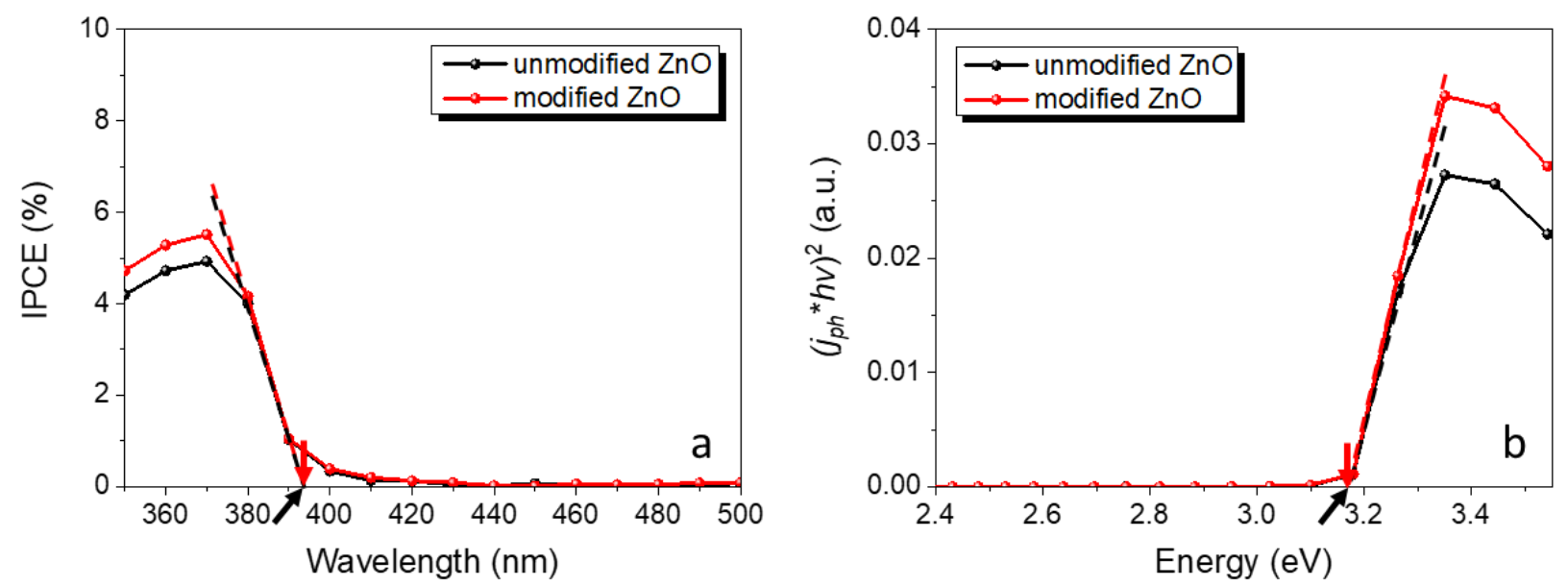

Figure 5.8 a) Incident Photon-to-Current Efficiency and b) Tauc plots of the $\mathrm{ZnO}$ before and after modification 
The changes in the capacitance of the space-charge region of $\mathrm{ZnO}$ were assessed from the MottSchottky plot and are presented in Figure 5.9. The frequency used for its evaluation was $1000 \mathrm{~Hz}$, and the dielectric constant for the $\mathrm{ZnO}$ was 8.5 [123]. The slope of this plot was used to calculate the donor density which was $3.08 \times 10^{20} \mathrm{~cm}^{-3}$ for the pristine $\mathrm{ZnO}$ and $5.39 \times 10^{20} \mathrm{~cm}^{-3}$ after the partial reduction. However, Tauc plot shows that such modification did not influence the bandgap of the $\mathrm{ZnO}$. And in accordance to what was observed in the $\mathrm{CV}$ curves, the capacitance property was also not significantly affected as observed in the almost unchanged slopes from the curves. However, the flatband potential was affected, which can be seen from the intercept of the slope to the energy axis: $0.31 \mathrm{eV}$ before modification and $0.24 \mathrm{eV}$ after. The latter suggests that holes and electrons can be separated more effectively, which may be a reason for the improvement of IPCE.

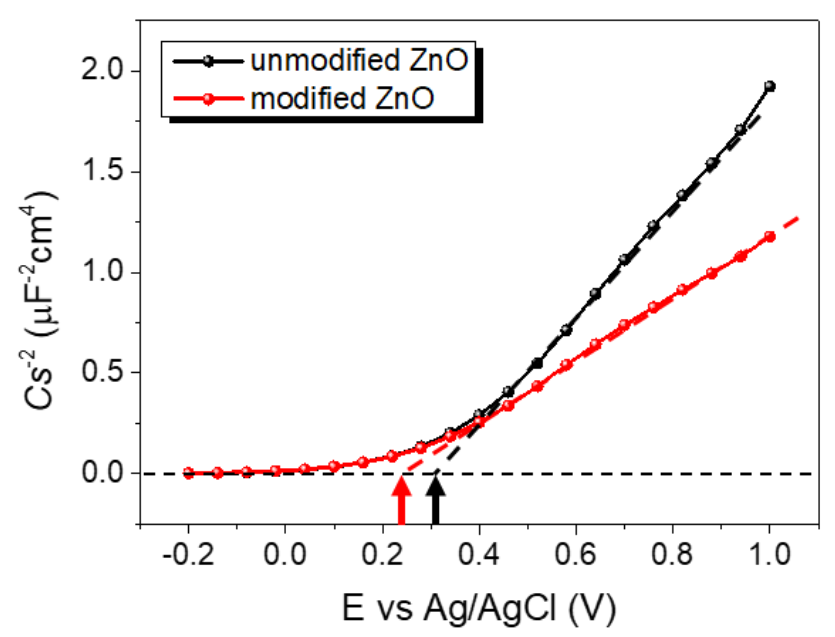

Figure 5.9 Mott-Schottky plots of the $\mathrm{ZnO}$ before and after modification

It can be observed from the band gap structure of $\mathrm{ZnO}$ that the oxygen vacancies produced on the surface of $\mathrm{ZnO}$ had little influence on the energy diagram. The bandgap is unaltered, but a small shift towards more negative potential was obtained as a consequence of the partial reduction. This conclusion agrees well with our previously mentioned result, which indicates a slight improvement 
in the photoelectrocatalytic performance of $\mathrm{ZnO}$.

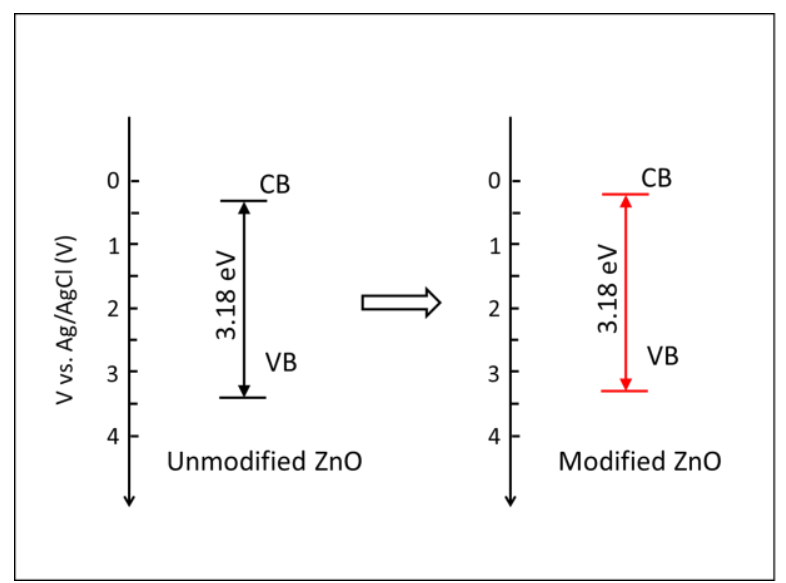

Figure 5.10 Bandgap structure of the $\mathrm{ZnO}$ before and after modification 


\section{Conclusions}

In this work, we studied three types of inexpensive, non-toxic and abundant materials that can be manufactured by simple methods: $\mathrm{TiO}_{2}, \mathrm{WO}_{3}$, and $\mathrm{ZnO}$. An electrochemical reduction method was introduced to modify these nanostructured electrodes to improve their energy conversion efficiency and expand their absorption spectrum.

Physicochemical measurements in these electrode materials showed that it is possible to change the optoelectronic properties of the materials by the partial reduction modification. For all of the samples, according to the analysis of XRD and Raman data, the modification did not change the crystallinity of the materials, but facilitated the oxygen vacancy generation based on the XPS measurements. The electrons donated from the oxygen vacancies improved the light response of these materials. For future work, Electron spin resonance (ESR) and electron paramagnetic resonance (EPR) can be used to characterize the samples and prove the existence of oxygen vacancies produced in the materials.

While the physicochemical characterizations did not reveal significant changes in the bulk materials, the changes were proven by a systematic demonstration through electrochemical measurements. The remarkable increase of $C_{\mathrm{sc}}$ and $j_{\mathrm{ph}}$ was obtained for the anatase $\mathrm{TiO}_{2} \mathrm{NT}$ and $\mathrm{WO}_{3}$ analyzed by the CVs and further confirmed by Mott-Schottky plots, owing to the oxygen vacancies produced during the partial reduction modification on the surface. In the $\mathrm{TiO}_{2}$ rutile nanorod sample, different mechanism operated in the enhancement of the $j_{\mathrm{ph}}$, via proton intercalation. For all of the samples, the self-doping modification did not increase the visible light absorption, as not any new chemical species substituted atomic positions in the crystal lattice. 
However, a higher IPCE was obtained in the UV region that confirmed that new reaction sites were generated on the surface. In conclusion, this simple and fast approach demonstrated to significantly promote the activation of nanomaterials and represented a method that could be extended to similar semiconductor-based photocatalysts. 


\section{References}

1. Oelkers, E.H. and D.R. Cole, Carbon dioxide sequestration a solution to a global problem. Elements, 2008. 4(5): p. 305-310.

2. Kumar, B., et al., Photochemical and photoelectrochemical reduction of $\mathrm{CO}_{2}$. Annual review of physical chemistry, 2012. 63: p. 541-569.

3. Duyck, S., The Paris Climate Agreement and the Protection of Human Rights in a Changing Climate. Yearbook of International Environmental Law, 2015. 26: p. 3-45.

4. Wood, T. and D. Blowers, Sundown, sunrise: how Australia can finally get solar power right. 2015: Grattan Institute.

5. Jain, I., C. Lal, and A. Jain, Hydrogen storage in Mg: a most promising material. International Journal of Hydrogen Energy, 2010. 35(10): p. 5133-5144.

6. Blok, K., et al., Hydrogen production from natural gas, sequestration of recovered $\mathrm{CO}_{2}$ in depleted gas wells and enhanced natural gas recovery. Energy, 1997. 22(2-3): p. 161168.

7. Peng, W. and Q. Wu, Production of fuels from biomass by pyrolysis. New Energy Sour, 2000. $22(11):$ p. 39-44.

8. Fujishima, A. and K. Honda, Electrochemical photolysis of water at a semiconductor electrode. nature, 1972. 238(5358): p. 37.

9. Plotnikow, J., Textbook of Photochemistry. Verlag von Willhelm Knapp, Berlin, 1910.

10. Meng, X., Z. Zhang, and X. Li, Synergetic photoelectrocatalytic reactors for environmental remediation: a review. Journal of Photochemistry and Photobiology C: Photochemistry Reviews, 2015. 24: p. 83-101. 
11. Neville, R.C., Solar energy conversion: the solar cell. 1995: Elsevier.

12. Kudo, A. and Y. Miseki, Heterogeneous photocatalyst materials for water splitting. Chemical Society Reviews, 2009. 38(1): p. 253-278.

13. Maeda, K., Photocatalytic water splitting using semiconductor particles: history and recent developments. Journal of Photochemistry and Photobiology C: Photochemistry Reviews, 2011. 12(4): p. 237-268.

14. Liu, H., et al., Photoelectrocatalytic degradation of sulfosalicylic acid and its electrochemical impedance spectroscopy investigation. The Journal of Physical Chemistry A, 2000. 104(30): p. 7016-7020.

15. Luo, J. and M. Hepel, Photoelectrochemical degradation of naphthol blue black diazo dye on $\mathrm{WO}_{3}$ film electrode. Electrochimica Acta, 2001. 46(19): p. 2913-2922.

16. Christensen, P., et al., Photoelectrocatalytic and photocatalytic disinfection of E. coli suspensions by titanium dioxide. Applied Catalysis B: Environmental, 2003. 41(4): p. $371-386$.

17. Su, Y.-F. and T.-C. Chou, Comparison of the photocatalytic and photoelectrocatalytic decolorization of methyl orange on sputtered $\mathrm{TiO}_{2}$ thin films. Zeitschrift für Naturforschung B, 2005. 60(11): p. 1158-1167.

18. Jia, Q., K. Iwashina, and A. Kudo, Facile fabrication of an efficient BiVO 4 thin film electrode for water splitting under visible light irradiation. Proceedings of the National Academy of Sciences, 2012. 109(29): p. 11564-11569.

19. Byun, S., et al., Effects of a $\mathrm{SnO}_{2}$ hole blocking layer in a BiVO4-based photoanode on photoelectrocatalytic water oxidation. Journal of Materials Chemistry A, 2017. 5(15): p. 6905-6913. 
20. Sakai, Y., et al., Photoelectrochemical water splitting by tandem type and heterojunction amorphous silicon electrodes. Canadian journal of chemistry, 1988. 66(8): p. 1853-1856.

21. Khaselev, O. and J.A. Turner, A monolithic photovoltaic-photoelectrochemical device for hydrogen production via water splitting. Science, 1998. 280(5362): p. 425-427.

22. Xing, Z., et al., On the engineering part of solar hydrogen production from water splitting: photoreactor design. Chemical Engineering Science, 2013. 104: p. 125-146.

23. Pinaud, B.A., et al., Technical and economic feasibility of centralized facilities for solar hydrogen production via photocatalysis and photoelectrochemistry. Energy \& Environmental Science, 2013. 6(7): p. 1983-2002.

24. Wang, X., et al., A metal-free polymeric photocatalyst for hydrogen production from water under visible light. Nature materials, 2009. 8(1): p. 76.

25. Bockris, J.O.M., et al., Modern electrochemistry 2B: electrodics in chemistry, engineering, biology and environmental science. Vol. 2. 1998: Springer Science \& Business Media.

26. Bolton, J.R., S.J. Strickler, and J.S. Connolly, Limiting and realizable efficiencies of solar photolysis of water. Nature, 1985. 316(6028): p. 495.

27. Takanabe, K., Photocatalytic Water Splitting: Quantitative Approaches toward Photocatalyst by Design. ACS Catalysis, 2017. 7(11): p. 8006-8022.

28. Dutta, S., Technology assessment of advanced electrolytic hydrogen production. International Journal of Hydrogen Energy, 1990. 15(6): p. 379-386.

29. Hu, S., et al., An analysis of the optimal band gaps of light absorbers in integrated tandem photoelectrochemical water-splitting systems. Energy \& Environmental Science, 2013. 6(10): p. 2984-2993. 
30. $\quad$ Lewis, N.S., Light work with water. Nature, 2001. 414(6864): p. 589.

31. Salas, B.V. and M.S. Wiener, Corrosion engineering: principles and practice. Corrosion Engineering, Science, and Technology, 2009. 44(1): p. 8.

32. Davis, J.R., Corrosion: Understanding the basics. 2000: ASM International.

33. Gratzel, M., Energy resources through photochemistry and catalysis. 2012: Elsevier.

34. Nozik, A.J., Photoelectrochemistry: applications to solar energy conversion. Annual Review of Physical Chemistry, 1978. 29(1): p. 189-222.

35. Pleskov, Y.V. and Y.Y. Gurevich, Semiconductor photoelectrochemistry. 1986.

36. Archer, M.D., Nanostructured and photoelectrochemical systems for solar photon conversion. Vol. 3. 2008: Imperial College Press.

37. Wang, L., et al., Toxicity of CdSe nanoparticles in Caco-2 cell cultures. Journal of nanobiotechnology, 2008. 6(1): p. 11.

38. Henglein, A., Photo-Degradation and Fluorescence of Colloidal-Cadmium Sulfide in Aqueous Solution. Berichte der Bunsengesellschaft für physikalische Chemie, 1982. 86(4): p. 301-305.

39. Serpone, N. and E. Pelizzetti, Photocatalysis: fundamentals and applications. 1989: Wiley-Interscience.

40. Chen, X., et al., Increasing solar absorption for photocatalysis with black hydrogenated titanium dioxide nanocrystals. Science, 2011.331(6018): p. 746-750.

41. Liu, Y., et al., Photoelectrochemical performance of CdS nanorods grafted vertically aligned $\mathrm{TiO}_{2}$ nanorods. Materials Research Bulletin, 2013. 48(11): p. 4548-4554.

42. Linsebigler, A.L., G. Lu, and J.T. Yates Jr, Photocatalysis on TiO 2 surfaces: principles, mechanisms, and selected results. Chemical reviews, 1995. 95(3): p. 735-758. 
43. Fujishima, A., X. Zhang, and D.A. Tryk, $\mathrm{TiO}_{2}$ photocatalysis and related surface phenomena. Surface Science Reports, 2008. 63(12): p. 515-582.

44. Serpone, N., Is the band gap of pristine $\mathrm{TiO}_{2}$ narrowed by anion-and cation-doping of titanium dioxide in second-generation photocatalysts? 2006, ACS Publications.

45. Liu, G., et al., Synergistic effects of B/N doping on the visible-light photocatalytic activity of mesoporous $\mathrm{TiO}_{2}$. Angewandte Chemie International Edition, 2008. 47(24): p. 45164520.

46. Murphy, A., et al., Efficiency of solar water splitting using semiconductor electrodes. International journal of hydrogen energy, 2006. 31(14): p. 1999-2017.

47. Liao, W., et al., Photoelectrocatalytic degradation of microcystin-LR using Ag/AgCl/TiO nanotube arrays electrode under visible light irradiation. Chemical engineering journal, 2013. 231: p. 455-463.

48. $\quad \mathrm{Xu}$, A.-W., Y. Gao, and H.-Q. Liu, The preparation, characterization, and their photocatalytic activities of rare-earth-doped $\mathrm{TiO}_{2}$ nanoparticles. Journal of Catalysis, 2002. 207(2): p. 151-157.

49. Miao, L., et al., Heating-sol-gel template process for the growth of $\mathrm{TiO}_{2}$ nanorods with rutile and anatase structure. Applied Surface Science, 2004. 238(1-4): p. 175-179.

50. $\quad \mathrm{Ni}, \mathrm{M}$., et al., A review and recent developments in photocatalytic water-splitting using $\mathrm{TiO}_{2}$ for hydrogen production. Renewable and Sustainable Energy Reviews, 2007. 11(3): p. 401-425.

51. Li, Y. and J.Z. Zhang, Hydrogen generation from photoelectrochemical water splitting based on nanomaterials. Laser \& Photonics Reviews, 2010. 4(4): p. 517-528. 
52. Walter, M.G., et al., Solar water splitting cells. Chemical reviews, 2010. 110(11): p. 6446-6473.

53. Tada, H., et al., All-solid-state Z-scheme in CdS-Au-TiO $\mathrm{O}_{2}$ three-component nanojunction system. Nature materials, 2006. 5(10): p. 782.

54. Yoneyama, H., H. Sakamoto, and H. Tamura, A photo-electochemical cell with production of hydrogen and oxygen by a cell reaction. Electrochimica Acta, 1975. 20(5): p. 341-345.

55. Hodes, G., D. Cahen, and J. Manassen, Tungsten trioxide as a photoanode for a photoelectrochemical cell (PEC). Nature, 1976. 260(5549): p. 312.

56. Sivula, K., F.L. Formal, and M. Gratzel, $\mathrm{WO}_{3}-\mathrm{Fe}_{2} \mathrm{O}_{3}$ photoanodes for water splitting: A host scaffold, guest absorber approach. Chemistry of Materials, 2009. 21(13): p. 28622867.

57. Zhao, Z.G. and M. Miyauchi, Nanoporous-Walled Tungsten Oxide Nanotubes as Highly Active Visible-Light-Driven Photocatalysts. Angewandte Chemie International Edition, 2008. 47(37): p. 7051-7055.

58. Kim, J., C.W. Lee, and W. Choi, Platinized $\mathrm{WO}_{3}$ as an environmental photocatalyst that generates $\mathrm{OH}$ radicals under visible light. Environmental science \& technology, 2010. 44(17): p. 6849-6854.

59. Sun, S., et al., Preparation of ordered mesoporous $\mathrm{Ag} / \mathrm{WO}_{3}$ and its highly efficient degradation of acetaldehyde under visible-light irradiation. Journal of hazardous materials, 2010. 178(1-3): p. 427-433. 
60. Choi, H.W., E.J. Kim, and S.H. Hahn, Photocatalytic activity of Au-buffered $\mathrm{WO}_{3}$ thin films prepared by RF magnetron sputtering. Chemical Engineering Journal, 2010. 161(12): p. 285-288.

61. Bamwenda, G.R. and H. Arakawa, The visible light induced photocatalytic activity of tungsten trioxide powders. Applied Catalysis A: General, 2001. 210(1-2): p. 181-191.

62. Sayama, K., et al., Highly active $\mathrm{WO}_{3}$ semiconductor photocatalyst prepared from amorphous peroxo-tungstic acid for the degradation of various organic compounds. Applied Catalysis B: Environmental, 2010. 94(1-2): p. 150-157.

63. Morales, W., et al., Combustion synthesis and characterization of nanocrystalline $\mathrm{WO}_{3}$. Journal of the American Chemical Society, 2008. 130(20): p. 6318-6319.

64. Yang, B., et al., Strong photoresponse of nanostructured tungsten trioxide films prepared via a sol-gel route. Journal of Materials Chemistry, 2007. 17(26): p. 2722-2729.

65. Cole, B., et al., Evaluation of nitrogen doping of tungsten oxide for photoelectrochemical water splitting. The Journal of Physical Chemistry C, 2008. 112(13): p. 5213-5220.

66. Sun, Y., et al., Photoelectrochemical and structural characterization of carbon-doped $\mathrm{WO}_{3}$ films prepared via spray pyrolysis. International Journal of Hydrogen Energy, 2009. 34(20): p. 8476-8484.

67. Van Zeghbroeck, B., Principles of semiconductor devices. Colarado University, 2004.

68. Skorupska, K., Optical properties of semiconductors. Lecture notes.

69. Schneider, J., et al., Understanding $\mathrm{TiO}_{2}$ photocatalysis: mechanisms and materials. Chemical reviews, 2014. 114(19): p. 9919-9986.

70. Ohtani, B., Titania photocatalysis beyond recombination: A critical review. Catalysts, 2013. 3(4): p. 942-953. 
71. Zhou, H. and Y. Zhang, Electrochemically self-doped $\mathrm{TiO}_{2}$ nanotube arrays for supercapacitors. The Journal of Physical Chemistry C, 2014. 118(11): p. 5626-5636.

72. Díaz-Real, J.A., et al., Light-harvesting $\mathrm{Ni} / \mathrm{TiO}_{2}$ nanotubes as photo-electrocatalyst for alcohol oxidation in alkaline media. Electrochimica Acta, 2016. 206: p. 388-399.

73. Liu, B. and E.S. Aydil, Growth of oriented single-crystalline rutile $\mathrm{TiO}_{2}$ nanorods on transparent conducting substrates for dye-sensitized solar cells. Journal of the American Chemical Society, 2009. 131(11): p. 3985-3990.

74. Liu, Y., et al., Fabrication and Properties of a Branched (NH4) $x \mathrm{WO}_{3}$ Nanowire Array Film and a Porous $\mathrm{WO}_{3}$ Nanorod Array Film. ACS applied materials \& interfaces, 2015. 7(6): p. 3532-3538.

75. Wang, M., et al., Activating $\mathrm{ZnO}$ nanorod photoanodes in visible light by $\mathrm{Cu}$ ion implantation. Nano Research, 2014. 7(3): p. 353-364.

76. Chen, C.-c., et al., Electrochemical characteristics of surface of titanium formed by electrolytic polishing and anodizing. Journal of materials science, 2005. 40(15): p. 40534059.

77. Pourbaix, M., Atlas of electrochemical equilibria in aqueous solution. NACE, 1974. 307.

78. Dezfoolian, M., F. Rashchi, and R.K. Nekouei, Synthesis of copper and zinc oxides nanostructures by brass anodization in alkaline media. Surface and Coatings Technology, 2015. 275: p. 245-251.

79. Liu, Y., et al., $\mathrm{TiO}_{2} / \mathrm{CdSe}$ core-shell nanofiber film for photoelectrochemical hydrogen generation. Nanoscale, 2014. 6(13): p. 7397-7404.

80. Qian, F., G. Wang, and Y. Li, Solar-driven microbial photoelectrochemical cells with a nanowire photocathode. Nano letters, 2010. 10(11): p. 4686-4691. 
81. Lee, J.-W., J.-H. Im, and N.-G. Park, Quantum confinement effect of CdSe induced by nanoscale solvothermal reaction. Nanoscale, 2012. 4(20): p. 6642-6648.

82. Liu, X., et al., Facile preparation of $\mathrm{BiVO}_{4}$ nanoparticle film by electrostatic spray pyrolysis for photoelectrochemical water splitting. International Journal of Hydrogen Energy, 2015. 40(38): p. 12964-12972.

83. Zhou, B., et al., Fabrication and photoelectrocatalytic properties of nanocrystalline monoclinic. 2011.

84. Gelderman, K., L. Lee, and S. Donne, Flat-band potential of a semiconductor: using the Mott-Schottky equation. Journal of chemical education, 2007. 84(4): p. 685.

85. Acevedo-Peña, P., et al., Effect of heat treatment on the crystal phase composition, semiconducting properties and photoelectrocatalytic color removal efficiency of $\mathrm{TiO}_{2}$ nanotubes arrays. Electrochimica Acta, 2014. 140: p. 564-571.

86. Mor, G. and C. Grimes, $\mathrm{TiO}_{2}$ nanotube arrays-Synthesis, Properties and Applications. 2009, Springer, New York.

87. Ohsaka, T., F. Izumi, and Y. Fujiki, Raman spectrum of anatase, TiO2. Journal of Raman spectroscopy, 1978. 7(6): p. 321-324.

88. Tang, H., et al., Electrical and optical properties of $\mathrm{TiO}_{2}$ anatase thin films. Journal of applied physics, 1994. 75(4): p. 2042-2047.

89. Samara, G. and P. Peercy, Pressure and Temperature Dependence of the Static Dielectric Constants and Raman Spectra of $\mathrm{TiO}_{2}$ (Rutile). Physical Review B, 1973. 7(3): p. 1131.

90. Le, T.K., et al., Surface fluorination of single-phase $\mathrm{TiO}_{2}$ by thermal shock method for enhanced UV and visible light induced photocatalytic activity. Applied Catalysis B:

Environmental, 2014. 144: p. 1-11. 
91. Liao, W., et al., Electrochemically self-doped $\mathrm{TiO}_{2}$ nanotube arrays for efficient visible light photoelectrocatalytic degradation of contaminants. Electrochimica Acta, 2014. 136: p. 310-317.

92. Berger, T., et al., An electrochemical study on the nature of trap states in nanocrystalline rutile thin films. The Journal of Physical Chemistry C, 2007. 111(27): p. 9936-9942.

93. Berger, T., et al., The electrochemistry of nanostructured titanium dioxide electrodes. ChemPhysChem, 2012. 13(12): p. 2824-2875.

94. Kuznetsov, V.N. and N. Serpone, Visible light absorption by various titanium dioxide specimens. The Journal of Physical Chemistry B, 2006. 110(50): p. 25203-25209.

95. Oliva, F.Y., et al., Photoelectrochemical characterization of nanocrystalline $\mathrm{TiO}_{2}$ films on titanium substrates. Journal of photochemistry and photobiology A: chemistry, 2002. 146(3): p. 175-188.

96. Grimes, C.A. and G.K. Mor, $\mathrm{TiO}_{2}$ Nanotube Arrays: Synthesis, Properties, and Applications, ed. Springer. 2009.

97. Parker, R.A. and J.H. Wasilik, Dielectric Constant and Dielectric Loss of TiO 2 (Rutile) at Low Frequencies. Physical review, 1960. 120(5): p. 1631.

98. Beranek, R., (Photo) electrochemical methods for the determination of the band edge positions of $\mathrm{TiO}_{2}$-based nanomaterials. Advances in Physical Chemistry, 2011. 2011.

99. Berger, T., et al., The Electrochemistry of Nanostructured Titanium Dioxide Electrodes. ChemPhysChem, 2012. 13(12): p. 2824-2875.

100. Jankulovska, M., et al., Trap States in $\mathrm{TiO}_{2}$ Films Made of Nanowires, Nanotubes or Nanoparticles: An Electrochemical Study. ChemPhysChem, 2012. 13(12): p. 3008-3017. 
101. Wagner, C.D., The NIST X-ray photoelectron spectroscopy (XPS) database. 1991: US Department of Commerce, National Institute of Standards and Technology.

102. Shpak, A., et al., XPS studies of active elements surface of gas sensors based on $\mathrm{WO}_{3}-x$ nanoparticles. Journal of electron spectroscopy and related phenomena, 2007. 156: p. $172-175$.

103. Lynch, R.P., A. Ghicov, and P. Schmuki, A photo-electrochemical investigation of selforganized $\mathrm{TiO}_{2}$ nanotubes. Journal of The Electrochemical Society, 2010. 157(3): p. G76-G84.

104. Deb, S., Optical and photoelectric properties and colour centres in thin films of tungsten oxide. Philosophical Magazine, 1973. 27(4): p. 801-822.

105. Deb, S., Electron spin resonance of defects in single crystal and thin films of tungsten trioxide. Physical Review B, 1977. 16(3): p. 1020.

106. Wang, G., et al., Hydrogen-treated $\mathrm{TiO}_{2}$ nanowire arrays for photoelectrochemical water splitting. Nano letters, 2011. 11(7): p. 3026-3033.

107. Wang, G., et al., Facile synthesis of highly photoactive $\alpha$-Fe $\mathrm{F}_{2} \mathrm{O}_{3}$-based films for water oxidation. Nano letters, 2011. 11(8): p. 3503-3509.

108. Kay, A., I. Cesar, and M. Grätzel, New benchmark for water photooxidation by nanostructured $\alpha-\mathrm{Fe}_{2} \mathrm{O}_{3}$ films. Journal of the American Chemical Society, 2006. 128(49): p. $15714-15721$.

109. Lee, S.H., et al., Crystalline $\mathrm{WO}_{3}$ nanoparticles for highly improved electrochromic applications. Advanced Materials, 2006. 18(6): p. 763-766. 
110. Chang, C.-J., C.-Y. Lin, and M.-H. Hsu, Enhanced photocatalytic activity of Ce-doped $\mathrm{ZnO}$ nanorods under $U V$ and visible light. Journal of the Taiwan Institute of Chemical Engineers, 2014. 45(4): p. 1954-1963.

111. Chang, Y.-C., et al., Fabrication of Cu-doped ZnO nanoneedles on different substrate via wet chemical approach: Structural characterization and photocatalytic performance. Applied Surface Science, 2018. 447: p. 213-221.

112. Li, Z., et al., Morphology control and transition of ZnO nanorod arrays by a simple hydrothermal method. Materials Letters, 2008. 62(10-11): p. 1503-1506.

113. Deng, H., et al., Microstructure control of $\mathrm{ZnO}$ thin films prepared by single source chemical vapor deposition. Thin Solid Films, 2004. 458(1-2): p. 43-46.

114. Fujimura, N., et al., Control of preferred orientation for $\mathrm{ZnO}_{x}$ films: control of selftexture. Journal of Crystal Growth, 1993. 130(1-2): p. 269-279.

115. Van Heerden, J. and R. Swanepoel, XRD analysis of ZnO thin films prepared by spray pyrolysis. Thin Solid Films, 1997. 299(1-2): p. 72-77.

116. Koyano, M., et al., Photoluminescence and Raman spectra of ZnO thin films by charged liquid cluster beam technique. physica status solidi (a), 2002. 193(1): p. 125-131.

117. Zhang, R., et al., Photoluminescence and Raman scattering of ZnO nanorods. Solid State Sciences, 2009. 11(4): p. 865-869.

118. Yu, H., et al., A general low-temperature route for large-scale fabrication of highly oriented $\mathrm{ZnO}$ nanorod/nanotube arrays. Journal of the American Chemical Society, 2005. 127(8): p. 2378-2379.

119. Rothenberger, G., D. Fitzmaurice, and M. Graetzel, Spectroscopy of conduction band electrons in transparent metal oxide semiconductor films: optical determination of the 
flatband potential of colloidal titanium dioxide films. The Journal of physical chemistry, 1992. 96(14): p. 5983-5986.

120. Boschloo, G. and D. Fitzmaurice, Electron accumulation in nanostructured $\mathrm{TiO}_{2}$ (anatase) electrodes. Journal of the Electrochemical Society, 2000. 147(3): p. 1117-1123.

121. Boschloo, G. and D. Fitzmaurice, Spectroelectrochemical investigation of surface states in nanostructured $\mathrm{TiO}_{2}$ electrodes. The Journal of Physical Chemistry B, 1999. 103(12): p. $2228-2231$.

122. Asahi, R., et al., Visible-light photocatalysis in nitrogen-doped titanium oxides. science, 2001. 293(5528): p. 269-271.

123. Zribi, A. and J. Fortin, Functional thin films and nanostructures for sensors: synthesis, physics and applications. 2009: Springer Science \& Business Media. 